\title{
Suzie Robichaud
}

Professeure de science politiques, Université du Québec à Chicoutimi

$$
\text { (2007) }
$$

\section{Lettres à Jean-Élie.}

\section{Clin d'œil aux amants de la sagesse.}

\author{
Un document produit en version numérique par Jean-Marie Tremblay, bénévole, \\ professeur de sociologie au Cégep de Chicoutimi \\ Courriel: jean-marie tremblay@uqac.ca \\ Site web pédagogique : http://www.uqac.ca/jmt-sociologue/ \\ Dans le cadre de: "Les classiques des sciences sociales" \\ Une bibliothèque numérique fondée et dirigée par Jean-Marie Tremblay, \\ professeur de sociologie au Cégep de Chicoutimi \\ Site web: http://classiques.uqac.ca/ \\ Une collection développée en collaboration avec la Bibliothèque \\ Paul-Émile-Boulet de l'Université du Québec à Chicoutimi \\ Site web: http://bibliotheque.uqac.ca/
}




\section{Politique d'utilisation de la bibliothèque des Classiques}

Toute reproduction et rediffusion de nos fichiers est interdite, même avec la mention de leur provenance, sans l'autorisation formelle, écrite, du fondateur des Classiques des sciences sociales, Jean-Marie Tremblay, sociologue.

Les fichiers des Classiques des sciences sociales ne peuvent sans autorisation formelle:

- être hébergés (en fichier ou page web, en totalité ou en partie) sur un serveur autre que celui des Classiques.

- servir de base de travail à un autre fichier modifié ensuite par tout autre moyen (couleur, police, mise en page, extraits, support, etc...),

Les fichiers (.html, .doc, .pdf, .rtf, .jpg, .gif) disponibles sur le site Les Classiques des sciences sociales sont la propriété des Classiques des sciences sociales, un organisme à but non lucratif composé exclusivement de bénévoles.

Ils sont disponibles pour une utilisation intellectuelle et personnelle et, en aucun cas, commerciale. Toute utilisation à des fins commerciales des fichiers sur ce site est strictement interdite et toute rediffusion est également strictement interdite.

L'accès à notre travail est libre et gratuit à tous les utilisateurs. C'est notre mission.

Jean-Marie Tremblay, sociologue

Fondateur et Président-directeur général, LES CLASSIQUES DES SCIENCES SOCIALES. 
DE LA MÊME AUTEURE :

Le Bénévolat. Entre le coeur et la raison. Chicoutimi, Les Éditions JCL, 2e édition revue et corrigée, 2003, 274 pages. [Livre disponible dans Les Classiques des sciences sociales. JMT.]

Désastres et Sinistrés. Danielle Maltais, Suzie Robichaud, Anne Simard, coll. : Au coeur des catastrophes. Chicoutimi, Les Éditions JCL, 2001, 408 pages.

Sinistres et Intervenants. Danielle Maltais, Suzie Robichaud, Anne Simard, coll. : Au coeur des catastrophes. Chicoutimi, Les Éditions JCL, 2001, 276 pages. 
Cette édition électronique a été réalisée par Jean-Marie Tremblay, bénévole, professeur de sociologie au Cégep de Chicoutimi à partir de :

\section{Suzie ROBICHAUD}

\section{LETTRES À JEAN-ÉLIE. Clin d'œil aux amants de la sagesse.}

Chicoutimi, Ville de Saguenay, Québec, Les Éditions JCL inc., 2007, 234 pp.

[Autorisation accordée par l'auteure le 2 novembre 2009 et par l'éditeur, Les Éditions JCL inc. le 14 décembre 2009, de diffuser ce livre dans Les Classiques des sciences sociales.]

Mme Robichaud est professeure de science politique à l’Université du Québec à Chicoutimi.

Courriels: suzie_robichaud@uqac.ca et jclarouche@jcl.qc.ca

Site de l’éditeur : http://www.jcl.qc.ca/welcome.html

Polices de caractères utilisée :

Pour le texte: Times New Roman, 12 points.

Pour les citations : Times New Roman, 12 points.

Pour les notes de bas de page : Times New Roman, 12 points.

Édition électronique réalisée avec le traitement de textes Microsoft Word 2008 pour Macintosh.

Mise en page sur papier format : LETTRE (US letter), 8.5’’ x 11’')

Édition numérique réalisée le 22 février 2009 à Chicoutimi, Ville de Saguenay, province de Québec, Canada. 


\section{Suzie ROBICHAUD}

Professeure de science politiques, Université du Québec à Chicoutimi

\section{"LETTRES À JEAN-ÉLIE. Clin d'œil aux amants de la sagesse”}

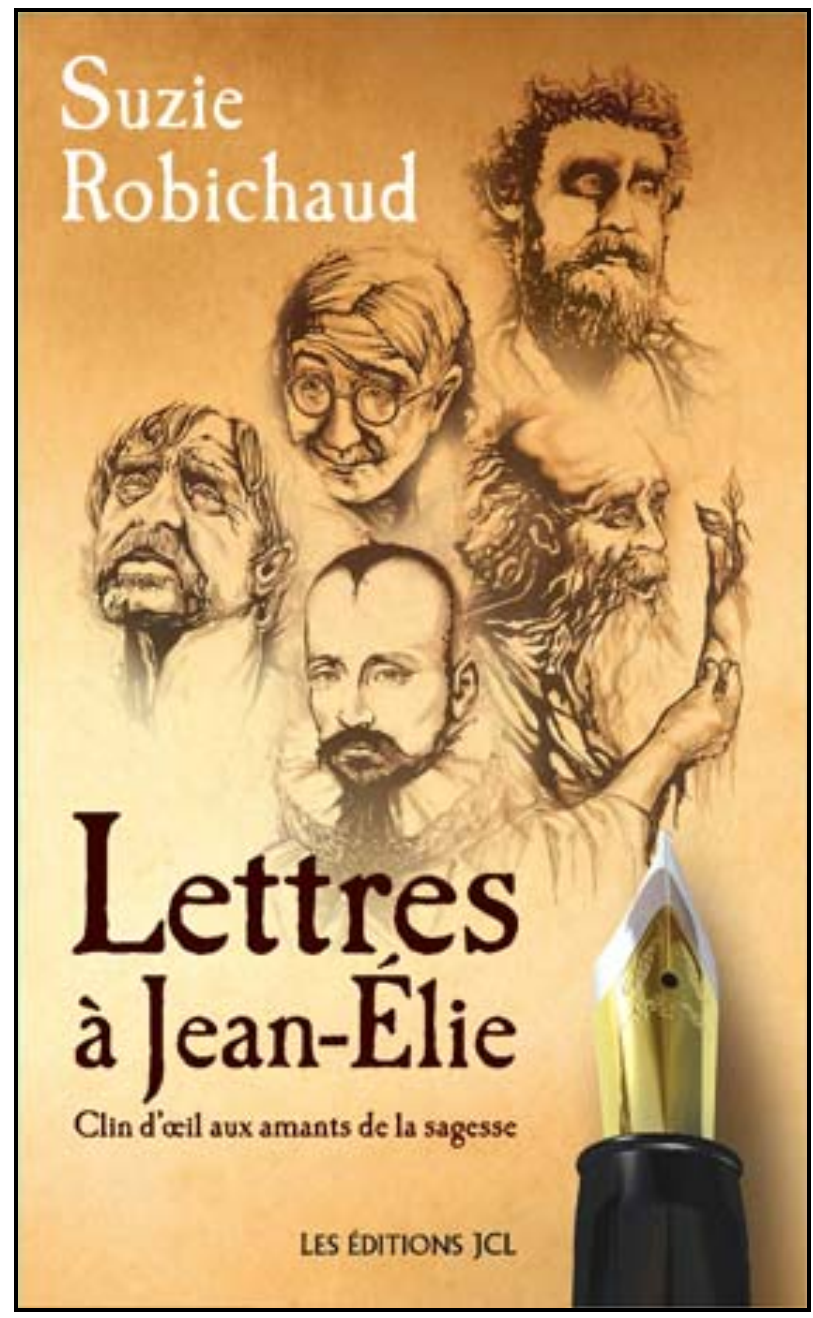

Chicoutimi, Ville de Saguenay, Québec, Les Éditions JCL inc., 2007, 234 pp. 
Catalogage avant publication de Bibliothèque et Archives nationales du Québec et Bibliothèque et Archives Canada

Robichaud, Suzie, 1949-

Lettres à Jean-Élie

Comprend des réf. bibliogr.

ISBN 978-2-89431-376-3

1. Vie - Philosophie. 2. Philosophes - Citations.

3. Robichaud, Suzie, 1949- . I. Titre.

BD431.R62 2007 113'.8 C2007-941101-0

\section{Les éditions JCL inc.}

930, rue Jacques-Cartier Est, CHICOUTIMI (Québec) CANADA G7H 7K9

Tél. : (418) 696-0536 - Téléc. : (418) 696-3132 - www.jcl.qc.ca

ISBN : 978-2-89431-376-3

\section{Illustrations :}

CHANTALE VINCELETTE 


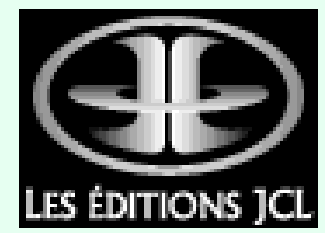

http://www.jcl.qc.ca/fr/detail_livre.php?id=366\&SESSID

Nous sommes infiniment reconnaissants à M. Jean-Claude Larouche, président, Les Éditions JCL, de nous accorder son autorisation de rendre disponible sur Internet, en format numérique, en accès libre et gratuit, dans Les Classiques des sciences sociales, ce livre de Mme Suzie Robichaud, professeure de science politique à l’Université du Québec à Chicoutimi, Lettres à Jean-Élie. Clin d'œil aux amants de la sagesse (2007)

Ce livre est disponible, en édition papier, directement chez l'éditeur ou en toute bonne librairie.

Site web : http://www.jcl.qc.ca/fr/detail_livre.php?id=366\&SESSID

Courriel : jclarouche@jcl.qc.ca 


\section{Table des matières}

Quatrième de couverture

Préface de Jacques T. Godbout

Note au lecteur

$\underline{\text { PARTIE I }}$

Lettre I. $\quad$ La belle espérance

Lettre II. Les chemins du temps

Lettre III. Les rivages de la vie

Lettre IV. $\quad$ L'expression de la bonté

Lettre $\mathrm{V}$. $\quad$ Les jeux sont faits

Lettre VI. Les arrêts du destin

Lettre VII. La distance

Lettre VIII. La saison de la sagesse

Lettre IX. Le temps des soupirs nostalgiques

Lettre $X$. La bienveillance

Lettre XI. La reconnaissance

Lettre XII. Les choses du coeur

Lettre XIII. La Sonate à la lune

Lettre XIV. Le cours heureux de la vie

Lettre XV. Et toi, que dis-tu?

PARTIE II

Héritage

Compagnons d'aujourd'hui

$\underline{\text { Alain }}$

Épictète

Marc Aurèle

Montaigne

Sénèque

Bibliographie choisie

Remerciements 


\title{
ILLUSTRATIONS
}

\author{
Chantale Vincelette
}




\section{LETTRES À JEAN-ÉLIE}

est le trois cent soixante-seizième livre

publié par Les éditions JCL inc.

(C) Les éditions JCL inc., 2007 
Nous reconnaissons l'aide financière du gouvernement du Canada par l'entremise du Programme d'aide au développement de l'industrie de l'édition (PADIÉ) pour nos activités d'édition. Nous bénéficions également du soutien de la SODEC et, enfin, nous tenons à remercier le Conseil des Arts du Canada pour l'aide accordée à notre programme de publication.

Gouvernement du Québec - Programme de crédit d'impôt pour l'édition de livres - Gestion SODEC 
À ma mère 


\section{Lettres à Jean-Élie. \\ Clin d'œil aux amants de la sagesse \\ QUATRIÈME DE COUVERTURE}

$\underline{\text { Retour à la table des matières }}$

Il y a longtemps que Suzie Robichaud boit à la source des philosophes qu'elle appelle ses « professeurs de vie »

Elle a trouvé un moyen pratique de nous les faire connaître et aimer.

Elle nous invite, notamment, à partager quinze lettres adressées à Jean-Élie, son père, dans lesquelles elle traite de la vie et de tout ce qui pourrait la composer pour la rendre meilleure.

Bien sûr, ces épîtres intimistes ne sont qu'une entrée en matière pour mieux nous plonger dans la richesse inouïe du message livré par ses amis : Sénèque, Alain, Marc-Aurèle, Épictète, Montaigne et bien d'autres.

Car, comme le dit si bien Alain, « en toute chose, il faut apprendre à être heureux ».

Simplement. 
Lettres à Jean-Élie. Clin d’œil aux amants de la sagesse

\section{PRÉFACE}

\section{Jacques T. Godbout}

Jamais les fleurs du temps d'aimer n’ont poussé dans un coeur fermé. La nuit, le jour, l'été, l’hiver, il faut dormir le coeur ouvert.

\section{$\underline{\text { Retour à la table des matières }}$}

Il m’arrive souvent de penser à Suzie Robichaud lorsque je fredonne cette chanson de Gilles Vigneault, dont les paroles auraient pu être d'un grand auteur classique fréquenté par elle. Suzie dort le coeur ouvert. J’ai rarement rencontré une personne aussi spontanément généreuse, sensible aux autres, de bonne humeur, optimiste, ouverte, sans arrière-pensées, sauf de bonnes.

Toutes ces qualités semblent tellement lui aller comme un gant qu'on a l'impression qu'elles lui sont naturelles et qu'elle n'a aucun besoin de les cultiver. C'est pourquoi on reste surpris, lorsqu'on la connaît un peu mieux, de s'apercevoir qu'après un sourire, au détour d'une phrase, pour répondre à une question, pour nous en poser une, pour conclure une conversation, elle se met tout à coup à citer Alain, Sénèque, Plutarque, Marc Aurèle, Montaigne et autres sages de l’histoire de l'humanité. Suzie est en vérité la seule personne que je connaisse pour qui leurs pensées lui viennent si naturellement à l'esprit et aux lèvres qu'on a l'impression qu'elle est en dialogue constant avec eux et qu'ils font partie de sa vie quotidienne. Ils l'habitent.

Je n’ai donc pas été étonné d'apprendre qu'elle avait eu la bonne idée de pousser sa générosité un peu plus loin : au lieu de nous les présenter goutte à 
goutte et un à un, au fil de la conversation, elle nous donne aujourd'hui, dans ce petit ouvrage, une vue d'ensemble de ses réflexions en leur compagnie. Sous forme de lettres à son père, elle met en scène différents personnages. Mêlant ses réflexions sur les événements de la vie quotidienne aux grandes questions auxquelles l'humanité a toujours été confrontée, la souffrance, la mort, le don, le bonheur, elle nous familiarise avec eux, ses amis, comme elle le dit.

Tout cela est bien sympathique, me rétorquerez-vous. Les pensées profondes de ces philosophes étaient certes très utiles aux hommes et aux femmes de leur époque. Mais le monde a tellement changé. Tout sages qu'ils fussent, comment quelqu'un qui a écrit il y a deux mille ans - et même il y a cent ans, avec «l'accélération de l'histoire »... - peut-il nous aider à affronter les problèmes actuels ? Comment ces auteurs pourraient-ils encore être pertinents dans ce monde postmoderne régi par les règles de la mondialisation marchande et confronté au réchauffement de la planète ?

Je suis loin d'avoir fréquenté tous ces sages comme Suzie l'a fait. Permettezmoi toutefois de vous faire part d'une expérience à cet égard. Je fais des recherches sur le don dans la société actuelle depuis des années. Pour ce faire, j’ai lu de nombreux ouvrages. Apprenant que je travaillais sur ce thème, un de mes amis m’a recommandé de lire un livre de Sénèque : Des bienfaits. Considérant qu'un tel ouvrage ne pouvait être conforme au sujet traité, je n’avais pas donné suite à la suggestion. Il y a quelque temps, j'ai enfin décidé d'y jeter un coup d'oeil. La lecture de cet ouvrage m'a non seulement passionné, elle m'a paradoxalement presque découragé. Sénèque discute tous les problèmes et tous les aspects du don. Alors que ce sage vivait à l'époque de l'empire romain, j'ai souvent eu l'impression en le lisant qu'il n'avait rien omis sur le sujet ! Vous en doutez ? Et si je vous disais que Sénèque aborde même le problème du don face au marché et qu'il parle du danger de le transformer en marchandise en rendant l'équivalent : « Rends ce que tu dois semble une maxime absolument équitable. [...] Eh bien elle est souverainement honteuse lorsqu'il s'agit d'un bienfait (don). [...] Rendra-t-il la vie, s'il la doit ? l'honneur, la santé ? Rendre est précisément impossible toutes les fois que les bienfaits sont parmi les plus grands. Du moins en échange, dit-on, doit-on rendre un service qui en soit l'équivalent! Voilà bien ce que je disais : toute la dignité de ce geste sera perdue si de ce bienfait nous en faisons une marchandise. » 
« Si beneficium mercem facimus. » Transformer le don en marchandise : y at-il réflexion plus actuelle ? Si donc vous avez l'impression que les amis de Suzie sont dépassés, que leurs réflexions ne s’appliquent plus, lisez ce petit livre. Vous m'en donnerez des nouvelles.

\author{
Jacques T. Godbout
}


Lettres à Jean-Élie. Clin d’œil aux amants de la sagesse

NOTE AU LECTEUR

\section{L'auteure}

Tu n'as aujourd'hui aucun pouvoir sur tes lendemains ! Il n’est pure mélancolie que le souci du lendemain ! Ne perds pas cet Instant si tu n’es pas insensé !

Car on ne peut savoir le temps qui nous est dispensé !

Omar Khayyâm

$\underline{\text { Retour à la table des matières }}$

Il y a de ces rencontres qui sont plus déterminantes que d'autres. Ma rencontre avec les amis de la sagesse fait partie de celles-là. Ces derniers sont vite devenus mes compagnons de vie. Et ils m’ont aidée à comprendre de petites choses, mais de grandes aussi : qu'il faut, entre autres, un apprentissage en tout, même pour le bonheur ; qu'il n'y a qu'un bien à la base d'une vie heureuse : la confiance en soimême ; que l'effort est l'aliment des âmes nobles. Mes amis philosophes m’ont appris à accueillir les petites contrariétés de la vie et m’ont enseigné à accepter l'inévitable. J'ai beaucoup de considération, d'admiration et d'affection pour chacun d'eux et pour leur oeuvre : l'oeuvre du bonheur, me chuchotent-ils. Bien que je les aime tous, je converse plus facilement avec certains : Sénèque, Épictète, Marc Aurèle, Montaigne, Alain, par exemple, sont ceux qui me suivent de plus près. Ils ont l'accueil aimable. C'est ainsi que, depuis plus de vingt ans, ces stoïciens de coeur acceptent de marcher avec moi sur le chemin de la sagesse en ayant la bonté de ralentir le pas. C’est qu’ils ont une longueur d'avance, mes amis; en connaissances scientifiques, en savoir philosophique et en maturité d’âme. 
En dépit de cette différence, nous éprouvons beaucoup de plaisir à nous retrouver. Un trait nous solidarise : nous sommes tous des curieux de la nature humaine, comme Alain se plaît à dire. Et puis, nous avons d'autres points en commun : le plaisir d'enseigner et le bonheur de partager. Tout bien dont la possession n’est pas partagée perd sa douceur, dit Sénèque. Faut-il s'étonner qu’il fasse parvenir des livres à son ami Lucilius en soulignant les passages que lui-même accueille et affectionne ? Il tente de lui éviter quelques détours. Mes amis ont l’âme généreuse. Ils s’entretiennent quotidiennement avec moi et me livrent des formules qui font réfléchir, des pensées qui bercent l’âme. Professeurs de vie autant que de pédagogie, ils m’ont appris à accorder une attention particulière aux aspirations des étudiants et à leurs attentes, puis à les soutenir dans leurs actions, comme celle de porter leurs désirs vers un idéal. Dès lors, les présentes lettres, dédiées à ma mère mais adressées à mon père, s’adressent aussi à mes étudiantes. Elles s'adressent également à mes soeurs, à mes amies, à mon amour, bien sûr. Puis, elles se veulent un clin d'oeil à tous les amants de la sagesse, c'est-à-dire à ceux qui, comme moi, cherchent à s’instruire ; mieux, à apprendre à vivre.

\section{L’auteure}


Lettres à Jean-Élie.

Clin d'œil aux amants de la sagesse

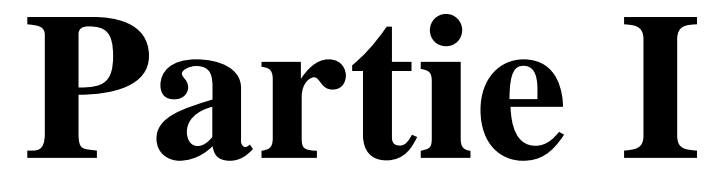

$\underline{\text { Retour à la table des matières }}$ 
Lettres à Jean-Élie.

Clin d'œil aux amants de la sagesse

PARTIE I

Lettre I

\section{La belle espérance}

\section{$\underline{\text { Retour à la table des matières }}$}

Depuis ton départ, mon cher Jean-Élie, je soigne mon coeur et tente de le distraire de sa peine. Comme si ce n’était pas assez, une foule de pensées s'agitent à tout vent : le sens de l'existence, de la souffrance, de la mort que le mitan de la vie s'amuse à amplifier. Je m’inquiète. Je refuse de te perdre. Mais comment retrouver nos instants de complicité ? Me vint alors ce mot d'Alain : Regarde au loin. Quelle bénédiction ! Et, par un superbe matin de juin, à quelques jours des vacances, alors que le mal à l’âme qui m’habitait ressemblait à cette mélancolie que Victor Hugo définit comme le bonheur d'être triste, une idée s'amène : celle de t'écrire. Pour te dire quoi ? Que beaucoup de choses me parlent de toi ? Tu me connais, je suis généreuse dans mes souvenirs. Que je me débrouille à ma façon avec mon coeur plus tendre que du lilas, comme le chantait ton interprète préférée ? C’est bien peu. Dans ce cas-là, pourquoi ne pas te faire partager mes leçons de sagesse? La communication ne facilite-t-elle pas le rapprochement et l'apprentissage aussi ? Quoi qu'il en soit, la voilà, la belle espérance, me dit Sénèque. Tu te souviens, il y a plusieurs années déjà, alors que je me posais mille et une questions sur le bonheur et la signification que le mot suggère, un de mes 
amis m’invita à lire Propos sur le bonheur. Et pour la première fois de ma vie mieux vaut tard que jamais - je réalisai que la philosophie, au-delà des grandes interrogations auxquelles elle permet de répondre à travers la logique, la physique ou la canonique, pouvait aussi nous aider à vivre. Pour une personne dont la propension au bonheur n'est pas innée, ce fut une magnifique découverte, voire un véritable cadeau. C'est ainsi qu'Alain m'a conduite à Montaigne, et Montaigne à Sénèque, qui s'empressa de m'accueillir à l'École du Portique tout en me faisant découvrir le Jardin d'Épicure ${ }^{1}$. Les amis de la sagesse sont donc entrés dans ma vie avec tendresse et fidélité, ils ont su se montrer disponibles et discrets, bienveillants et exigeants. Je les ai lus et relus et cités plus d'une fois et toujours sans prétention.

Écrire. Tout à coup un air de doute, avec plusieurs variations par-dessus le marché, se met à résonner dans ma tête. Écrire. Ce n’est pas une mince affaire ! Il faut dire que, pour moi qui vois l'écriture comme une entreprise empreinte de chaleur et de passion, j’ai éprouvé plusieurs déceptions à me faire ramener à un style plus direct, parfois administratif, que ce soit dans des articles scientifiques ou des rapports de recherche. Pourtant, j'ai souvenir encore d'un morceau de musique que j'ai composé à la suite des remarques de mon professeur de piano qui m’invitait, fort heureusement, à respecter avec plus de rigueur la durée dans la troisième mesure d'un arrangement du Concerto no 1 de Tchaïkovski. Riche de cette remarque, j’ai néanmoins décidé de composer une petite pièce, que tu as appréciée d'ailleurs - amitié paternelle -, en plaçant dans plusieurs mesures une noire entre deux groupes de croches. Eh bien! oui, cet exercice m’a réconciliée avec moi-même. Il en sera de même pour ces lettres : elles respecteront les règles d'usage, mais je me presse de dire qu'elles seront écrites selon mon bon vouloir et avec ce que je suis. À cet égard, tu te rappelles le mot de Buffon que mon directeur de thèse avait utilisé en parlant de mon style d'écriture : ...le style c'est (aussi...) la femme. On a beau essayer de le discipliner, il en reste toujours quelque chose. Et il est bien qu'il en soit ainsi. Alors, qu'il en soit ainsi ! C'est donc avec un coeur rempli d'espoir, celui de me rapprocher de toi, que le bateau est prêt à

1 École du Portique ou stoïcienne parce que son fondateur Zénon de Citiium enseignait au Portique des peintures. École épicurienne ou école du Jardin. Épicure enseignait dans le jardin de sa maison. Voir, de Christian Boissinot, Martin Godon et Isabelle Rivard, L'Art de vivre, p. 8 et 11. 
larguer les amarres pour enfin quitter le port. C'est l'action qui sauve, dit encore Alain. *

Mille tendresses.

* Au fil du temps, dans un petit cahier, j'ai noté des mots que je me suis permis d'écouter, des mots qui m’ont été soufflés, des mots qui m’ont charmée. C’est ainsi que dans mon esprit plusieurs poètes sont nés. Et, à présent, c'est leur accent de sincérité, leurs beautés exprimées que je veux partager. 
Lettres à Jean-Élie.

Clin d'œil aux amants de la sagesse

PARTIE I

\section{Lettre II}

\section{Les chemins du temps}

$\underline{\text { Retour à la table des matières }}$

Hier, je te laissais entendre que je voulais te faire partager mes leçons de sagesse, te dire ce en quoi mes amis m’instruisent. Aujourd'hui, c'est une pensée d'Alain qui m'invite à la réflexion : ...dans les chemins du temps, on ne peut ni retourner en arrière, ni refaire deux fois la même route ${ }^{2}$. C'est parce que je suis arrivée à un tournant que cette pensée prend tout son sens. Les quatre années de ma vie consacrées au Décanat des études de cycles supérieurs et de la recherche viennent de se terminer ${ }^{3}$. Or, cette période de ma vie professionnelle, passée au coeur de l'économie du savoir et des réseaux qui s'y inscrivent, cette aventure donc, m’a ravie. Elle fut riche en expériences de toutes sortes à la fois intellectuelles et humaines. La fin d'une étape, le début d'une autre, n'est-ce pas une invitation à poser son regard sur le trajet parcouru ? Je voudrais donc insister sur deux

2 Alain. Propos sur le bonheur, p. 135. [Livre disponible dans Les Classiques des sciences sociales. JMT.]

3 Le Décanat des études de cycles supérieurs et de la recherche est le service qui, dans certaines universités, dynamise et soutient les études avancées et le développement de la recherche. La personne qui en est responsable porte le titre de doyen. 
mots qui retiennent mon attention et précisent mon observation : dureté et solidarité. Regardons le premier.

En ce début du XXIe siècle, nous sommes loin des ineffables délices que prodiguent l'exercice de la pensée, la recherche des idées, les contemplations tranquilles de la science, comme se plaisait à raconter Balzac ${ }^{4}$. Au contraire, le bonheur de penser, quoi qu'on en dise, se paie de renoncement et de sacrifices. Le travail de professeur d'université est rigoureux et bien capricieux. Non seulement il est laborieux par la diversité et l'ampleur des tâches (préparation de cours, recherche, course aux subventions, services aux collectivités, tâches administratives), mais il requiert une bonne dose de courage et de persévérance. Un article ou une demande de subvention peuvent se voir refusés, par exemple, pour des raisons qui ne sont pas toujours bien graves, en tout cas pour des raisons qui ne sont pas uniquement scientifiques. Pour justifier le refus d'un écrit ou d'un projet, il est permis de croire, de temps à autre du moins, qu'il y a, au mieux, des explications d’ordre idéologique, au pire, des attitudes peu généreuses. Il faut dire aussi que sous le couvert de l'anonymat la plume évaluatrice se révèle bien courageuse. Et pourtant, depuis le créateur de La Comédie humaine, aucune découverte en ce sens : nous ignorons encore le remède au mal que produit une phrase ${ }^{5}$. Alors que l'on sait depuis toujours que les flèches percent le corps, et les mauvaises paroles l'âme (Gracián) ${ }^{6}$. En cela, Un tout petit monde de David Lodge, préfacé par Umberto Eco, qui tente de nous révéler la face cachée du monde des universités ne fait pas fausse route. Donc, pour se consoler d'un insuccès dû au jugement d'autrui, il est pertinent de répéter ce mot d'Alain: ...de toutes les formes d'esclavage ou de la dépendance, celle qui dépend de l'opinion est de loin la plus redoutable ${ }^{7}$. Mais, dans ce tout petit monde, il se fait de bien grandes choses. Et participer à la mission d'une institution de haut savoir ressort du privilège. Quoi qu'il en soit, au cours de ce mandat, une autre particularité a soulevé ma curiosité : la différence notable entre la situation du professeur et celle de l'administrateur. En effet, j'ai pu observer une grande solitude chez le premier, une forte solidarité chez le second. Alors que le travail du chercheur favorise

4 Balzac. La Peau de Chagrin, p. 500.

5 Ibidem, p. 573.

6 Baltasar Gracián. L’Art de la prudence, p. 201.

7 André Bridoux. Alain, p. 65 
l'individualisme - pas toujours, mais souvent - le travail de ceux qui le supportent est, règle générale, empreint de camaraderie et d'entraide. Pourquoi ? Les personnes qui oeuvrent dans les services comprennent vite la nécessité de faire équipe pour réaliser les mandats qui sont les leurs. La société du savoir évolue dans un contexte de mondialisation teinté d'une logique de concurrence qui, dans les universités, s'observe dans le recrutement des étudiants et de chercheurs hautement qualifiés, ainsi que par l'obtention de subventions. Concurrence, compétition, rivalité, les mots attirent par leur proximité. Aussi j’y ai vu se défaire des beaux rêves d'amitié (Stendhal). Tu me permets de tout dire ? L'activité pratiquée au décanat fut pleine de douceur, d'attendrissement, de rires aussi. Et, à certains égards, plus facile à mener que celle réalisée comme professeur, même si j’y ai laissé quelques plumes. Qu'est-ce qui explique le sentiment de bienêtre éprouvé dans l'exercice de cette fonction, me demandes-tu ? J'ai une petite idée. Une partie est certes due à ce que je suis, mais une autre est liée au travail lui-même. Si tu écoutes Alain parler des hommes d'action, tu comprendras. En passant, c'est l'anniversaire de son décès aujourd'hui. En effet, mon ami est mort le 2 juin 1951 à 11 heures 35 dans sa petite chambre du Vésinet en France à l'âge de quatrevingt-trois ans. Les rosiers étaient en fleurs, nous dira André Sernin. Mais revenons à nos hommes d'action. Un préfet de police est, par mon goût, dit mon philosophe, l'homme le plus heureux. Pourquoi ? Parce qu'il agit toujours, et toujours dans des conditions nouvelles et imprévisibles ${ }^{8}$. Et, il faut bien l'admettre, il est entouré de personnes dévouées; des personnes qui, au fil du temps, font partie de votre famille étendue, invoquerait assurément Kurt Vonnegut ${ }^{9}$. Ce n’est pas un petit détail !

8 Alain. Propos sur le bonheur, p. 104. [Livre disponible dans Les Classiques des sciences sociales. JMT.]

9 Un homme sans patrie. Traduit de l'américain par Pierre Guglielmina, Éditeur, Seven Stories Press, New York, 2005, et Éditions Genoël, 2006. 
Lettres à Jean-Élie.

Clin d'œil aux amants de la sagesse

PARTIE I

\section{Lettre III}

\section{Les rivages de la vie}

\section{$\underline{\text { Retour à la table des matières }}$}

Mon ami Sénèque m’a initiée à un certain rituel : recueillir et méditer chaque jour un petit quelque chose, non un grand quelque chose, précise-t-il, qui aide à affronter la vie. C’est dans sa sagesse que j’ai puisé la réflexion d'aujourd'hui. Tout le monde veille à vivre longtemps, alors qu'en fait il est donné à tout le monde de bien vivre, mais de vivre longtemps, à personne ${ }^{10}$. Hier, à l'université, une petite fête était organisée afin de souligner le départ à la retraite de plusieurs des nôtres. Terrain fertile à la réflexion. Une certaine fébrilité était palpable chez certains, alors que d'autres affichaient un enthousiasme débordant ou modéré. Oui, la retraite ne représente plus une étape de vie associée à la vieillesse, bien que celle-ci soit au rendez-vous. Mais il n'en demeure pas moins que la fin d'une carrière constitue une escale. Partout où l'homme travaille, il laisse une partie de son coeur, disait le poète. Mais, en laissant une partie de soi, on emporte un trésor inestimable : celui d'avoir côtoyé des gens de qualité, d'avoir tissé des liens d’amitié et de s’être engagé dans sa communauté. Aussi se détacher de cet univers n'est pas une petite affaire.

10 Apprendre à vivre. Lettres à Lucilius, traducteur Alain Golomb, tome I, p. 32. 
Et il y a plus. Une page de vie qui tourne soulève une valse de questions, d'émotions et d'espérances. À la quiétude du moment vient se mélanger l'inquiétude du lendemain. Comment se manifesteront les fantaisies de la Fortune ? De celles qui peuvent mettre fin brutalement à un parcours qui s’annonce plein de promesses. Ces fantaisies prendront-elles la forme d'une existence qui tourne autour de soins qu'il faut recevoir ou procurer à un proche malade ? Ou celle du départ d'un être cher ? Dans pareilles circonstances, comment surmonter l'épreuve, comment refaire surface suite à ce rendez-vous manqué avec le bonheur ? Oh, attention ! Voilà le coeur qui s’affole. En proie à une pareille agitation, tu m'avais dit un jour, mon cher Jean-Élie: Le malheur n'a pas forcément l'obligation de se présenter. Cette pensée m’a plus d'une fois réconfortée. D'autant plus que les craintes ne nous permettent guère d'avancer, sereinement en tout cas. Car en quoi un trouble intense peut-il nous préserver, non seulement des revers de la Fortune, mais des situations inhérentes à notre condition de vivant ? Du reste, on ne peut toujours pas démissionner du bonheur par crainte du malheur.

Une chose est certaine : la fin de la vie professionnelle modifie l'organisation du temps. Mais ne présente-t-elle pas une occasion à saisir pour développer d'autres centres d'intérêt, élaborer de nouveaux projets et donner libre cours à des ambitions qui, pour toutes sortes de raisons, n'avaient pu, jusqu'ici, s'exprimer? Tisser de nouveaux liens, nourrir les anciens, accorder de l'importance aux petites choses, cueillir les douceurs et les tendresses qui s’amènent ${ }^{11}$. Voilà des prétextes à saisir. Enchantement ou désenchantement, quoi qu'il en soit, la retraite, cette sortie du tourbillon, appelle une rentrée en soi-même. La grande affaire ! Aussi aije demandé à mes amis s’ils n'avaient pas quelques indications à me donner. Il te faut, dit Montaigne, choisir une occupation non pénible, ni ennuyeuse, et cela dépend de ton goût. Pourquoi ne pas choisir la route qui est plus selon ton humeur comme le suggère le poète Properce ? Je pense aussi que la retraite appelle le retrait de l'ambition: gloire et repos ne peuvent loger en même gîte; tout comme elle réclame la fuite des passions qui empêchent la tranquillité du corps et

11 Consulter l'article de Suzie Robichaud, Danielle Maltais, Léandre Bouffard et Nicole Tremblay. "Vieillir à deux au seuil de la quiétude », Le Gérontophile, vol. 22, n 4. p. 9-15. 
de l'âme ${ }^{12}$. Et n'oublie pas le jardin - ce deuxième garde-manger - et la beauté d'un champ soigneusement cultivé, ajoute Cicéron qui, d'un air paisible, vante les joies et le charme de la vieillesse aux champs ${ }^{13}$. À ces doux conseils, Sénèque ajoute sa pensée. Ce temps qu'on te dérobait et qui t'échappait, récupère-le, prends-en soin. Travaille sur toi en t'occupant de la partie que tu sens la moins solide. Et accomplis des actions plus grandes et plus belles que celles que tu as laissées ${ }^{14}$. Se tourner vers autrui alors. Il y a tant à faire. Et les moyens ne manquent pas : l'engagement bénévole, la production artistique, l'écriture d’ouvrages, l'étude des anciens, l'attention pour nos proches, l'adhésion à un groupe, qu'il soit musical, théâtral ou sportif. À bien y penser, aller vers l'autre, c'est aller à la rencontre de soi-même. C'est se porter au-devant de ces mille choses qui semblent des riens et qui cependant sont la moitié de la vie ${ }^{15}$, nous dit Balzac.

12 Montaigne. Essais, tome I, p. 362-365.

13 Cicéron. Savoir vieillir, p. 60-61.

14 Apprendre à vivre. Lettres à Lucilius, traducteur Alain Golomb, tome I, p. 17 et 75 .

15 Balzac. La Peau de chagrin, p. 528. 
Lettres à Jean-Élie.

Clin d'œil aux amants de la sagesse

PARTIE I

\section{Lettre IV}

\section{L’expression de la bonté}

Retour à la table des matières

Hier, j’ai reçu le message d'une femme qui se disait indignée par la façon insolente dont un bénévole avait été traité par l’organisme pour lequel il oeuvrait depuis plusieurs années déjà. En fait, il a été remercié de ses services. Que faire devant un geste aussi irrévérencieux, me demande-t-elle, face à quelqu'un qui, somme toute, cherche à exprimer sa bonté ? Il est malaisé de porter un jugement sur cette situation, car je ne connais pas tous les éléments qui la composent. Néanmoins, j’ai assez réfléchi sur la question pour connaître quelques-unes des difficultés qui sont liées au parcours. En scrutant le phénomène du bénévolat dans toutes ses ramifications, on réalise qu'il sert des intérêts autres que ceux visés par les bénévoles. Les élans du coeur, les actes d'assistance, au nom de l'efficacité recherchée, s’enferment rapidement dans des structures hiérarchiques qui sont le reflet des organisations étatiques. Outre la ségrégation implicite qui tend à se dessiner entre les bénévoles et les dirigeants qui les encadrent, la professionnalisation des interventions et la complexification des problèmes sociaux affectent les personnes qui tentent d'apaiser la détresse. Et ce n'est pas tout. Aux transformations que connaît le bénévolat en ce début de siècle, à tout le moins celui pratiqué dans le domaine de la santé et des services sociaux, viennent s’ajouter les désillusions, les petits désenchantements que la générosité peut susciter. Tu veux des exemples? 
En voici deux. Une bénévole est soupçonnée de vouloir s’approprier une partie de l'héritage qu'une personne âgée destine à ses enfants. Une autre qui court après son souffle - le temps se fait rare - doit essuyer de lourds reproches de la dame qu'elle visite une fois chaque semaine. Elle comprend la solitude qui abrite le blâme, mais les bénévoles ont la culpabilité facile ${ }^{16}$. Toutes ces situations, mon cher Jean-Élie, quelle qu'en soit l'importance, laissent un mal de dent au coeur et peuvent faire éclater l'idéal d'entraide que poursuivent des personnes en rendant assistance à autrui. Et elles montrent aussi que faire le bien contrevient parfois à nos espérances.

Le sociologue Raymond Aaron a affirmé quelque chose qui m’a marquée en regard de l'engagement de l'intellectuel. Ce qu'il en dit peut s'appliquer, il me semble, à quiconque cherche à être utile aux autres. L'intellectuel ne refuse pas l'engagement et, le jour où il participe à l'action, il en accepte la dureté. Mais il s'efforce de n'oublier jamais ni les arguments de l'adversaire, ni l'incertitude de l'avenir, ni les torts de ses amis, ni la fraternité secrète des combattants ${ }^{17}$. Dans cette optique, faire grief des malaises, voire des déceptions que peut produire toute action, fût-elle bénévole, c’est oublier la complexité des relations humaines. La beauté du geste, on le voit bien, ne représente pas une assurance contre la médiocrité de la réaction. Toutefois, ma pensée, c’est que le bénévolat dévoile une manière d'être ensemble, une façon de marquer son rapport à l'autre, et constitue le support indispensable de tout lien social. Du reste, même si les appels du coeur ne sont pas toujours compatibles avec les réponses de la raison, la vie moderne serait encore moins humanisée sans les actions bénévoles. Et donner rend heureux, on l'a dit plus d'une fois. Sénèque, dans son magnifique ouvrage Des bienfaits, écrit : ... il s'agit d'apprendre aux hommes à donner de bon coeur, à recevoir de bon coeur, à rendre de bon cœur ${ }^{18}$. Et ça, tu me l'as appris.

16 Voir Suzie Robichaud. Le Bénévolat. Entre le coeur et la raison, 2003. [Livre disponible dans Les Classiques des sciences sociales. JMT.]

17 Face à l'impossibilité de retracer l’origine de cette citation, Sénèque m’a répété à peu près ce qu'il avait dit un jour à son ami Lucilius : Peu importe où cette citation a été puisée, l'important c'est qu'elle t'aide à comprendre. Et celui qui l'a dit l'a dit pour tout le monde. Et il a ajouté : Toute belle pensée, d'où qu'elle vienne, est mon bien... Voir Apprendre à vivre. Lettres à Lucilius, traducteur Alain Golomb, tome II, p. 36 ; tome I, p. 66.

18 Sénèque. Des bienfaits, p. 10. 
Lettres à Jean-Élie.

Clin d'œil aux amants de la sagesse

PARTIE I

\section{Lettre V}

\section{Les jeux sont faits}

$\underline{\text { Retour à la table des matières }}$

Il y a plusieurs mois déjà, quelque temps avant ton départ, un événement m’a fortement secouée. J’ai décidé alors de taire mon chagrin afin de ne pas ébranler ton coeur de père. Je connais ton amour absolu, celui qui accepte sans condition, soutient sans contestation et ressent par fusion la douleur de l'autre. Mais ma détresse était telle - je m'en étonnais moi-même - que j’ai dû faire appel à mes amis. Trois d'entre eux sont accourus à ma rescousse. Un à un, ils ont sonné à la porte de mon âme ; non pour me faire des discours, mais pour m'apporter des paroles réconfortantes. Le premier à se présenter fut Épictète ${ }^{19}$. Cet homme à la vie rude m'a rappelé la condition essentielle à l'atteinte du bonheur pour chacun de nous: Ne demande pas que ce qui arrive, arrive comme tu veux. Mais veuille que les choses arrivent comme elles arrivent, et tu seras heureuse. Il m’a signalé également qu'en pareille circonstance il fallait considérer avec attention la vraie nature et la nécessité de chaque chose, et résister à la tentation d'ajouter des idées

19 Pensées pour moi-même suivies du Manuel d'Épictète, traducteur Mario Meunier, p. 187, 190, 207. Voir aussi Alain. Propos I, Collection La Pléiade, p. 94. 
aux faits. Un exemple? me demande-t-il d'un air bienveillant. Si un homme te bouscule dans la rue, tu n'as pas à chercher pourquoi. La seule évidence c'est qu'un homme t'a bousculée sans plus. Et, avant de s'en aller, il m’a glissé un petit billet. Je l'ai conservé quelques instants : on aurait dit que j’espérais un miracle. Qu'est-ce à dire ? Un mot qui prendrait le large avec ma peine. Son message ? Le voici : L'heure de la lutte est venue, tu es aujourd'hui comme aux Jeux olympiques, tu ne peux différer et il ne tient qu'à un seul jour et qu'à une seule chose, que tes progrès soient compromis ou confirmés.

Après son départ, Marc Aurèle 20 est entré. En lisant la vie de cet empereur on a meilleure opinion de soi-même, parce qu'on a meilleure opinion des hommes, disait Montesquieu. Alors peux-tu t'imaginer ce que l'on ressent en voyant cet homme d'action et de réflexion, le meilleur et le plus grand de son siècle (Renan) 21 ? D’un ton teinté de respect, de bonté et d'affection, il m’a livré son message : Il te faut aimer pour deux raisons ce qui t'arrive. L'une parce que cela était fait pour toi ; l'autre, parce que ce qui arrive à chaque être contribue à la bonne marche de l'univers. Et il m'a quittée en ajoutant une autre pensée à ma consolation. Il vit avec les dieux, celui qui constamment leur montre une âme satisfaite des lots qui lui ont été assignés, docile à tout ce que veut le génie que, parcelle de lui-même, Zeus a donné à chacun comme chef et comme guide. Et ce génie, c'est l'intelligence et la raison de chacun. Mais j'ai eu beau m'appliquer à intégrer ces règles de conduite, à implorer le bon sens, rien n'y faisait, ma peine n'en finissait plus de finir. Bien humblement, on ne peut s’y tromper : le chagrin m’a emportée. Et il y a plus encore, j'avais tout plein de remords tant il est vrai que le malheur peut distraire de la sagesse la débutante que je suis. Mes amis, voyant que la mer était encore trop agitée, ont décidé d’un commun accord d'appeler du renfort. Devine qui est arrivé ? Nul autre que Sénèque. En le voyant mon coeur a souri (Homère). Écoute, je pourrais te dire que les dieux ont décidé autrement. Eh bien! par Hercule, je veux t'offrir une formule encore plus forte, encore plus juste, qui puisse soutenir ton âme : les dieux ont décidé mieux pour toi ${ }^{22}$. Le vent

20 Pensées pour moi-même suivies du Manuel d'Épictète, traducteur Mario Meunier, p. 75 et 80.

21 Ibidem, p. 24.

22 Apprendre à vivre. Lettres à Lucilius, traducteur Alain Golomb, tome I, p. 135-136 ; Lettres à Lucilius, traducteur Henri Noblot, livre II, p. 143. 
est tombé. Mon coeur s’est apaisé. En paroles secourables, ils s’y connaissent, mes amis, n’est-ce pas?

Or, cet événement m’a fait comprendre une chose, mon cher Jean-Élie. Lorsque les dés sont jetés et que les jeux sont faits, un dernier geste s’impose : s’unir au destin afin d'accueillir son verdict; un verdict qui pourrait émouvoir notre sensibilité. D’un naturel bien capricieux, le destin, sans ambages, jouit d'une grande liberté. Au vrai, il a tout autant la possibilité de nous faire gagner que de nous faire perdre. De plus, il faut reconnaître que la conduite d'une affaire reste soumise à diverses considérations. Il y a, entre autres, le temps, la conjoncture, les alliances, les rivalités, la loi du talion. En tout cas, le coeur et le courage, l'enthousiasme et l'énergie ne suffisent pas à faire naître le succès ; pas toujours du moins. Tandis que le chagrin se recueille et se couvre, il y a donc lieu de regarder bien en face la situation : elle laisse percevoir un chagrin impatient de s’envoler, une consolation empressée d'adoucir et, ce qui peut surprendre davantage, une aptitude prête à instruire. C'est ainsi que s'amène l'apprentissage. Tout doucement elle prête à Shakespeare une oreille attentive. Alors, le poète de dire tout bas : Beaucoup de bruit pour rien ${ }^{23}$. Parole douce à méditer sur la scène de l'espérance. Car il n’est pas inconcevable de penser que l'échec d'aujourd'hui nous convoquera vers la réussite de demain. Qui sait ? On ne saurait prévoir, dans ce moment de tristesse solennelle (George Sand), les aventures pleines de promesses qui sommeillent dans l’antichambre et nous sont réservées.

23 Pièce écrite par le célèbre poète dramatique anglais en 1658: Much Ado About Nothing. Au regard de ce génie, lire le bel ouvrage de Mustapha Fahmi, Shakespeare's Poetic Wisdom, aux Éditions Continents Publishing, 2e édition, 2005. 
Lettres à Jean-Élie.

Clin d'œil aux amants de la sagesse

PARTIE I

\section{Lettre VI}

\section{Les arrêts du destin}

$\underline{\text { Retour à la table des matières }}$

Tu te souviens, il y a dix ans déjà, portés par l'enthousiasme que soulève le désir de faire plaisir à maman, nous lui avions organisé une petite fête pour souligner son soixante-dixième anniversaire de naissance. Il y avait une certaine excitation dans l'air et la réjouissance était au rendez-vous. Au reste, les années m’ont appris à profiter pleinement des plaisirs que renferment les préparatifs d'une activité ou d'une festivité, car, le jour venu, comme le dit si bien Alain, un rien peut briser nos espérances. La Fortune aussi a ses caprices. Coup de barre ! Coup du sort ! Toujours est-il que nous n’étions pas les seuls à nous exciter. En effet, c'est avec ferveur que la météo s’est emballée. La pluie s’est mise à tomber avec une telle intensité et une telle régularité que quarante-huit heures plus tard la ville était inondée. Nous avons vite compris qu’il n’est pas facile de célébrer quand l'ami de la rue voisine a les yeux mouillés. Et voilà qu'aujourd'hui, en ce 19 juillet 2006, les médias se préparent à commémorer le dixième anniversaire de ce désastre. De notre côté, nous nous apprêtons - sans toi cette fois-ci - à réunir parents et amis afin de souligner le quatre-vingtième anniversaire de notre jubilaire. Nous gardons l'espoir d'un ciel plus clément. Quelle chance ! On nous assure une journée 
ensoleillée. Au fond, dans l'ordinaire de la vie, on a beau se dire que le temps ne devrait pas émouvoir notre humeur, il n'en demeure pas moins que le soleil a suffisamment de talent pour changer un banal épisode en une merveilleuse entreprise, voire une inoubliable aventure. À tout événement, rien ne s'oppose à notre gaieté. Maman est en forme - sa meilleure période depuis ton départ - nos invités semblent ravis et le soleil promet d’être généreux. Alors je me dis en moi-même que la vie est bien bonne. Mais voilà que sans crier gare le destin fait son entrée. C’est maman : son coeur souffre d'une sérieuse altération ; elle a failli mourir. Je tiens à te rassurer sur-le-champ. Elle a survécu à un infarctus, à une angioplastie qu'on lui a pratiquée et, comme si ce n'était pas assez, à un accident vasculaire cérébral. Voilà en raccourci. Je te raconterai plus tard, si tu le permets, toutes les craintes et les agitations de l’âme que ce désordre a soulevées. En attendant, point n’est besoin de te préciser que la petite fête est reportée.

Tu sais, Sénèque me rappelle constamment de ne pas me fier à la tranquillité présente. Instantanément, dit-il, la mer est retournée; le même jour où les bateaux jouaient, ils sont engloutis ${ }^{24}$. Sais-tu ce qui m'étonne ? C'est de voir comment la bonace peut nous faire oublier la tempête. Et pourtant les catastrophes ne manquent pas, les épreuves non plus. On dit que les unes surprennent par leur caractère subit et violent, mais les autres aussi arrivent souvent sans s’annoncer. Et toutes deux nous plongent au coeur d'une série de deuils qu'il nous faut apprendre à traverser. Je pense à la perte de sa maison et de ses biens occasionnée par des inondations, un glissement de terrain ou un incendie, par exemple. Bien qu'une forme de sagesse nous invite à un certain détachement par rapport aux valeurs matérielles, est-il si facile de vivre cet abandon qui nous sépare de notre demeure, de nos objets, voire de nous-mêmes ? Les choses ne valent-elles pas par l'importance qu'on leur accorde? Et ne constituent-elles pas notre patrimoine affectif et social ? En outre, ne représentent-elles pas une partie de notre mémoire et de notre présent 25 ? Et je te fais grâce pour le moment de l'immensité du chagrin qu'entraîne la perte d'un être cher.

24 Lettres à Lucilius, traductrice Marie-Ange Jourdan-Gueyer, p. 39.

25 Voir l'article de Suzie Robichaud, Danielle Maltais, Gilles Lalande, Anne Simard et Guy Moffat. "Les inondations de juillet 1996: une série d’événements stressants », Service Social, p. 48 (1), p. 16-33 ; voir aussi, de 
Comment loger dans un coin de ses souvenirs des événements aussi douloureux, sachant que la mémoire a l'impertinence de venir souvent à contretemps (Gracián) et que la guérison ne peut précéder la souffrance. Elle a pris l’habitude de lui succéder. Pareille réflexion appelle une sortie de soi-même, pour ne pas dire un partage. J’ai alors rejoint mon ami Sénèque. Il est de bon conseil. Puis, je ne te le cache pas : sa sagesse me conforte. Veux-tu que je te livre sa pensée ? La voici. Pour éviter d'être submergé par les catastrophes, me dit-il, il faut envisager la Fortune sous tous ses aspects et éviter de prendre pour tout à fait exceptionnels des événements qui sont justes un peu inhabituels. Quand le malheur s'emballe, dire « un jour » c'est lui accorder bien du temps. Une heure, un instant suffisent à faire basculer les empires. De là l'importance, voire la nécessité d'affermir notre âme contre tout ce qui peut arriver. Au regard des épreuves qui sillonnent la vie de tous et chacun - ces arrêts du destin -, ajoute-t-il avec tendresse, je n'ai qu'une question à te poser. Que préfères-tu ? Vivre dans un marché (lieu de plaisir et d'oisiveté) ou dans un camp (quartier militaire) ? Eh bien, vivre, comme je l'ai souvent signalé à notre ami Lucilius, c'est être soldat 26 ! J'ai alors saisi qu'au-delà de la malchance, et il y a des personnes qui n’ont vraiment pas de chance, le destin ne pourra nous soustraire à tous les chagrins ni épargner les êtres que l'on aime plus que tout au monde. Un chagrin ? Demain peut-être. Et, encore, qui sait? À tout le moins, aujourd'hui le temps est beau.

Danielle Maltais, Suzie Robichaud et Anne Simard. Désastres et Sinistrés, aux Éditions JCL, 2001.

26 La pensée de Sénèque a été puisée dans l'ouvrage Apprendre à vivre. Lettres à Lucilius, tome I, p. 115, 116, 132. Pour l'indication concernant le marché et le camp, voir L'Art de vivre, p. 86. 
Lettres à Jean-Élie.

Clin d'œil aux amants de la sagesse

PARTIE I

\section{Lettre VII}

\section{La distance}

$\underline{\text { Retour à la table des matières }}$

Anne, ma soeur Anne, ne vois-tu rien venir ? Maman échappe ce mot tiré de Barbe-Bleue - tu connais son sens de l'humour -, constatant que j'observe avec attention les allées et venues du personnel hospitalier : c'est le médecin que l’on attend. En effet, nous avons besoin de son autorisation pour quitter l'hôpital, pour quelques heures, du moins. Et ce n'est pas une petite affaire, tu peux me croire. Il est seize heures. Comme le temps file. Je me renseigne : Non le docteur n'est pas encore passé. Nous continuerons d'attendre. La patience est de mise, ici. Et pas n’importe laquelle. Oh non ! La patience d'ange. Maman et moi décidons de faire quelques pas dans le corridor. Et les yeux des malades qui croisent notre regard nous paraissent bien tristes. Dix-huit heures. Que voyons-nous à l'horizon ? Le médecin. Il circule dans le département d’à côté. Les journées sont longues, pas seulement pour les malades et leurs familles ; pour les médecins aussi. Alors, d'un commun accord nous décidons, maman et moi, de presser le pas. Dix-neuf heures. Il faudra se faire une raison. Le médecin ne viendra pas ce soir. Il a quitté l'hôpital, pour le moment du moins. Il reviendra probablement ; il est de garde. La maladie n'attend pas le lever du jour pour exiger. Ah ! On nous apprend finalement que c'est tôt le matin, au tout début de sa tournée, que le docteur s’est présenté. Maman s’était alors absentée pour une séance d’ergothérapie. Il aurait fallu s’y prendre autrement, je pense bien. Je m’en veux un peu. Aussi, je me répète ce 
mot d'Épictète : Accuser les autres de ses malheurs est le fait d'un ignorant ; s'en prendre à soi-même est de quelqu'un qui commence à s'instruire ; n'en accuser ni un autre ni soi-même est de quelqu'un parfaitement instruit 27.

À tout événement, tu me demandes pourquoi je te raconte cette anecdote peu signifiante pour ne pas dire insignifiante, alors que depuis plus de deux mois nous assistons à des scènes plus dramatiques les unes que les autres, des scènes empreintes de grands espoirs aussi bien que de grandes déceptions. Et que nous vivons une période où la santé de maman, comme le dirait Alain, a une cote comme les valeurs en bourse ; tantôt elle est en hausse, tantôt elle est en baisse ${ }^{28}$. Je pourrais te répondre, à la blague, que cette anecdote en vaut bien une autre. Mais il y a plus. C'est que dans ce monde plein de chagrin le coeur se referme : il ne veut pas faire de bruit. Au reste, je voudrais partager avec toi une observation qui donne matière à réflexion, il me semble. Mais avant de te livrer ma pensée laissemoi t'apporter des précisions sur la gamme de personnes qualifiées qui entourent maman. Sois très attentif, je te les présente de ce pas. Il y a la préposée, l'auxiliaire infirmière, l'infirmière, l'infirmière bachelière, l'assistante infirmièrechef, l'assistante infirmière chef-bachelière, l'infirmière-chef, l'infirmière de liaison. Et n’oublie pas les horaires de travail, n'oublie pas non plus qu'il y a trois fois huit heures dans une journée, puis les vacances, puis les congés, puis la mobilité. D’autres professionnelles viennent à leur tour : l'ergothérapeute, la physiothérapeute, l’orthophoniste, la neuropsychologue, la pharmacienne, la travailleuse sociale, la nutritionniste ${ }^{29}$. Oh ! j’oubliais : il y a l'aumônier aussi. Et, bien sûr, les médecins spécialistes et les médecins de famille - nous en avons rencontré six à ce jour. C'est de la connaissance qui circule, ça, monsieur, beaucoup de connaissances.

Eh bien, c'est à peine si elle a le temps de s'arrêter, la connaissance. À un point tel que personne ne connaît son malade, dans son entièreté du moins. Et j'entends encore le cri du coeur de Balzac : N'oublions pas le malade... L'homme

27 Pensées pour moi-même suivies du Manuel d’Épictète, traducteur Mario Meunier, p. 186.

28 Alain. Propos, tome I, p. 9.

29 Puisque la majorité de ces professionnelles sont des femmes, le féminin est utilisé à titre épicène. 
n'a-t-il pas une âme, un corps et une raison 30 ? Comment le malade peut-il s'abandonner et se laisser deviner, laisser deviner la personne vraie qui se cache derrière lui ? D’ailleurs Alain dira : Les malades ne sont pas vrais; un homme malade est un homme qui ne s'arrange plus de son milieu physique, et qui ne gouverne plus sa propre machine; disons qu'il se sent vaincu ou tout au moins dominé et diminué par les actions extérieures ${ }^{31}$. Et la douleur qui accapare. Dans un tel contexte, comment ne pas se sentir démuni ? Comment ne pas se sentir isolé au milieu de tant d'étrangers qui ne savent pas qui tu es ? Minute silencieuse. Maman me dit tout bas : L'absence de relations significatives donne l'impression de ne pas exister.

Ainsi, pour peu que l'on repasse les événements, on ne peut faire autrement que de noter une certaine défaillance. Tu veux que je précise ma pensée. Ici, un exemple est bon à considérer. Il y a, comme tu as pu le constater, beaucoup d'intervenants auprès du patient. Il y a aussi beaucoup de patients pour un seul intervenant. Or, les soignants s'épuisent. Les patients, pour leur part, se sentent bien seuls. Au fait, c'est la voix de l'impuissance que l'on perçoit. Pour cause ! La difficulté d'établir un lien important, dans ce moment de grande vulnérabilité, creuse un fossé. Au vrai, elle sépare le malade de ceux qui le traitent. Et c’est ainsi qu’au coeur de la distance j’ai vu énormément de souffrance. Et de mélancolie, également. Ne vois pas de blâme dans mon propos. J’ai croisé trop de gens compétents, intentionnés et généreux qui, dans des conditions difficiles, avaient à faire face à l'impossible. C'est la faute à la fatalité, proclamerait bien haut madame Bovary ${ }^{32}$. Alain s’objecterait. Quoi qu'il en soit, est-il encore possible de nourrir de tendres espérances ? Un fait est certain : il faudra du temps, beaucoup de temps avant que le débat sur l'organisation des soins soit lancé. Les institutions ne se laissent pas faire facilement. Elles sont douées d'une grande ténacité. Et que devient maman ? Tu seras heureux d'apprendre qu'elle est finalement rentrée à la maison. Ce retour a nécessité le secours de la médecine, bien sûr, mais des dieux aussi, dirait sans doute Marc Aurèle.

30 Balzac. La Peau de chagrin, p. 606.

31 André Bridoux. Alain, p. 65.

32 Voir le roman de Gustave Flaubert. Madame Bovary. 
Lettres à Jean-Élie.

Clin d'œil aux amants de la sagesse

PARTIE I

\section{Lettre VIII}

\section{La saison de la sagesse}

$\underline{\text { Retour à la table des matières }}$

À l'heure où Victor Hugo écrit à Juliette Drouet : Ma bougie vient d'expirer. Le jour commence à poindre... J'y vois à peine sur mon papier. Mais il fait à toute heure grand jour dans mon coeur quand il s'agit d'y lire que je t'aime, à cinq heures du matin donc, je réveille mon amour pour lui apprendre ma dernière trouvaille. Je n’ai pu le faire la veille : il est rentré trop tard, je me suis couchée trop tôt. Quel est ce quelque chose qui justifie un réveil aussi précoce ? Je te le donne en mille, mon cher Jean-Élie. Eh bien, voici. Platon ne s'appelait pas Platon mais plutôt Aristoclès. C’est son maître de gymnastique qui l'a surnommé ainsi en raison de sa robustesse. Et le mot Platon en appelle à la largeur de son front ${ }^{33}$. Ah bon ! répond mon amour. J'entends alors son murmure : C'est toute une nouvelle ! Toujours est-il que ses yeux acquiescent au lever du jour. J'y lis alors une autorisation à poursuivre. Il aurait sans doute souhaité que j'enchaîne avec les mots de notre grand romantique : Dors, mon pauvre ange, moi je vais t'écrire. Oh! Je voudrais que toutes les tendres pensées que j'ai pour toi dans le coeur

33 Note de François Préchac et Henri Noblot dans les Lettres à Lucilius, tome II, p. 80 . 
descendissent sur ton beau front endormi en rêves charmants! Ce serait bien juste que mon amour jetât de la douceur sur ton sommeil ${ }^{34}$. C'est qu'il est jeune, notre Hugo : la jeune trentaine. Non que les années nous éloignent des mots d'amour - bien que l'ivresse se présente moins folle pour se faire plus tendre c'est que, ces temps-ci, mon âme est hors de son assiette ordinaire (Stendhal) 35. Douce tristesse, car, en pareille circonstance, peu importe le cadran de mon coeur, mon amour se montre bon prince. Je glisse alors sur la pensée du jour. Et à l'habituel, miracle un autre jour à voir ! ou bien, je me lève parce que j'ai charge d'hommes, comme le disait chaque matin Marc Aurèle, c'est une formule de Sénèque qui paraît. La vieillesse: Accueillons-la! Aimons-la! Elle est pleine de douceur, si l'on sait s'y prendre avec elle. Les fruits ne sont jamais si savoureux que lorsqu'ils sont presque trop mûrs ${ }^{36}$.

Cette maxime m'invite à prêter une attention toute particulière au temps. Le temps qui file et qui dans sa fuite nous conduit, tantôt avec déférence, tantôt avec arrogance, dans cette époque de la vie que les anciens appellent la saison de la sagesse. Car il faut une puissante dose de maturité pour accueillir cette grande dame au visage parfois inquiet et tourmenté. Vision à courte vue, peut-être. S'amènent alors Cicéron ${ }^{37}$ et Sénèque 38 : tous les deux ont longuement réfléchi au grand âge. Écoute-les bien. Il me semble que leur pensée va te rejoindre. Le premier reconnaît quatre raisons possibles de trouver la vieillesse détestable : elle nous écarterait de la vie active; elle affaiblirait notre corps ; elle nous priverait des meilleurs plaisirs ; elle nous rapprocherait de la mort. Justifications bien modernes, ne trouves-tu pas ? Ensuite Cicéron commente lui-même ses arguments. Suivons-le, si tu veux bien. Celui qui avance en âge, dit l'homme politique, peut mettre sa sagesse, sa clairvoyance, sa réflexion, son jugement et son discernement

34 Les deux citations de Victor Hugo se retrouvent dans Les Plus Belles Lettres d'amour, France, Éditions De Saint-Clair, 1967, p. 254-255. Souvenir d'une amie.

35 Stendhal. La Chartreuse de Parme, p. 261.

36 Apprendre à vivre. Lettres à Lucilius, traducteur Alain Golomb, tome I, p. 24.

37 Les idées de Cicéron, présentées tout au long de cette lettre, ont été tirées de l'ouvrage Savoir vieillir, p. 29-32, 39, 40, 54-57, 74, 87.

38 Les idées de Sénèque ont été récoltées dans le volume Apprendre à vivre. Lettres à Lucilius, traducteur Alain Golomb, tome I, p. 25, 132 et tome II, p. 110, 111. 
au service des autres. D'ailleurs, si ces qualités n'existaient pas chez les personnes âgées, nos ancêtres n'auraient jamais appelé le conseil suprême Sénat, c'està-dire assemblée des anciens. Et d'un ton affectueux il enchaîne avec la nécessité de cultiver sa mémoire et de demeurer intellectuellement actif. Cette invitation à l'étude me rappelle une anecdote que mon ami Alain a racontée dans ses Propos sur l'esthétique. Alors que Michel-Ange était presque rendu à la fin de sa vie (il est mort à quatre-vingt-neuf ans), comme on lui demandait: Où vas-tu si vite, Michel-Ange, par ce froid d'hiver ? Je cours à l'école, répondit-il, pour essayer d'apprendre quelque chose. Cicéron poursuit en donnant d'autres exemples d'une vieillesse studieuse : lui-même dans le grand âge a étudié la littérature grecque ; Socrate, la lyre ; Solon se vante de s'instruire quotidiennement sur quelque chose. Sénèque avoue suivre la même trajectoire. Je me déplace chaque jour, dit-il, afin d'écouter un philosophe et je consacre une partie de mes nuits à lire les Grands. Car on ne doit jamais sa sagesse au hasard. Et puis, il serait bien stupide de ne pas apprendre sous prétexte qu'on est resté longtemps sans le faire? Au fond, sagesse ne vient-il pas de savoir? comme le souligne Balzac dans Peau de chagrin. Or, la vigueur dans tout cela ? Il faut, annonce Cicéron, se servir de ce que l'on a et, quoi qu'on fasse, le faire en fonction de ses moyens, user de ses forces avec parcimonie, en somme. Du reste, pour notre orateur latin, l'exercice physique et la tempérance permettent de conserver jusque dans la vieillesse un peu de la résistance d'autrefois. Il nous raconte un petit fait. Milon de Crotone, devenu vieux, se rend dans un stade et observe les jeunes athlètes. Il se regarde et s'écrie, en pleurant: Hélas, mes biceps sont fichus. Cicéron de répondre : Ce n'est pas seulement tes biceps, imbécile, mais toi-même. Et Sénèque d'ajouter : Comment? Tu ne savais pas que tu te souhaitais tout cela en souhaitant vieillir? Dans une vie qui dure, comme dans un long voyage, l'on trouve la poussière, la pluie et la boue. Et là s'amène une question bien délicate. Qu'advient-il des plaisirs ? Il y a, précise Cicéron, la satisfaction des repas équilibrés, le bonheur des conversations partagées, la joie d'être retiré : la solitude favorise le rapprochement avec soimême. D'ailleurs, peut-on souffrir d'être privé de ce qu'on ne regrette point ? Sénèque abonde dans le même sens, mais avec des mots différents : Comme il est doux d'avoir épuisé ses désirs, de les avoir laissés derrière soi. Jusque-là, rien pour consoler le grand Chateaubriand : l'illustre séducteur ${ }^{39}$. Le conduire vers la

39 Jean D’Ormesson. Mon dernier rêve sera pour vous. Une biographie senti- 
résignation, peut-être ; l'acceptation, jamais. Quoi qu'il en soit, nous voilà rendus au point crucial : la mort. La mort ! dit Cicéron. Elle est un risque aussi partagé par la jeunesse. Ne perdons pas de vue également que la nature nous offre un gîte provisoire et non un domicile. Je ne veux pas me faire trop longue, je m'arrête donc ici, cher Jean-Élie. La mort peut devenir un sujet tellement grave et sérieux ; trop grave. Trop sérieux. Qu'en penses-tu ? Nous en discuterons une prochaine fois, si tu le veux bien. En attendant, la vie s'enfuit, ne te montre point si difficile envers le bonheur qui se présente, hâte-toi de jouir, comme le dit encore Stendhal 40 .

mentale de Chateaubriand. Paris, Éditions Jean-Claude Lattès, 1982. Cadeau d'un ami.

40 Stendhal. La Chartreuse de Parme, p. 86. 
Lettres à Jean-Élie.

Clin d'œil aux amants de la sagesse

PARTIE I

\section{Lettre IX}

\section{Le temps des soupirs nostalgiques}

$\underline{\text { Retour à la table des matières }}$

Nul mois de l'année tant que septembre ne contient de douceur simplement donnée ni de ferveur prête à tout perdre ${ }^{41}$. Ce mot d'Anne Philippe nous invite tout doucement à poursuivre notre réflexion, mon cher Jean-Élie. Tu te souviens ? Celle où nous abordions le thème du grand âge avec Cicéron et Sénèque. Nous méditions sur la quatrième raison qui, selon le premier, nous fait trouver la vieillesse antipathique : elle nous rapprocherait de la mort. Au fait, j'oubliais, c'est l'anniversaire du décès de Montaigne aujourd'hui. Oui, il est décédé le 13 septembre 1592 à l'âge de cinquante-neuf ans. Savais-tu qu'il s'était retiré dans sa bibliothèque à l'âge de trente-sept ans pour livrer, avec plein de saveur, l'observation qu'il faisait de la conduite humaine. Cet examen de la vie a donné naissance aux Essais. Ouvrage plein de sagesse, tu peux me croire. Cela dit, tu me demandes pourquoi la question de la mort apparaît d'une si grande importance ? C'est que, selon mes amis, il est impossible d'apprendre à vivre sans apprendre à mourir. Ils se montrent intraitables sur cette question tant ils demeurent convaincus que la peur de la mort empoisonne notre existence et nous empêche de saisir

41 Anne Philippe. Spirale, Paris, Éditions Gallimard, 1971, p. 37. 
l'instant, celui qui raconte la vie et nous invite à faire alliance avec la Fortune. Au reste, si elle nous effraie, demande notre écrivain français, comment est-il possible d'aller en avant, sans fièvre? Il y a plus. Nos grands philosophes savent que le courage devant la mort est la seule chose dont il faudra à coup sûr faire preuve le jour venu ${ }^{42}$. Comme la vie est courte, ils ne sont pas sans ignorer que personne n'est assez vieux pour ne pas espérer vivre un an de plus (Cicéron), non, un jour de plus (Sénèque) ${ }^{43}$.

Toujours est-il que la mort, cette chère voisine, diraient certains, sillonne le coeur et fait écho à l'âme : à l'idée de son immortalité, à tout le moins. Sur cette question, Cicéron avoue qu'il peut se tromper, mais que c'est de bon cœur ${ }^{44}$. Tant que je vivrai, fait-il savoir, je refuserai toujours qu'on me prive de cette « erreur » qui m'est si douce. Car grande est mon impatience à l'idée de revoir tous ceux que j'ai personnellement connus, de rencontrer ceux dont on m'a parlé. Et il avoue aussi qu’il refuserait toute offre, si généreuse soit-elle, qui le ramènerait enfant, c'est-à-dire sur la ligne de départ après avoir, pour ainsi dire, parcouru toute l'arène. Or, poursuit-il, pourquoi se tourmenter ? Si l'âme vit, on gagnera la possibilité de gagner notre véritable séjour, c'est-à-dire le ciel. Si nous croyons qu'elle périt avec le reste du corps, nous ne sentirons plus rien. Le défaut de la vie, ajoute Sénèque, c'est qu'elle est toujours inachevée. Et notre erreur ? Voir la mort devant nous. Alors que, pour l'essentiel, elle est déjà passée. N'estce pas la pire des stupidités de pleurer de n'avoir pas vécu il y a mille ans ? Il est aussi stupide de pleurer parce que dans mille ans on ne sera plus en vie ${ }^{45}$. Si, bien sûr, ajoute Montaigne. C'est pourquoi je veux qu'on agisse et qu'on allonge les offices de la vie tant qu'on peut, et que la mort me trouve plantant mes choux, mais nonchalant d'elle, et encore plus de mon jardin imparfait ${ }^{46}$. Je me dis que

42 Sénèque. Apprendre à vivre. Lettres à Lucilius, traducteur Alain Golomb, tome I, p. 84.

43 Cicéron. Savoir vieillir, p. 36 et Sénèque, Apprendre à vivre. Lettres à Lucilius, traducteur Alain Golomb, tome I, p. 25

44 La pensée de Cicéron a été puisée dans les ouvrages suivants : Savoir vieillir, p. 80-89, et Devant la mort, p. 40, 41, 46, 87.

45 La pensée de Sénèque se retrouve dans l’ouvrage : Apprendre à vivre. Lettres à Lucilius, traducteur Alain Golomb, tome I, p. 42-158 et tome II, p. 27.

46 Montaigne. Essais, tome I, p.137. 
mes amis ont une bonne connaissance de la nature humaine. Et je vois bien que leur sensibilité les rend attentifs à notre désaveu.

Au bout du compte, ils ont beaucoup à raconter. Dans ces conditions, pourquoi ne pas continuer à entendre ce qu'ils ont à nous dire ? Il me semble que leurs propos peuvent semer l'espérance et prêter secours aux coeurs qui frissonnent. La mort nous écarterait des joies de la vie, renchérit Cicéron. Attention! Il serait plus juste de dire : «Des maux. » La mort ne met-elle pas à la vie un terme audelà duquel nous n'aurons plus rien à redouter? Et il poursuit. Mourir avant l'heure. Quelle heure ? La Nature n'a fait que de nous prêter la vie, comme une somme d'argent, sans fixer d'échéance! De quel droit vas-tu te plaindre, si elle la réclame quand elle le décide, puisque c'est à cette condition que tu l'avais reçue ? Sais-tu à quoi je pense, mon cher Jean-Élie ? Combien de fois n'avons-nous pas espéré déserter ce gîte provisoire ? Qui de nous, à trente ans (peut-être avant, peut-être après) ne s'est pas tué deux ou trois fois ? soupire Balzac ${ }^{47}$. En effet, qui de nous ne s’est pas réveillé en souhaitant déposer le fardeau de son âme afin d'échapper à la détresse ; se dérober à un immense chagrin, se soustraire à des inquiétudes pas toujours bien grandes au demeurant. Ou s’écrier, comme Pauline en extase - le bonheur aussi à ses extravagances : Vienne la mort quand elle voudra ! J'ai vécu ${ }^{48}$. Je m'éloigne de mon propos ? Pas autant que les apparences le laissent croire. Néanmoins revenons à notre discussion. Apprendre à mourir c'est aussi, et surtout, apprendre à vivre. Une question surgit alors : comment avancer dans cet apprentissage ?

Il faut, avant tout, dit Sénèque, savoir que le prix de la vie n'est pas dans sa durée mais dans son usage. Alors, le bien, ce n'est pas de vivre, mais de vivre bien. Vivre longtemps, c'est le destin qui décide. Vivre pleinement, c'est notre âme. Mais comment sortir de cette peur qui nous assaille et qui nous pousse à s’interroger, trop s'interroger ? Du reste, en pareille circonstance, Alain dira qu'on se répond bien mal. Où cela va-t-il aboutir ? Combien me reste-t-il à vivre ? Et dans quelles conditions ? Par quel moyen échapper à ce vertige ? enchaîne alors Sénèque. Un seul : faire en sorte que notre vie ne soit pas tendue vers l'avenir mais qu'elle se concentre sur elle-même. Car seuls s'accrochent à

47 Balzac. La Peau de chagrin, p. 545.

48 Ibidem, p. 579. 
l'avenir ceux dont le présent est stérile. Il poursuit : Il y a plus de choses qui nous font peur que de choses qui nous font mal. Que gagne-t-on à courir au devant de sa douleur? Notre douleur! On l'exagère; on l'anticipe; on se la forge. Et c'est ainsi que chacun descend aux Enfers tout vivant, comme Dante ${ }^{49}$, ajoute encore Alain. Écoute bien, ce n’est pas tout. Au terme de cette réflexion, Sénèque livre un conseil à son ami Lucilius, conseil qui a le don de raviver notre courage. Il n'y a, prétend-il, aucune raison de vivre, aucune limite à nos misères, si l'on se met à redouter tout ce qui est redoutable. C'est ici que la sagesse va t'aider, ici que tu dois repousser de toute la vigueur de ton âme la crainte, même fondée. Si tu ne peux pas, combats au moins un vice par un autre, tempère la crainte par l'espoir. Au fait, sais-tu que la mauvaise fortune a, elle aussi, son inconstance ? Peut-être le mal sera-t-il ? Peut-être ne sera-t-il pas ? En attendant, il n'est pas. Envisage le meilleur. Difficile d'ajouter quelque chose à des propos aussi éloquents qui, avec respect, passion et considération, nous entraînent vers une certaine sérénité en dépit des inquiétudes vives. On dit que, pour le poète, le temps des soupirs nostalgiques a pris fin. Pour le sage aussi. Mais qu'en est-il pour les amants de la sagesse ? Ces apprentis qui tentent de s'imprégner de la pensée des anciens ? Ne pas désespérer ; continuer à s'instruire ; vivre pleinement aujourd'hui ; avoir foi au lendemain. Quant à moi, tout est de bon augure si je le veux. Car quoi qu'il arrive, il dépend de moi d'en tirer avantage. Cette parole d'Épictète m'apaise et me berce. Puisse-t-il en être de même pour toi.

49 Alain. Les Idées et les Âges, p. 52. [Livre disponible dans Les Classiques des sciences sociales. JMT.] 
Lettres à Jean-Élie.

Clin d'œil aux amants de la sagesse

PARTIE I

\section{Lettre X}

\section{La bienveillance}

$\underline{\text { Retour à la table des matières }}$

Le mois de septembre dure encore (Balzac) et le marché déborde de produits de toutes sortes. On se croirait au pays de cocagne tant l'abondance laisse échapper de couleurs, de saveurs et de senteurs. Le plaisir des yeux est intense. Je me dis alors qu'il y a bien de l'amour dans ces mille et un petits pots. Le temps des récoltes réclame le souvenir, mais la reconnaissance aussi. Or, ce beau samedi d'automne soulève un élan de gratitude ; rien de surprenant. La profusion nous ramène aisément à l'intervention du soleil, de la pluie, de la terre, des producteurs et des agriculteurs, ceux-là mêmes qui nous permettent de passer d'une saison à l'autre avec une plus grande sérénité. Au fait, il me faut t'avouer, mon cher JeanÉlie, que c'est à Épictète que revient, en partie, le mérite de ma réflexion. C'est une de ses pensées qui m’a mise sur la route de la méditation aujourd'hui. Chaque événement arrivant dans le monde, dit-il, est une occasion facile de louer la providence si l'on possède deux qualités, la faculté de voir (afin de percevoir ce qui est arrivé) et le sentiment de reconnaissance (afin d'exprimer notre gratitude) 50. La providence, donne-t-elle souvent lieu à notre pensée ? La remercier, pour sa

50 Arrien. Entretiens d'Épictète, p. 820. 
nature fidèle et ses beautés, le fait-on assez ? Quoi qu'il en soit, à cette première belle chose qu'est la reconnaissance, nous dit Sénèque, vient s'en ajouter une deuxième : le bienfait. Notre cher philosophe s’est grandement intéressé au sujet. La preuve ? Il a produit un magnifique ouvrage dont je t'ai déjà parlé d'ailleurs : Des bienfaits. Laisse-toi séduire par le charme de ses propos. Tu y entendras parler de bienfaisance et de reconnaissance ; tu y rencontreras les Trois Grâces. Ce n'est pas rien.

Mais regardons ensemble, si tu le veux, le bienfait. Examinons avec Sénèque les principales règles que soulève cet acte de bienveillance qui, selon lui, constitue le lien le plus puissant de la société humaine ${ }^{51}$. En d'autres mots, il tente, et cela en toute modestie, de nous éclairer sur les lignes de conduite qui peuvent guider notre geste : celui d’offrir un présent. Sa pensée va nous instruire, j’en suis certaine. Car donner n'est pas toujours simple ; plus, donner, c'est risqué, me disait un ami d'ici qui a longuement réfléchi à la question ${ }^{52}$. Tu ne le sais que trop, toi, dont la générosité est légendaire. Eh bien, j’arrive à mon propos. Voici les principales prescriptions de notre sage : faire le bien sans attendre rien en retour : en réclamer le paiement, c'est imiter ceux qui prêtent à intérêt. Accompagner un bienfait de joie : c'est le coeur qui est interpellé. Donner avec empressement : tarder à vouloir revient à ne pas vouloir, en somme, toujours la générosité se hâte. La façon de donner est importante aussi. En effet, donner sans la manière reviendrait à être généreux dans la contrainte. C'est ainsi que le langage et l'air du visage peuvent rompre le charme du geste. Tout compte fait, c'est bien simple : donnons de bon coeur, comme nous y invite Sénèque.

Mais il y a autre chose. Il faut également deviner le désir de chacun. Je demande est un mot qui pèse : un service, si prompt soit-il, est venu trop tard s'il est venu sur demande, dit le philosophe. Oh ! j’entends les psychologues. Ils sont réunis en conseil. Certains s'étonnent, d'autres désapprouvent, mais tous discutent. On appelle Alain. Il répétera ce qu’il a écrit dans Les Dieux : Savoir deman-

51 Sénèque. Des bienfaits, p. 10. Et les autres idées qui suivent se retrouvent dans les pages 1-39, 55, 68-74.

52 Le principal danger du don, c'est, pour le donneur, que le don soit mal reçu, nous dit Jacques T. Godbout dans son beau livre Ce qui circule entre nous. Il y a lieu de consulter un autre ouvrage tout aussi séduisant que le sociologue a écrit en collaboration avec Alain Caillé : L'Esprit du don, livre d'ailleurs traduit en plusieurs langues : anglais, italien, portugais, espagnol, turc. 
der est le premier savoir, ouf! Protagoras a raison d'affirmer qu'en tout et en toute chose, on peut aussi bien défendre le pour que son contraire ${ }^{53}$. Quoi qu'il en soit, pour le moment, Sénèque nous révèle une autre pensée ; une pensée qui habite son âme. Une pensée douce à cueillir et à approfondir. En matière de bienfait il faut, dit-il, oublier à la hâte ce que l'on a donné. Se rappeler toujours ce que l'on a reçu. Une question plane pourtant : quoi offrir ? Cela dépend de notre bon vouloir, bien sûr. Mais que désire réellement le coeur humain quand il offre un présent ? Faire plaisir. Voilà le beau mot de notre sage. Et, à la fin, il nous convoque à donner ce qui va durer. Pour quelle raison ? me demandes-tu. Afin que notre présence soit renouvelée autant de fois que celle de l'objet, dit mon ami, l’objet lui-même réveillant le souvenir prêt à s'évanouir. Bref, l'homme le meilleur, précise Sénèque, est celui qui a donné avec facilité, n’a jamais réclamé son dû, s'est vu payé de retour avec joie après avoir oublié de bonne foi ce qu'il avait fait pour autrui ; qui a eu, en recevant le prix de ses bienfaits, les sentiments d'un obligé ${ }^{54}$. C'est ainsi qu'ils se faisaient des présents où celui qui donnait croyait toujours avoir l'avantage, disait Montesquieu 55.

Je ne saurais avancer si les règles de pratique concernant le bienfait bousculent les pensées et causent une rêveuse mélancolie, mais toujours est-il qu'avant de se laisser secouer par le remous, à tout le moins par la tristesse, il y a peut-être lieu de regarder de près le sens qui l'anime : donner de la joie, comme Sénèque nous l'a montré. Et puis, mon ami présente une observation pleine de saveur : C'est l'intention qui fait la valeur du don et mieux encore, lui assure tout son charme. Du reste, la réflexion du philosophe ne cherche surtout pas à faire obstacle à notre désir de donner, car, dit-il, plus souvent la bienfaisance se manifestera, plus elle nous fera honneur. Mais les ailleurs de l'âme, comme l'exprime le poète, nous conduisent parfois bien loin des tranquilles bonheurs. Néanmoins, malgré les interrogations, voire les appréhensions, que soulève le parcours, à quoi bon se priver du plaisir de faire plaisir ? Certes, des situations délicates se présentent à l'occasion. La Fortune ne montre pas toujours son côté débonnaire. Elle nous vole tantôt un bien précieux : le temps ; tantôt nous enlève des ressources : la santé,

53 Apprendre à vivre. Lettres à Lucilius, traducteur Alain Golomb, tome I, p. 111.

54 Ibidem, p. 42.

55 Montesquieu. Lettres persanes, p. 36. 
l'argent. Ah ! Un autre débat pointe le bout de son nez. Quoi qu'il en soit, la bienveillance nous entraîne tout doucement sur la voie de la reconnaissance. Nous en reparlerons un peu plus tard, si tu veux bien. Pour le moment, je suis ailleurs. Mon âme s'est laissé distraire par les choses qui me parlent de toi. 
Lettres à Jean-Élie.

Clin d'œil aux amants de la sagesse

PARTIE I

\section{Lettre XI}

\section{La reconnaissance}

$\underline{\text { Retour à la table des matières }}$

La semaine dernière, j’ai saisi l'occasion de ma visite au marché et d'une pensée cueillie dans le jardin d'Épictète pour te parler du bienfait. Et c'est ainsi que s’est amenée la reconnaissance. Or, pour te faire voir toute la beauté de la chose, j'aimerais te présenter les Trois Grâces - elles suscitent l'intérêt quand vient le temps de parler du bienfait -, et te faire découvrir, l’interprétation que Sénèque fait de ce mythe. Je reviens souvent, pour ne pas dire tout le temps, à cet ami, mais, que veux-tu, son coeur parle facilement au mien. J'espère que tu me comprends et que tu me pardonnes aussi. Cela dit, regardons attentivement les Trois Grâces. Ces trois soeurs vêtues d'une robe sans ceinture et transparente se tiennent par la main et affichent sourire, jeunesse et virginité. Sois attentif aux explications que formule mon ami, bien qu'il se moque un peu de ce genre de savoir. Pourquoi les mains sont-elles entrelacées en cette ronde qui revient sur ellemême ? Parce que le bienfait forme chaîne et, tout en passant de main en main, ne laisse pas de revenir à son auteur... [...] Elles ont un air joyeux, comme ordinairement celui qui donne ou celui qui reçoit ; elles sont jeunes parce que le souvenir des bienfaits ne doit pas vieillir ; vierges, parce que qu'ils sont sans tache, 
sans mélange, sacrés pour tout le monde. Ils ne sont, à aucun degré un lien, une gêne ; aussi les robes qu'elles portent n'ont-elles pas de ceinture ; et elles sont transparentes parce que les bienfaits ne craignent pas les regards 56 .

Et j'aime plutôt cette légende. L’image qu'elle évoque constitue un beau détour pour rentrer, tout en douceur, dans l'univers concret de notions plus abstraites. Et elle permet de saisir, je le crois du moins, toute la beauté, la finesse et la délicatesse du geste : celui de donner ; celui de recevoir. Le premier, nous nous y sommes intéressés dans ma dernière lettre. Alors, passons au second tout en suivant Sénèque. Il ouvre la porte et nous pose une question toute simple : Comment se comporter lorsqu'on reçoit un bienfait ? Des choses qu'il a dites, deux d'entre elles m’ont particulièrement touchée. J'aimerais te les confier, si tu veux bien. Tout d'abord, il y a l'accueil. Eh oui, il s'agit d'accepter le présent avec un visage qui exprime la joie et la gaieté, la gentillesse et la sincérité, avec un élan du coeur, quoi. Et là, s’opère la magie, car, ainsi que le dit mon ami, le coeur suffit pour répondre au coeur. Puis, il y a le souvenir. L’évocation, au vrai, le rappel permet, comme nous y convie Sénèque, de trouver un constant délice au bienfait qu'on nous a donné : Le souvenir fait la reconnaissance. Au fond, garder dans sa mémoire et graver dans son coeur le présent ou le service rendu dévoilent une trace d’âme. Une trace d'amitié qui laisse voir les liens que nous avons tissés et nous rappelle combien nous sommes privilégiés.

Il me semble que ces remarques pourraient interpeller ceux qui, persuadés qu'il est plus facile de donner que de recevoir, acceptent un présent avec un certain malaise. N’y a-t-il pas danger de fragiliser la chaîne du bienfait en voulant garder pour soi le plaisir d'offrir un cadeau et la joie ressentie par celui qui l'accueille ? En tout cas, s’il fallait, mon cher Jean-Élie, soustraire à mon décor tous les bienfaits que j'ai reçus au fil des ans, le vide apparaîtrait à vive allure : matériel, certes, affectif, bien sûr. À bien y penser, la gratitude demeure une composante essentielle du bonheur. C'est ce que je pense, à tout le moins. Avec élégance, elle exerce une grande influence sur notre façon de voir le monde, soi et l'autre; elle éveille les émotions, ranime les aspirations, fait circuler l'enthousiasme, naître et embellir les relations tout en veillant sur elles. Au reste,

56 La pensée de Sénèque est puisée dans son ouvrage Des bienfaits, p. 7, 8, 11, 42-66. 
n’oublions pas que les deux plus belles choses qui existent dans la société, comme Sénèque nous l'a déjà révélé, sont l'âme reconnaissante et le bienfait. Quoi qu’il en soit, il m'est difficile d'exprimer jusqu'à quel point cet échange me trouble. On dirait qu'il a le don d'accroître mon ennui. J'apprécie la douceur de t’écrire même si cette correspondance est active seulement de mon côté (Balzac) ${ }^{57}$. Ces lettres maintiennent vivante ma pensée et ma reconnaissance aussi. Mais elles n’arrivent pas à me consoler de l'absence. Alors, je me dis : faut-il désespérer de se revoir parce que toutes ces années se sont écoulées ? Une idée m’habite depuis quelque temps déjà. Pourtant je la taisais. Un léger tourment? Pas vraiment. Une certaine gêne ? Je crois bien que oui. Mais, aujourd'hui, j'ose passer à l'aveu en faisant appel à ton coeur de père.

Je pars pour Victoria dans quelques semaines. Et ce voyage me conduira dans une partie est de la côte du Pacifique qui te plaît tout particulièrement. Tu t'en souviens ? Tu m’en as si souvent parlé. Quelles sensations réveille en toi le son de Nanaimo ? Je te vois sourire. Or, que dirais-tu d'un petit rendez-vous ? Je te promets la plus grande discrétion. Si le coeur t'en dit et que tu te laisses séduire par ma proposition, retiens bien ce qui suit. Je serai dans ce coin magnifique au cours du mois prochain. Nous pourrions nous rencontrer le 10 novembre à midi à la petite auberge Bastion. Et tu n'as pas à t'inquiéter : tu me reconnaîtras. Je n’ai pas beaucoup changé. C’est vrai que c’est moi qui le dis, mais tout de même... Quelques lignes en plus cependant. Malgré tout, un espoir m’anime : que tu te souviennes de la chanson qui f lattait nos anniversaires : Le temps te laissera quelques rides au front qui t'embelliront. De mon côté, aucun souci à cet égard : je sais que le temps n'a pas beaucoup d'emprise sur toi. Pour le moment, peu m’importe. Les images défilent dans ma mémoire et la pensée même de cette rencontre adoucit le manque. En attendant, je me laisse guider par mon rêve. Il porte merveilleusement l'espoir. Car je sais bien que sans l'espérance je ne rencontrerai jamais l'inespéré. Encore Sénèque ? Non. C'est Héraclite cette fois-ci ${ }^{58}$.

57 Balzac. Le Lys dans la vallée, p. 314.

58 Penseurs grecs avant Socrate, de Thalès de Milet à Prodicos, p. 75. 
Lettres à Jean-Élie.

Clin d'œil aux amants de la sagesse

PARTIE I

\section{Lettre XII}

\section{Les choses du coeur}

\section{$\underline{\text { Retour à la table des matières }}$}

Le samedi 11 novembre, Journée du Souvenir. Moment privilégié pour se recueillir et se rappeler. Laisse-moi donc te raconter aujourd'hui notre rendez-vous d'hier. Six heures du matin. Début de jour magnifique. Nanaimo se réveille tout délicatement. Elle cherche ses plus beaux atours. C’est qu'elle ne veut pas décevoir. Pendant qu'elle se fait une beauté, je m’habille le coeur. N'empêche que c’est avec fébrilité que je traverserai les prochaines heures. D’un côté, je me demande : As-tu entendu ma voix ? Répondras-tu à mon appel ? De l'autre, je me dis en moi-même : Est-il possible de résister à une si aimable invitation et, par surcroît, dans un coin si tendre de la planète? Je dirais bien du pays, mais j’affectionne la sensibilité des gens de mon coin. Toujours est-il que je fais comme si... J'arrive tôt à notre rendez-vous : une heure à l'avance. J'aimerais te voir entrer. J'aimerais te voir me chercher ; un petit peu, du moins. Une chose est certaine, si tu t'amènes, tu ne seras pas en retard. Je connais le cadran de ta montre ; il indique dix minutes avant l'heure. Toujours à l'avance; jamais d'attente pour qui s’amène. Lent, vite, vite, la cadence, la cadence, disait mon professeur de danse. Bien qu'en ce moment c’est mon âme qui tente de suivre le rythme. 
Midi moins un quart. Voilà le coeur qui s’affole. Et si tu ne venais pas ? Car, aussi belle soit-elle, elle n'est quand même pas à la porte, cette cité de l'île de Vancouver. Nanaimo la douce. Celle qui paradoxalement pour toi éveille le souvenir de la Seconde Guerre mondiale. Elle t’aura néanmoins permis de réchauffer les coeurs. Les coeurs serrés de ces hommes qui rentraient le soir fatigués, les yeux inquiets, et qui, tant bien que mal, cherchaient un sens au jour passé. Mais, aux portes du camp, la table était toute servie. Une bonne soupe chaude les attendait. Et le sourire de celui qui la versait avait le don de les réchauffer ; de les réconforter, aussi. Car c'est comme cuistot que tu as pris part à ce sombre événement, une petite anomalie à un doigt de pied t’ayant évité d'aller au combat. Souvenir triste et doux à la fois, m’as-tu rapporté. Triste parce que la guerre révèle ce qu'il y a de moins beau dans l'homme ; doux parce que, tel un véritable poème, rappelle Alain, elle fait briller l'entraide et la solidarité ; la camaraderie et l'amitié. Cela dit, les minutes s'étirent pendant que le coeur s’exécute crescendo. Il en reste une, une de ces minutes à la fois interminables et douces. C'est fou comme un infime espace de temps peut ralentir le regard, et le pas, bien sûr. Miracle ! Je constate à l'instant que le tien semble toujours aussi empressé. Eh bien, oui ! Ta vision s'impose à mon regard. Tu freines ta marche, observes : tu es à la bonne enseigne ; tu enlèves ton béret. Le soleil éclaire ton abondante chevelure. Enfin, tu fais ton entrée. L’air confiant, le sourire espiègle. L'allure fière d'un gars de vingt ans. Ici le coeur s'arrête; le bonheur me porte. Comme tu es beau dans ton habit militaire! Ta tête tourne, mais pas dans la bonne direction. Tu continues d'avancer. J'échappe encore à ton regard. Oh! Tu viens de m’apercevoir. Comment suspendre cet instant ; instant qui comble l'espérance ? Alors que tu t'amènes à table, c'est la voix du silence que l'on entend, celui qui parle mieux que les mots, murmure le poète. Le serveur s'approche, saisit en un clin d'oeil qu'il doit se taire et dépose une coupe de vin et, pour notre jeune soldat, un verre de bière. J’avais anticipé.

Et là, bien malgré moi, il y a entracte : le propriétaire de l'auberge se pointe. On me demande à la réception. Je reviens. Quelques instants à peine se sont écoulés. Stupéfaction ! Tu n’y es plus. Je scrute les alentours. Rien. Je cours à la fenêtre. Et là, je te vois reprendre ta route. Le coeur léger, la démarche tranquille, tandis qu'un son fait écho à mon âme : le son de l'harmonica. C'est What a Wonderful World que l’on entend. La chanson préférée de maman. Trop tôt, trop vite, tu 
échappes à mon regard. Je retourne donc tranquillement à ma place. Je n’ai nulle envie de partir : intriguée, sans être bouleversée. Mélancolique, sans être triste. J'ai tout plein de belles images qui se promènent dans ma tête. Images qui, à tout jamais, resteront gravées dans mon coeur. Je songe au service que je voulais te demander. De fait, j'espérais avec beaucoup d'ardeur que tu remettes une invitation à deux de mes amis: Alain et Sénèque. Ils ne sont plus atteignables ces temps-ci. Étonnamment, la ligne est toujours occupée. Ce n'est pas leur coeur, ils sont trop généreux pour cela et, par surcroît, si gentils pour moi. Aussi j'avais foi en ton coup de pouce pour m'aider à les rejoindre. Ce sera demain, peut-être. Qui sait ? Les choses du coeur recèlent parfois d'insondables mystères. Quoi qu'il en soit, il me faut rentrer. Riche d'un souvenir qui fait naître l'émotion et la reconnaissance, mais qui cause tout de même un petit pincement ; le bonheur suppose sans doute toujours une pointe de douleur qui nous éveille à nous-mêmes ${ }^{59}$. Je me lève et dis : Dieu que j'ai de la chance d'avoir un père comme toi.

59 Alain. Propos sur le bonheur, p. 111. [Livre disponible dans Les Classiques des sciences sociales. JMT.] 
Lettres à Jean-Élie.

Clin d'œil aux amants de la sagesse

PARTIE I

\section{Lettre XIII}

\section{La Sonate à la lune}

$\underline{\text { Retour à la table des matières }}$

Ce n'est qu'un au revoir, me disent les oies blanches, en tout cas les plus hésitantes. Peut-être appréhendent-elles le voyage. Elles savent qu'il sera long ; très long. Ont-elles retenu la leçon de Goethe qu'on ne voyage pas pour arriver mais pour voyager ? Pendant que je me laisse emporter par ma rêverie, je me demande si en cours de route elles n'auront pas la chance de croiser mes amis. C'est qu’Alain et Sénèque sont toujours inatteignables. Faut-il désespérer ? Certainement pas. M’inquiéter ? Oui ; un brin. Mais j’ai décidé de passer outre. Alors, laisse-moi te raconter ma petite aventure, l'aventure d'une idée heureuse, dirait Balzac ${ }^{60}$. Le dimanche 26 novembre dernier, je me rends au Domaine Forget à Saint-Irénée, village pittoresque de Charlevoix. Je ne suis pas sans connaître la passion d'Alain pour la musique classique. Je me dis : pourquoi ne pas l'inviter à un concert. Au programme : les sonates de Beethoven. Il les connaît bien ; il les

60 Le portrait que je fais de mon ami Alain, et les données qui le concernent et le caractérisent prennent principalement leur source dans une formidable biographie. Écrite par André Sernin, elle s’intitule : Alain. Un sage dans la cité. Pour la citation de Balzac, voir « Lettres choisies » dans La Comédie humaine, Éditions Omnibus, 1999, p. 765. 
joue au piano. Mais, pour être franche, la pensée d'une séance musicale m'arrange. C'est que, pour tout avouer, j'éprouve un certain malaise à l'idée d'un tête-à-tête. Tu veux une explication ? J'ai deux raisons au moins. Tout d'abord, Alain m'intimide un peu. Et il semble que je ne sois pas la seule à éprouver cette gêne. En effet, je me suis laissé raconter que certaines personnes avaient refusé de faire sa connaissance. Elles auraient été gênées de se retrouver en face de lui. Ensuite, je ne suis pas une agrégée de philosophie. Donc je ne peux lui parler ni de Socrate, ni de Kant, ni de Spinoza, ni de l'étude qu'il fait lui-même de ces grands personnages. Et la musique ? Cette science des phénomènes d'amour dont Platon a vanté les mérites de l'accord et du rythme lors de son célèbre Banquet, la musique donc, ne pourrait-elle pas nous rapprocher ? Douce fantaisie. Et pourtant j'ai failli abandonner mon projet après l'avoir entendu dire : Les auteurs passés sont d'admirables amis, mais je n'aime point ceux qui voudraient les ressusciter en chair et en os, car tout serait médiocre alors, ou bien comédie 61 . Tu admettras avec moi qu'une pensée comme celle-là tempère l'ardeur, et le désir aussi.

J'interroge mon coeur (Paul Valéry). Il me dit d'être bienveillante envers moi-même. Indulgente également. Ce que mes amis m’ont enseigné par ailleurs. Tu veux tendre l'oreille à Alain et à Sénèque; les rendre présents dans l'absence ? Une solution s'amène: les faire parler et écouter ce qu'ils ont à te signaler. Les mots de Sénèque se pointent en toute hâte : Peut-être as-tu compris les leçons d'Alain tout de travers? Ne l'as-tu pas entendu dire aussi qu'il faut toutes les fois qu'on le peut ressusciter les morts par une pieuse imitation. Ne disait-il pas que Descartes est comme un ami et qu'Auguste Comte lui parle beaucoup et de près 62 ? Tu relèves une contradiction dans ses propos ? Eh bien, c'est qu'Alain fait tout simplement partie du monde des hommes. Et il n'y a pas d'homme sans contradiction. Ensuite, c'est un mot d'Alain lui-même que je perçois: Décider d'avance que les choses feront obstacle au vouloir, ce n'est pas

61 J'ai retracé ce mot d'Alain dans mes notes d'écoliers, comme il l'a déjà dit lui-même. Et à cette époque, je transcrivais la sentence et le nom de son auteur, sans plus. Une chose est certaine : cette pensée d'Alain se retrouve dans l'un des ouvrages cités en bibliographie.

62 Alain avait affirmé ces propos dans un entretien qu'il avait accordé et que j’ai retracé dans un exemplaire numéroté de l'ouvrage Les Idées et les Âges, p. 380. C'est une amie qui m'a offert ce beau livre. 
vouloir ; la foi ne peut aller sans l'espérance ${ }^{63}$. Ces paroles pleines de sagesse ravivent mon courage. En conséquence, c'est un coeur léger et confiant qui porte mon souhait : celui de me rapprocher de mon ami. J'ai tant de choses à lui dire. Tout d'abord, lui confier que je lui dois beaucoup. À Alain je dois tout, déclarait pour sa part André Maurois qui, avec émotion et conviction, avait annoncé la gloire de notre philosophe ${ }^{64}$. Il faut qu'il sache également que je lui suis redevable de ma rencontre avec Montaigne. Un véritable cadeau. De plus, je veux lui faire savoir que son enthousiasme m’a incitée à lire Consuelo, La Comédie humaine, Wilhelm Meister, La Chartreuse de Parme. Et qu'ainsi, George Sand, Balzac, Goethe, Stendhal sont entrés dans ma vie.

Il y a autre chose. Je veux lui avouer que j'ai accepté son invitation : celle de marcher sur le chemin du bonheur. Quelle belle aventure ! Enfin, j'ai hâte de lui apprendre que les propos qu'il a tenus sur le sujet, tout comme ses autres ouvrages, ont été traduits en plusieurs langues : japonais, anglais, allemand, italien et roumain 65. Ainsi Propos sur le bonheur s'est vendu à plus de cinq cent mille copies, et ces statistiques datent de vingt ans déjà. Ce n'est pas rien. Au reste, mon libraire me faisait remarquer qu'avec tous les exemplaires que j'ai achetés au cours des dernières années, le chiffre du demi-million devait être dépassé. Ce livre, que l'on doit à sa précieuse amie Monique More-Lambelin - c'est elle qui a fait le choix des textes -, Alain l'a jugé mineur, nous a-t-on confié. Pourtant son impact aura été majeur. Il lui aura permis de réussir son pari : celui de donner à des lecteurs des raisons de vivre, nous rappelle André Sernin. C’est dire beaucoup.

L'heure du concert approche. La salle est pleine. Une seule place vide : celle à ma droite. Les minutes s'écoulent et puis tout doucement la Sonate pathétique

63 Ibidem, p. 241.

64 Des écrivains de ce siècle, qui durera ? Pour la plupart je n’oserai répondre. Mais je suis certain de celui-là et ne demande pour moi d'autre gloire parmi nos arrière-neveux que d'avoir annoncé la sienne, avait déclaré un jour André Maurois. Voir André Servin. Alain. Un sage dans la cité, p. 17.

65 Alain a été un auteur prolifique. Il a écrit, entre autres, plus de 5000 propos. Chaque année, seulement en France, se vendent 20000 volumes, dont 3500 des quatre volumes de La Pléiade. D’ailleurs, en 1985, il y avait déjà 90000 exemplaires du premier qui étaient vendus. Alain demeure très lu et constamment réédité, rapporte André Sernin. 
parfume mon oreille, mots délicieux du poète. Je ferme les yeux et me laisse charmer par la musique : tendre consolation. Alain ne viendra pas. Et pourtant... ce n'est pas faute d'avoir espéré, ni d'y avoir cru. Bien que... je songe à une de ses paroles: Quand le bonheur paraît être dans l'avenir, songes-y bien, c'est que tu l'as déjà. Espérer c'est être heureux ${ }^{66}$. Et puis, soudain, la sonnette de mon coeur tinte : le bonheur fait son entrée. Il est beau, grand, dans la quarantaine, a le regard aimable et amical, intelligent et transparent, sa présence évoque solidité et éloquence. D’un air doux et bienveillant, il me sourit. Oui, mon cher Jean-Élie, le bonheur, c'est lui ; celui que les étudiants appelaient l'Homme. J'ai compris pourquoi. Alors que se font entendre les premières notes du mouvement adagio de la Sonate à la lune, de ces beaux yeux bleus, je vois glisser une larme. Ainsi, il n’y a pas juste une phrase de Platon qui peut le faire pleurer. Une fois de plus, je réalise pourquoi il est mon ami. Pendant que les notes continuent de s'aimer entre elles (Mozart), c'est un merci profondément ressenti que je t'adresse. Merci pour cet après-midi des plus merveilleux : je le garderai en mémoire tout au long de ma vie. Le fleuve, les sonates de Beethoven, Alain; ce radieux dimanche d'automne me transporte. Au fait, si Alain y était, c'est que ton coeur a su lire dans le mien. Et qu'au surplus cette sensibilité t’a donné matière à générosité, ajouterait certainement Sénèque. Du fond du coeur, merci.

66 Alain. Propos sur le bonheur, p. 199. [Livre disponible dans Les Classiques des sciences sociales. JMT.] 
Lettres à Jean-Élie.

Clin d'œil aux amants de la sagesse

PARTIE I

\section{Lettre XIV}

\section{Le cours heureux de la vie}

\section{$\underline{\text { Retour à la table des matières }}$}

Il y a quelques jours déjà je recevais un appel du Décanat des études de cycles supérieurs et de la recherche : on me demande de participer à une émission à la radio de Radio-Canada. La question du jour : La vie est-elle belle ? Ce sujet me laisse pensive. Je me dis tout bonnement : la vie ? Tantôt elle est belle, tantôt elle ne l'est pas. Envers certains elle se montre généreuse, envers d'autres, plus mesquine. À certains instants, elle sait se faire douce, à d'autres moments, elle se révèle plus impétueuse. Et ce n'est pas tout. Alors que certaines personnes paraissent douées pour le bonheur, d'autres semblent démontrer moins d’habiletés en la matière. Et si le bonheur était inscrit dans nos gènes ? Là, une pensée m’échappe : que répondrait Sénèque à la question ? Sénèque. Figure-toi, mon cher Jean-Élie, que je suis toujours sans nouvelles de lui. C'est étrange. Et sais-tu ce qui me trouble le plus ? La pensée qu'il aurait pu lui arriver un malheur. Douce inquiétude d'un coeur ami (Homère). Pendant que je cherche à t'expliquer une fois de plus pourquoi ce compagnon m'est si cher, j'entends les paroles que Goethe a soufflées au jeune Werther à l'heure des présentations de sa douce Charlotte : Tant de simplicité alliée à tant d'intelligence, tant de bonté alliée à tant de fermeté et le 
calme de l'âme. Voilà mon ami ! Tu comprends aisément pourquoi ces jours-ci mon coeur aurait besoin de se faire bercer par le célèbre musicien qui consolait Balzac en si bémol. Mais je ne désespère pas et continue de nourrir l'espoir d'un signe prochain. Une chose est certaine : Sénèque comprendrait mon hésitation à vouloir discuter du thème présenté. N'a-t-il pas dit un jour : Tout le monde veut une vie heureuse, mais lorsqu'il s'agit de voir clairement ce qui la rend telle, c'est le plein brouillard ${ }^{67}$. Du reste, je suis un peu ébranlée. Je peux certes refuser d'assister à cette causerie. Mais si j'accepte d'y prendre part, je pourrai livrer le message de mon philosophe ; quelques filaments du moins. Et qui sait ? Cela sonnera peut-être doux à son coeur.

C’est ainsi que, dans un premier temps, je décide de converser avec Alain, cet optimiste incurable, dira un jour quelqu'un. C'est bien mal le connaître. Or, selon mon solide percheron ${ }^{68}$, la vie n'est pas facile mais toutes les belles choses sont difficiles. Et l'effort que l'on fait pour être heureux n'est jamais perdu. Au même moment, je lui livre mon inquiétude et lui avoue que j’aurais bien aimé parler à Sénèque avant de poursuivre la réflexion sur les saveurs de la vie. Cette considération l'invite à me prêter secours. Il me dit : Rappelle-toi la définition du bonheur que Sénèque se plaît à donner ; elle est de Zénon. Le bonheur, c'est le cours heureux de la vie ${ }^{69}$. Aussitôt, mon coeur se laisse entraîner vers une captivante histoire. Celle qui raconte comment un esprit scientifique, tourné vers la réalité du monde et désireux de vérité (Pierre Grimal), a rêvé de se faire avant tout apothicaire de l'âme (Alain Golomb). De la même manière, elle me rappelle comment Sénèque, ce tendre et fidèle ami, accueille et embrasse l'existence.

Tout d'abord, il dit oui au mot d'Hippocrate : La vie est courte mais l'art est long. Cependant, il affirme qu'elle offre de vastes perspectives pour qui sait bien l'administrer; donc longue si l'on sait bien en user. Pour notre philosophe, le plus grand obstacle à la vie, c'est l'attente, qui se suspend au lendemain et ruine l'aujourd'hui. C'est pourquoi il enrichit: Est heureux celui qui se contente du

67 Sénèque. De la vie heureuse, p. 723.

68 Alain est né en France à Mortagne-au-Perche. Pour la citation, voir Propos sur le bonheur.

69 Pour cette référence et celle qui vient, voir, de Pierre Grimal. Sénèque ou la conscience d'un empire, p. 40 et 71. Pour l'autre, il s'agit de consulter Alain Golomb. Apprendre à vivre. Lettres à Lucilius, tome I, p. 12. 
présent, quel qu'il soit, et se trouve ami de sa propre condition ${ }^{70}$. Dans cet esprit, on comprend aisément l'intention qui l'anime. Je travaille pour les hommes qui viendront. C'est pour eux que je consigne des choses qui pourront peut-être leur être utiles. Je leur adresse par écrit des avertissements salutaires, d'utiles préparations médicinales en quelque sorte, après en avoir testé l'efficacité sur mes propres blessures ${ }^{71}$. Tu me demandes ce que je retiens principalement de ce qu'il m'a montré ? De bien belles choses. Entre autres, de ne pas me disperser dans mes lectures - être partout c'est être nulle part - ; de faire le compte rendu de chacune de mes journées ; de discipliner ma pensée ; d’éviter les lamentations. Quelle folie de se laisser traîner plutôt que de suivre. Homme de réflexion mais aussi d'action, il m'a fait voir que vivre c'est être utile à soi-même, vivre c'est être utile aux autres. Bref, il m'a invitée à être l'artisan de ma vie ; plus encore, à être amie de moi-même. Sais-tu quoi ? Au cours de la discussion avec l'animateur et le journaliste, j'ai eu la chance et le bonheur de glisser quelques-uns de ces enseignements. Et essaie de deviner la suite des choses. Non, ne dis rien. J'enchaîne à l’instant.

L’émission étant terminée, je quitte doucement le studio en compagnie de mon collègue biologiste et me laisse guider par ma fantaisie. Le majestueux piano dans le hall d'entrée ravive le souvenir d'un concert magnifique : Sonate à la lune. Toujours est-il qu'avant de franchir la porte je lève la tête et, tout au haut de l'escalier, de cet escalier qui inspire grandeur et élégance, un homme attire mon attention. Bien qu'il ne porte pas sa toge, je le reconnais. Et de fait, je le reconnais cet homme accueillant la jeune soixantaine, aux cheveux poivre et sel, vêtu d'un pantalon de velours bleu marine, d'une chemise blanche et d'un cachemire à l'azur du ciel. Son visage affiche un sourire des plus radieux. Et ses yeux répandent une telle douceur qu'il devient difficile d'imaginer une présence plus réconfortante. Nul doute, c’est lui, cet avocat hors pair, ce spécialiste de l'éloquence qui, tout au long de sa vie, m’a-t-on dit, a su séduire par sa simplicité, son amabi-

70 Sénèque, De la brièveté de la vie, p. 695, 696, 704 ; Sénèque. De la vie heureuse, p. 728.

71 Apprendre à vivre. Lettres à Lucilius, traducteur Alain Golomb, tome I, p. 20 et 21 . 
lité et sa gentillesse ${ }^{72}$. Oui c'est bien lui, mon ami. Celui qui depuis plus de dix ans me soutient avec bonté et douceur dans l'apprentissage de la sagesse. Enfin ! Ton Sénèque, dirait maman. Eh bien, mon cher Jean-Élie, voilà un de ces moments qui valent la vie. Et grâce à qui ? Grâce à toi. Alors que je cherche les mots pour traduire la gratitude que ta bienveillance m'inspire, Goethe se présente à nouveau et me glisse sa plume : Il règne dans mon âme tout entière une merveilleuse sérénité semblable à ces douces matinées de printemps que je savoure de tout mon cœur ${ }^{73}$. Ah! Tu tiens à ce que je te confie ma propre pensée : La vie est-elle belle ? Je te la livrerai une prochaine fois si tu veux bien. Car, il me faut te l'avouer : je ne peux me détacher de cet instant si prodigieux.

72 Voir, de Pierre Grimal, Sénèque ainsi que Sénèque ou la conscience d'un empire. De Xavier Bordes, Sénèque. Sur la brièveté de la vie. De Tacite, les Annales.

73 Goethe. Les Souffrances du jeune Werther, p. 48. 
Lettres à Jean-Élie.

Clin d'œil aux amants de la sagesse

PARTIE I

\section{Lettre XV}

\section{Et toi, que dis-tu?}

$\underline{\text { Retour à la table des matières }}$

Décembre : temps idéal pour souscrire à nos rêves. Et, si tu me le permets, j'aimerais te livrer celui qui soutient mes espérances ces temps-ci : le rêve d'une humanité plus humaine, ainsi que le dit Montaigne. Une humanité qui favoriserait un meilleur équilibre des conditions de vie entre les hommes. Comme tu vois, c’est l'égalité des chances qui m’interpelle. As-tu déjà remarqué que, lorsqu’elle fait son entrée, l'inégalité ne se tient pas loin derrière et qu'elle prend facilement la parole ? Or, dès qu'elle se fait entendre, nous voilà plongés dans un moment trouble. Ce n'est guère étonnant puisque l'inégalité nous met aussitôt en contact avec l'impuissance. L’inégalité des chances. La traduire n’est pas une mince tâche. Bien que Goethe l'ait dépeinte au jeune Wilhelm avec une image des plus éloquentes au cours de ses années d'apprentissage. Il lui raconte que certains, dès leur naissance, ont l'avantage de faire la traversée sur le navire tout en profitant des vents favorables alors que d'autres s’épuisent à nager dans des courants peu propices ${ }^{74}$. Comment taire ? Le pire serait justement de taire. Ne pas taire et faire afin que chacun puisse avoir sa chance. À tout événement, pourquoi le douzième

74 Goethe. Les Années d'apprentissage de Wilhelm Meister, p. 206. 
et dernier mois de l'année se prête-t-il si bien à ce genre de réflexion ? C'est que l'entrée dans la saison froide nous conduit au coeur d'une fête pleine de chaleur : la fête de Noël. La magie qu'elle entraîne soulève de la joie, mais de la tristesse aussi. Il y a plus. C'est que les lumières qui scintillent nous plongent non seulement dans le monde de la féerie, mais dans une foule de contrastes. L'abondance fréquente la rareté ; la compagnie côtoie la solitude ; la richesse fait un signe à la pauvreté ; la santé entrevoit la maladie ; les plus âgés évoquent le jeune âge ; les vivants convoquent les disparus. Les souvenirs se réveillent et se raniment, puis s'étalent au grand jour. La détresse se raconte. La générosité s'exprime. Il faut dire qu'elle est très sollicitée à l'heure où le bon vieillard 75 se prépare à descendre du ciel.

Et ce n'est pas tout. Noël apporte - non à tous, mais à certains - les congés, le sapin, la bûche, le réveillon. J'oublie quelque chose ? Tu as raison. Il est difficile d'imaginer Noël sans les étrennes qui l'accompagnent. Et pourtant ! La surprise n'est pas toujours là où on l'attendait. En effet, si certains coeurs s'emballent en déballant les présents, d'autres jettent un voile avant même que l'objet soit dévoilé. Donner n'est pas simple. Recevoir ne l'est guère plus, nous en avons déjà discuté. D'ailleurs, il s'agit d'être attentif à l'expression des visages, de suivre les commentaires qui circulent, d'observer l'affluence dans les magasins la journée du 26 décembre. Que d'échanges! Que de retours! D’aucuns blâmeront la tradition ou la société de consommation et affirmeront qu'ils se sont donné beaucoup de peine pour rien. Mais moi, je dis que sans ces petits gestes d'attention à l'autre dont les cadeaux font partie, la vie perdrait de son charme. Mieux encore, le symbole qui enveloppe le geste justifie grandement l'effort qui doit être fourni, la plupart du temps en fait. Et veux-tu que je te dise toute ma pensée ? Même si l'on décidait de s'offrir l'un et l'autre une carte-cadeau - présent qui semble gagner en popularité -, le bienfait sortirait vainqueur. Quoi qu'il en soit, il y aura d'autres débats, le bienfait laissant échapper quelques considérations, fort délicates sans doute. En outre, le rythme accéléré de la vie, le partage du quotidien et de ses rituels, la diversité des points de vue, la disparité des ressources. Bien du tapage. Alors, malgré lui, le bienfait peut causer du chagrin, provoquer des désordres, soulever des tempêtes. Et l'espace d'une seconde me revient le souvenir de tous ceux qui depuis longtemps tentent d'échapper à la tourmente. Ils savent que le

75 Chanson populaire. 
bienfait, ce langage du coeur, est là pour adoucir, non durcir ; pour réconforter, non angoisser. Du reste, ils lui reconnaissent un don, soit celui de réchauffer les âmes. En somme, c'est avec foi que le bienfait invoque le compromis et l'indulgence, sollicite de nouvelles façons de faire - pourquoi pas ? - et appelle le plaisir d'être ensemble.

Et la vie dans tout cela ? C’est vrai, j'avais promis de te faire partager mon point de vue. Toujours est-il qu’à la question posée lors de ma présence à la radio, la vie est-elle belle ? je n’ai pu répondre ni par l'affirmative ni par la négative, un autre qualificatif m'ayant habité l'esprit. Et, finalement, j'ai dit qu'elle était grande. Grande dans sa beauté et dans sa fragilité ; grande dans sa simplicité et dans sa complexité ; grande dans son humanité et dans ses atrocités. Tu conviendras avec moi que tant de mystères annoncent une incroyable aventure. Une aventure qui peut être tout, sauf ennuyeuse. Mais comment s’y lancer? Avec humilité et sérénité, vaillance et reconnaissance. Je le pense, du moins. La vie. J'ai beau y songer, je me dis qu'on aurait avantage à la prendre avec beaucoup de confiance, un peu d'insouciance - grande et puissante ruse (Alain) - et un brin de folie. Dès lors, je songe à la force de la douce illusion ${ }^{76}$.

Je tenais à te faire part de cette réflexion puisque nous sommes à quelques jours de Noël. Le sixième sans toi. Déjà ! C’est fou comme le temps passe. Le temps. Tout bien considéré, il nous aide à apprivoiser notre peine ; tantôt en nous permettant de nous y dérober, tantôt en nous distrayant, tantôt en nous invitant à utiliser notre raison. Il y a des chagrins qui pèsent si lourd. Cela dit, imagine-toi qu'hier, pendant que je songeais à Moira, la déesse de la destinée, à ses fantaisies, pour ne pas dire ses caprices, tout en me demandant comment je pouvais être utile - chacun cherchant à faire sa part, si minime soit-elle -, on sonne, une fois de plus, à la porte de mon coeur. J'ouvre et, ce que je vois, c'est une petite fille qui n'a l'air de rien du tout. Bonjour, me dit-elle, je m'appelle l'Espérance. Intriguée, je lui tends la main et l'invite à entrer. Et là, je la reconnais, cette petite fille. C'est celle qui étonne Dieu. Tu te souviens, Charles Péguy nous a raconté son histoire

76 De la Revue québécoise de psychologie, consulter les numéros qui vont suivre. Tous deux sont présentés par Léandre Bouffard : "Le Bonheur », vol.18, no 2, 1997 ; « Le plus grand bonheur pour le plus grand nombre », vol. 28, no 1, 2007. 
dans un magnifique poème ${ }^{77}$. Merveilleux hasard. Je me demandais justement comment la retracer. Je voulais lui dire merci. Tu veux savoir pourquoi ? C'est que, eh bien, oui ! le bateau rentre au port. Je quitte alors l'univers de ces lettres. Avec une certaine mélancolie, mais avec beaucoup de gratitude. Car cette correspondance m'aura permis de me rapprocher de toi ; de m'instruire aussi. Elle m'a enseigné que les êtres qui ont fait partie de notre existence et qui nous ont quittés, pour un autre ici ou un ailleurs - et si le ciel nous attendait ? - ces êtres, dis-je, n’ont pas à sortir de notre vie. En fait, s’ils y restent, ils pourront nous aider à faire alliance avec le destin. Et notre héritage ? N’ont-ils pas laissé un peu d'euxmêmes à l'intérieur de nous ? Et, de belles images et de tendres souvenirs ? Les plus ombragés s’adoucissent au fil des ans. Je te prie de me croire, les charmes du passé savent donner de la grâce au moment présent. En tout cas, ceux qui ont de beaux souvenirs vivent longtemps, nous dit Alain 78 .

Enfin, je veux que tu saches que, si tout au long de mes lettres j’ai puisé dans le savoir de mes amis, c'est qu'il était important pour moi que tu apprennes à les connaître, à les aimer aussi. Je te voulais complice de mes leçons de sagesse, de cet apprentissage qui demande rigueur et douceur, patience et constance, pour les amants à tout le moins. Mais ça vaut le coup ; pour une vie plus heureuse. Ne crois-tu pas ? Je me rends compte que j’étire le temps comme il m’arrive de ralentir la lecture d'un ouvrage quand la fin approche et qu'il faille me soustraire aux personnages et aux propos qui me charment et me séduisent. Et pour tout avouer : ce n'est pas simple de mettre un terme à cette routine de bonheur (Balzac) si longtemps rêvée. Oh ! Une dernière chose, si tu me le permets. Sais-tu quel jour elle est née, la petite fille de rien du tout que j'ai rencontrée tout à l'heure ? Figure-toi qu'elle est venue au monde le jour de Noël. Quelle coïncidence! L'Espérance, la belle. C'est à cause d'elle que je ne t'ai pas perdu ; c'est à cause

77 La foi, dit Dieu, ça ne m'étonne pas. J'éclate tellement dans ma création. La charité ça ne m'étonne pas. Ces pauvres créatures sont si malheureuses qu'à moins d'avoir un coeur de pierre, comment n'auraient-elles point charité les unes des autres. Ce qui m'étonne, c'est l'espérance. Et je n'en reviens pas. Que ces pauvres enfants voient comme ça se passe aujourd'hui et qu'ils croient que ça ira mieux demain matin. Ça c'est étonnant et c'est bien la plus grande merveille de notre grâce. Charles Péguy. Le Porche du mystère de la deuxième vertu.

78 Voir Alain. Un sage dans la cité, p. 76. 
d'elle que tu es resté présent dans l'absence. Tu comprends maintenant pourquoi certaines dettes de reconnaissance ne seront jamais acquittées ${ }^{79}$, comme se plaît à dire Sénèque. L'espérance. Tout comme la générosité, elle nourrit le rêve. Et, l'absence de rêve ne laisserait-elle pas supposer l'absence d'avenir ? Voilà, de coeur à coeur, mon cher Jean-Élie, ce que je voulais te dire en cette journée du 20 décembre 2006. Et toi, que dis-tu?

79 Sénèque. Des bienfaits, p. 43. 
Lettres à Jean-Élie.

Clin d'œil aux amants de la sagesse

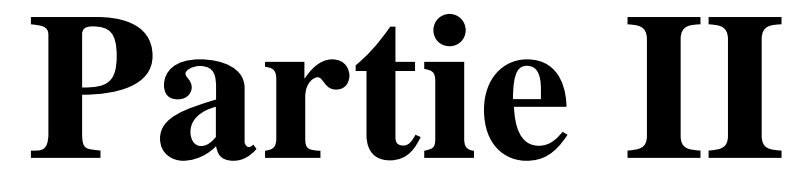

$\underline{\text { Retour à la table des matières }}$ 
Lettres à Jean-Élie.

Clin d'œil aux amants de la sagesse

PARTIE II

\section{HÉRITAGE}

Ce que t'ont légué tes ancêtres, acquiers-le pour le posséder. Goethe

$\underline{\text { Retour à la table des matières }}$

Le Livre premier des Pensées pour moi-même de Marc Aurèle s’ouvre sur la liste des dispositions qui lui ont été transmises par son bisaïeul, son grand-père, sa mère, son père adoptif, son frère et plusieurs stoïciens. La douceur de cette révélation m’a amenée à écrire quelques pages dédiées à l’héritage que j’ai reçu des êtres qui sont le plus près de moi et des philosophes qui m’habitent et m’accompagnent là où la vie me mène. Devoir de mémoire, me direz-vous ? Ah non ! C’est beaucoup plus. Les personnes qui traversent notre existence façonnent notre âme. Certaines croisent l'intimité de notre coeur, d'autres la franchissent et s'y installent, pour un moment ou pour y rester. Pourtant, il n'y a pas l'ombre d'un doute : toutes y laissent des traces. Et pour cause ! Elles ont semé la confiance et l'espérance, la délicatesse et la tendresse, et des mots qui murmurent au gré du vent. J'aurais souhaité identifier chacune. Or, qu’elles soient de sexe féminin ou masculin, elles se retrouvent sous le vocable ami. Au fond, je sais qu'au hasard d'une lettre, d'une pensée ou d'une évocation, elles sauront se reconnaître. Ainsi, c'est par un sourire rempli de reconnaissance que je tiens à les remercier. Au vrai, 
les valeurs et les bienfaits reçus, il s’agit à présent de les porter pour les acquérir et les posséder, comme Goethe le dit si bien.

De mes ancêtres :

La ténacité, la persévérance, la nature sentimentale d’Évangéline (récit du poète américain Henry Wadsworth Longfellow : Conte d'Acadie).

De ma grand-mère maternelle :

La grandeur d’âme.

De mon grand-père maternel :

Le dévouement.

De ma grand-mère paternelle :

La fierté.

De mon grand-père paternel :

La sollicitude.

De mes parents :

L’amour inconditionnel, la prodigalité, le sens de l'accueil ; la valeur de l’engagement ; la splendeur de l’acte bénévole ; la magie de la fratrie. 
De mon père :

L'amour du travail ; la maxime suivante : Il y a des gens pas gentils, mais les gentils sont en plus grand nombre; la joie de faire plaisir ; la serviabilité ; la confiance au lendemain.

De ma mère :

La recherche de l'autonomie : l'autonomie de la femme passe par son autonomie financière ; la curiosité intellectuelle ; la maxime qui suit : On ne sera jamais aussi jeune et aussi beau qu'aujourd'hui ; la force d’âme dans la maladie ; vaincre ma peur : comment ? En me retournant pour voir qui me suit : mon ombre.

De mes soeurs :

L’attachement ; la tendresse ; la complicité.

De ma soeur Ginette :

La vie n'est pas à prendre trop au sérieux ; une coupe de vin a mille vertus : elle apaise l'âme, favorise l'apprentissage, de l'anglais notamment, et maintient vivante l'amitié.

De ma soeur Andrée :

Le rire adoucit le chagrin, désamorce les situations délicates et atténue les difficultés ; l’humanité, la douceur et la sensibilité auprès des malades.

\section{De ma soeur Guylaine :}

Le plaisir de faire voir et de montrer, de découvrir et de partager ; le coeur et le courage, l’énergie et la détermination face aux aléas de l’existence. 
De mon amour :

L’importance de l'humilité ; l'observation de la lune : cet astre de la nuit nous montre de fausses vérités ; en outre, quand elle ressemble à un C c'est qu'elle décroît ; quand elle ressemble à un $\mathrm{D}$ c'est qu'elle croît; le sens de l'écoute : écouter peut aussi vouloir dire ne pas encourager, ne pas consoler, ne pas distraire ; le plaisir - ferment de l'apprentissage - fait fleurir la confiance en soi ; le bonheur d'un amour partagé.

De mon beau-frère Julien :

La bonté.

De mon beau-frère Alain :

La vaillance.

De mon beau-frère Bernard :

L’importance de vivre et de laisser vivre.

De ma nièce Cindy :

La vitalité.

De mon neveu Keven :

La débrouillardise.

De Vincent :

La fidélité. 
De Jacques T. :

La bienveillance.

De Danielle :

L’intensité du coeur.

De Marielle :

L’appel fraternel du dimanche.

De Josée :

La douceur d'une présence.

De mes amies :

L’affection.

De mes amis :

L’assurance.

De mes étudiants :

L’enthousiasme.

De mes amis les philosophes :

L’art de la sagesse. 


\section{D’Alain :}

La règle suivante: le bonheur dépend des petites choses; la nécessité d'accepter les contrariétés de la vie, de surveiller ses états d’âme, ses pensées et son imagination, aussi ; la puissance de la belle humeur ; la rencontre de Montaigne.

\section{De Montaigne :}

Le souci de l'autre ; la retenue ; la modération en tout, même dans la philosophie ; l’intention d'approcher ses semblables avec simplicité et cordialité ; la rencontre de Plutarque et de Sénèque.

\section{De Sénèque :}

L’acceptation de l'inévitable ; la confiance en soi comme composante essentielle d'une vie heureuse ; l’importance de ne pas désespérer de soi-même, de ne pas désespérer non plus d'atteindre la sagesse ; le détachement ; l'invitation à fréquenter l’École du Portique et à visiter le Jardin d’Épicure.

\section{D’Épictète :}

L'aptitude à laisser couler les choses qui ne dépendent pas de moi ; l'acceptation des événements tels qu’ils se présentent ; l’habileté à tirer avantage de ce qui arrive.

\section{De Marc Aurèle :}

Le sens du devoir ; l'ardeur ; la conscience de mon appartenance à la société des hommes. 
De toutes ces personnes

et des autres qui m'entourent :

Le luxe des relations humaines, pour reprendre un mot de Saint-Exupéry.

Et comme le dit Marc Aurèle dans ses Pensées : Tout ceci a exigé le secours des Dieux et de la Fortune.

D’ici j'aperçois mon amie Edmonde. Comme à l'accoutumée, elle adresse un sourire à la Reconnaissance.

Mille fois merci ! 
Lettres à Jean-Élie.

Clin d'œil aux amants de la sagesse

PARTIE II

\section{Compagnons d'aujourd'hui}

Ses disciples demandèrent au

poète Cheb T'Ao pourquoi il

consacrait tant de jours à calligraphier

les poèmes de ses amis, au détriment de son oeuvre propre.

Mon oeuvre propre, répondit-il, est de faire toucher le coeur de chacun par ce qui a touché mon coeur.

(Maxime citée par Claude Roy)

Il a fallu choisir.

Dans les ouvrages de mes amis

- les ouvrages lus évidemment -,

j’ai cueilli les pensées qui m’ont semblé les plus affectueuses. 
Lettres à Jean-Élie.

Clin d'œil aux amants de la sagesse

PARTIE II

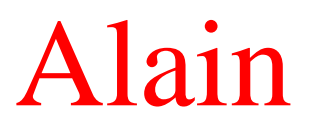

(1868-1951)

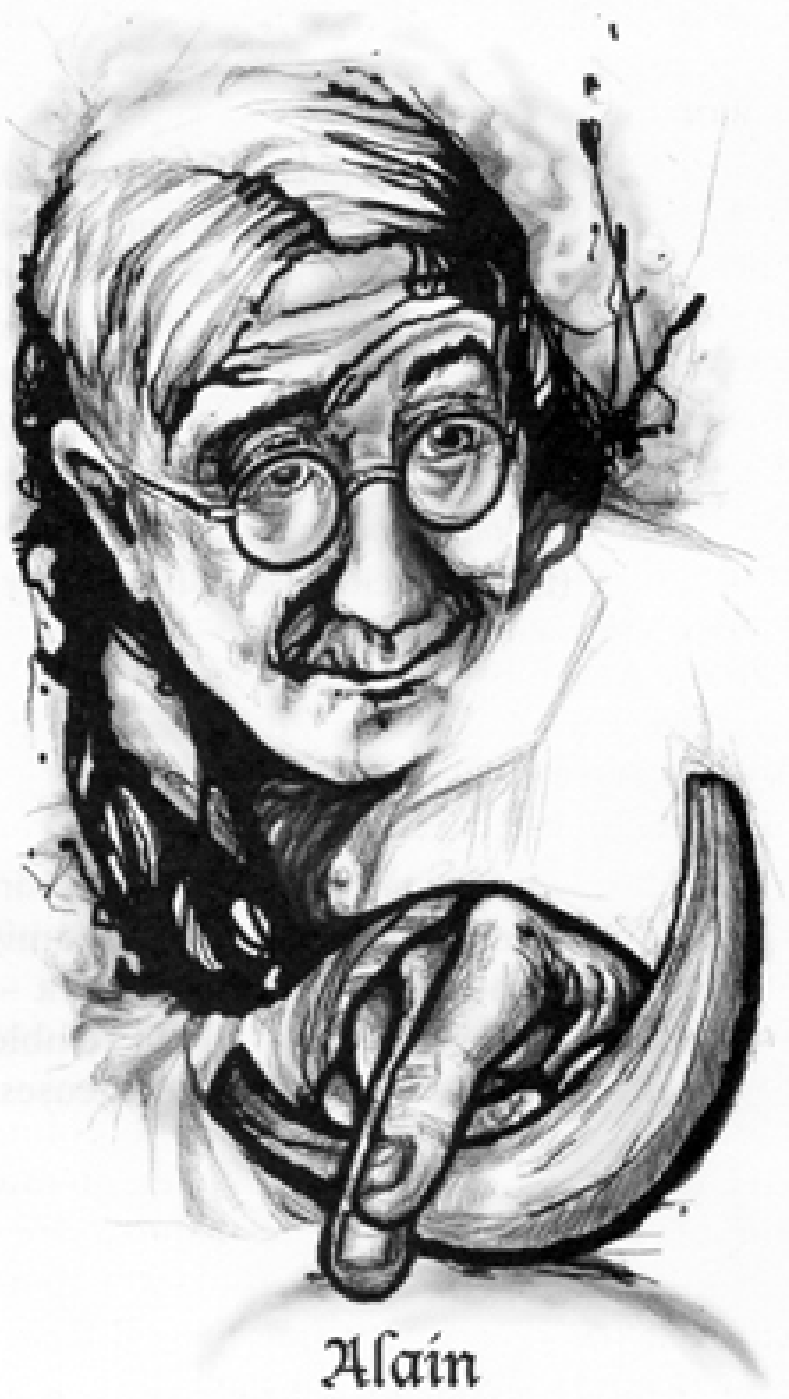

(1868-1951)

$\underline{\text { Retour à la table des matières }}$ 


\section{ALAIN BIOGRAPHIE}

Alain (Émile Auguste Chartier, dit), philosophe et essayiste, est né à Mortagne-au-Perche le 3 mars 1868 et est mort au Vésinet, le 2 juin 1951. Agrégé de philosophie, il enseigne dans différents lycées en province et à Paris. Professeur au tempérament d'artiste, doué d'une remarquable intelligence et d'une profonde humanité qu'il doit à Platon, à Comte, à Descartes et aux stoïciens, nous dit son élève André Bridoux, il exerça une grande influence sur ses lycéens. Même si son âge aurait pu l'en exempter, c'est comme brigadier - il refusa le titre d'officier qu'il prit part à la Première Guerre mondiale. Du reste, ce grand pacifiste en reviendra avec une blessure au coeur (Sernin) ; blessure qui ne guérira guère. Mais de cette douleur naîtront de beaux écrits, tels les 81 Chapitres sur l'Esprit et les Passions et le Système des beaux-arts. Sa retraite donne lieu à une étonnante production bien qu'une attaque cérébrale et de sévères rhumatismes le condamnent au fauteuil roulant : il ne manquait pas d'écrire chaque jour ; il faisait de la peinture aussi. Le 10 mai 1951, à sa résidence, le Grand Prix national de littérature lui est décerné, et ses amis le prient de ne pas le refuser. Son souvenir persiste par son oeuvre, entre autres par ses Propos - courts textes qui tirent leur inspiration du quotidien -, et à travers ses amis; L'Association des amis d'Alain, L'Association des amis du musée Alain et de Mortagne et L'Institut Alain du Vésinet. Et c'est à la 94e division du cimetière du Père-Lachaise à Paris que se trouve le tombeau d'Alain. Toujours est-il que sa philosophie nous offre des pensées qui nous permettent d'exercer une influence sur notre façon de percevoir le monde, nous-mêmes et les autres, et d'agir sur nous, bien sûr. Elle nous rappelle qu'à chaque instant une vie nouvelle nous est offerte..., que nos fautes sont vouées à l'oubli et c'est tout ce qu'elles méritent. 


\section{SOURCES :}

André Sernin, Alain. Un sage dans la cité, Biographie sans masque, Paris, Robert Laffont, 1985.

André Bridoux, Alain. Sa vie son oeuvre avec un exposé de sa philosophie, Paris, Presses universitaires de France, 1964. 


\section{Propos sur le bonheur}

...l'effort qu'on fait pour être heureux n'est jamais perdu.

...les meilleurs événements sourient en vain à l'homme malheureux. Et il y a plus de volonté qu'on ne croit dans le bonheur.

Au reste celui qui veut faire l'insouciant sait bien hausser les épaules, ce qui, à bien regarder, aère les poumons et calme le coeur, dans tous les sens du mot. Car ce mot a plusieurs sens, mais il n'y a qu'un coeur.

Sourire, hausser les épaules, sont des manoeuvres connues contre les soucis.

Nous craignons plus que nous souffrons.

...les plus grands maux sont de mal penser.

Les hommes craignent la mort dès qu'ils y pensent ; je le crois bien ; mais que ne craignent-ils pas, dès qu'ils pensent sans faire?

Contre tous les maux de l'ordre moral, et aussi bien contre les maladies à leur commencement, il faut assouplissement et gymnastique ; et je crois que presque toujours ce remède suffirait ; mais on n'y pense point.

Les coutumes de politesse sont bien puissantes sur nos pensées; et ce n'est pas un petit secours contre l'humeur et même contre le mal d'estomac si l'on mime la douceur, la bienveillance et la joie.

Dans les moments d'anxiété n'essayez point de raisonner, car votre raisonnement se tournera en pointes contre vous-même; mais plutôt essayez ces élévations et flexions des bras que l'on apprend maintenant dans toutes les écoles ; le résultat vous étonnera.

Et comme dirait Spinoza, maître de joie : «Ce n'est point parce que j’ai réussi que je suis content ; mais c'est parce que j’étais content que j’ai réussi. »

Pardonner à soi... c'est plus rare qu'il ne faudrait ; et c'est souvent la première condition si l'on veut pardonner aux autres. 
Et le marin ne rirait-il pas de vous si vous lui disiez que toute la traversée dépend du premier coup de barre?

D’abord la peur nous jette souvent dans le malheur que nous attendons.

...nos craintes, comme on sait, ne nous font pas moins souffrir que les catastrophes elles-mêmes.

L’homme n'a de ressource que dans sa propre volonté...

Le chasseur triste manque le lièvre et dit : "Voilà bien ma chance », et bientôt : «Ces choses-là n'arrivent qu'à moi. » Le chasseur gai admire la ruse du lièvre ; car il sait bien qu'il n'est pas dans la vocation du lièvre de courir à la casserole.

On n'agirait jamais, si l'on considérait le poids immense des choses et la faiblesse de l'homme.

Le plus petit effort entraîne des suites sans fin. Seulement si vous vous mêlez de dire des vérités désagréables à l'homme qui peut vous ouvrir les chemins, ne dites point que vous vouliez passer...

...le présent a sa force et sa jeunesse toujours.

Et qui trop s'interroge se répond toujours mal.

...je dis que plus les sentiments sont sincères et précieux, plus ils ont besoin de politesse.

...mieux on remplit sa vie, moins on a peur de la perdre.

Pourquoi la guerre ? Parce que les hommes se noient alors dans l'action.

Tous les métiers plaisent autant que l'on y gouverne, et déplaisent autant que l'on obéit.

La politique n'ennuie point dès que l'on sait le jeu ; mais il faut l'apprendre. Ainsi en toutes choses ; il faut apprendre à être heureux.

Le signe du progrès véritable en toute action est le plaisir qu'on y sait prendre.

...la foi est la première vertu, et l'espérance n'est que la seconde; car il faut commencer sans aucune espérance, et l'espérance vient de l'accroissement et du progrès. 
Tout change, tout passe. Cette maxime nous a attristés assez souvent ; c'est bien le moins qu'elle nous console quelquefois.

Il n'est pas difficile d'être malheureux ; ce qui est difficile c'est d'être heureux; ce n'est pas une raison pour ne pas l'essayer ; au contraire ; le proverbe dit que toutes les belles choses sont difficiles.

La confiance est un élixir merveilleux.

Les passions sont tristes. La haine est triste. La joie tuera les passions et la haine. Mais commençons par nous dire que la tristesse n'est jamais ni noble, ni belle, ni utile.

Celui qui pense à son passé ou à son avenir ne peut pas être heureux tout à fait.

...parler ensemble pour parler, pour geindre, pour récriminer, c'est un des grands fléaux de ce monde.

...exister c'est répondre aux chocs du monde environnant.

L'insomnie offre des drames où l'on souffre du mal que l'on se fait à soimême.

...aussi bien le jour que la nuit, si l'on a quelque sujet d'être mécontent, on y revient dès qu'on le peut ; on reprend sa propre histoire comme un roman bien noir que l'on a laissé ouvert sur sa table. On se replonge ainsi dans son chagrin.

...la tristesse engendre la tristesse.

...chacun est roi de soi-même et maître des tempêtes pour sa part. Pouvoir immense, que la masse des citoyens doit apprendre à exercer. Soyez heureux d'abord, comme dit le Sage ; car le bonheur n'est pas le fruit de la paix; le bonheur c'est la paix même. Mais je tiens qu'un des secrets du bonheur, c'est d'être indifférent à sa propre humeur ; ainsi méprisée, l'humeur retombe dans la vie animale, comme un chien rentre dans sa niche.

Un homme n'a guère d'autres ennemis que lui-même. Il est toujours à luimême son plus grand ennemi, par ses faux jugements, par ses vaines craintes, par son désespoir, par les discours déprimants qu'il se tient à lui-même.

Et chacun sait bien que la colère et le désespoir sont les premiers ennemis à vaincre. Il faut croire, espérer et sourire ; et avec cela travailler. 
Ainsi la condition humaine est telle que si l'on ne se donne pas comme règle des règles un optimisme invincible, aussitôt le plus noir pessimisme est le vrai.

...les animaux qui ont triomphé sur cette terre ne sont pas les plus colériques ; ce sont les raisonnables, ceux qui gardent leurs passions pour le juste moment.

...il est plus facile de gouverner directement l'humeur des autres que la sienne propre ; et qui manie avec précaution l'humeur de l'interlocuteur est médecin de la sienne propre par ce moyen ; car, dans la conversation ainsi que dans la danse, chacun est le miroir de l'autre.

Une de nos erreurs les plus étonnantes est d'attendre que la colère laisse sortir une pensée longtemps cachée ; cela n'est pas vrai une fois sur mille; il faut qu'un homme se possède s'il veut dire ce qu'il pense.

Si j'avais, par aventure, à écrire un traité de morale, je mettrais la bonne humeur au premier rang des devoirs.

Mais dès qu'une vraie peine tombe sur moi, je n'ai d'autre devoir alors que de me montrer homme et serrer fortement la vie ; et de réunir ma volonté et ma vie contre le malheur, comme un guerrier qui fait face à l'ennemi...

Si quelque tyran m'emprisonnait pour m'apprendre à respecter les puissances, j'aurais comme règle de santé de rire tout seul tous les jours ; je donnerais de l'exercice à ma joie comme j'en donnerais à mes jambes.

Je vous souhaite la bonne humeur. Voilà ce qu'il faudrait offrir et recevoir.

Il y a de ces visages qui portent affiché comme un blâme universel. En ce cas, fuyez si vous pouvez.

Impolitesse est toujours maladresse. La politesse est donc une habitude et une aisance.

Si l'on vous bouscule un peu dans une foule, ayez comme règle d'en rire; le rire dissout la bousculade. La vraie politesse est plutôt dans une joie contagieuse, qui adoucit tous les frottements. Et cette politesse n'est guère enseignée.

Gymnastique et musique étaient les deux grands moyens de Platon médecin.

L’égalité de l'âme ne reçoit pas, en général, de récompenses extérieures; mais elle est certainement favorable à la santé. 
Et il faut une contrainte au commencement et une difficulté toujours. Un travail réglé et des victoires après victoires, voilà sans doute la formule du bonheur.

C'est peu de prendre les êtres comme ils sont, et il faut toujours en venir là ; mais les vouloir comme ils sont, voilà l'amour vrai.

Il est bien vrai que nous devons penser au bonheur d'autrui ; mais on ne dit pas assez que ce que nous pouvons faire de mieux pour ceux qui nous aiment, c'est encore d'être heureux.

Eh bien, c'est surtout en temps de pluie, que l'on veut des visages gais. Donc, bonne figure à mauvais temps.

Aussi n'y a-t-il rien de plus profond dans l'amour que le serment d'être heureux.

Le pessimisme est d'humeur ; l'optimisme est de volonté.

Quelque étrange que cela paraisse d'abord, il faut jurer d'être heureux.

\section{Les Passions et la Sagesse}

...le sommeil apaise. Mais il faut apaiser d'abord si l'on veut aller au devant du sommeil.

...il faut pourtant que je ramène cette idée de méchanceté dans l'être même qui la porte, en considérant, à l'exemple de Platon, que le mal que l'on fait ou que l'on désire aux autres n'est que l'accident secondaire du mal que l'on se fait ou que l'on se désire à soi-même.

...la peur est toujours le vrai mal et le seul mal. D’où l'on verra peut-être enfin qu'il n'y a point de différence entre le savoir vivre et le savoir mourir.

Aussi n'est-ce pas peu de chose, en les occasions difficiles, si l'on sait se parler à soi-même comme on parle à un enfant pour le rassurer.

Il ne faut point dire que se vaincre est le jeu du sage, homme rare. C'est le jeu de tous.

C’est l'incertitude de soi qui donne l'incertitude de l'autre... 
...et il reste que l'amour est un bon maître d'amitié, par cette grâce qu'il inspire. On sait gré à l'être aimé d'être tout ce qu'il est; on fait grâce d'avance à tout ce qu'il sera.

Par l'appât d'un bonheur tout fait, qui toujours trompe, ils manquent le bonheur qu'ils auraient pu se faire par courage et constance.

L'épreuve nous instruit comme il faut et sans aucune ambiguïté ; mais il faut se mettre à l'épreuve, et faire provision de courage.

Car le parti de croire en soi n'enferme pas que tous les chemins s'ouvriront par la foi ; mais il est sûr seulement que tous les chemins seront fermés et tous les bonheurs retranchés si vous n'avez pas d'abord la foi.

La foi ne peut aller sans l'espérance... Essayer avec l'idée que la route est barrée, ce n'est pas essayer. Décider d'avance que les choses feront obstacle au vouloir, ce n'est pas vouloir.

Beaucoup portent devant eux, et souvent bien au-delà de l'adolescence, cette idée puérile que le succès dépend d'une bonne chance... Ici se montre l'envie, qui jamais ne tient compte des travaux...

Nul ne se choisit lui-même. Nul n'a choisi non plus ses parents ; mais la sagesse commune dit bien qu'il faut aimer ses parents. Par le même chemin je dirais bien qu'il faut s'aimer soi-même, chose difficile et belle.

Une belle vie serait donc comme un beau chant. À travers les saisons et les

âges, et sans jamais choisir un autre état que le sien, de l'ordre des choses, de l'ordre humain et de son petit monde, la modestie espère beaucoup et tout.

\section{Les Aventures du coeur}

Il me vient à l'esprit que la jalousie des amoureux consiste principalement dans une scrupuleuse recherche des moindres vérités qui concernent leur cher objet ; en cela ils sont peu compris.

Comme dit Stendhal, il y a des jours où l'on n'est pas disposé pour Raphaël. 
Le vrai travail est avec l'homme; c'est le travail des champs et des jardins, les heureux échanges formés sous le regard, et la division du travail, mais non point des hommes.

En bref, le travail nous communique la générosité ; mais plutôt il la réveille en nous ; et la générosité est le nom que veut donner Descartes au sentiment de notre liberté; car là se trouve notre noblesse.

Quelle est donc l'attitude de l'amour ? Sans doute de dépenser et donner son être, dont le sourire de bienvenue est une très belle marque ; car l'ambitieux ne sait pas sourire sans signifier qu’il va dévorer.

\section{Souvenirs de guerre}

Il faut peu de chose à l'homme qui a juré d'être heureux.

Le pouvoir corrompt le maître et l'esclave ; toutefois un peu moins l'esclave.

...savoir suppose répétition, familiarité, rapidité.

Je demeure persuadé qu'il faut refuser tout pouvoir ; c'est l'attitude la plus efficace contre les pouvoirs, et, comme on l'a dit, la plus offensante.

...il faut un apprentissage en tout. [...] Tout est difficile d'abord, et tout est facile par l'accoutumance.

Et en effet il n'y a rien de difficile dans le jeu d'échecs ni dans aucune combinaison ; mais il faut d'abord la connaître morceau par morceau, et ne rien oublier.

La précipitation est la seule faute; mais personne ne le croit.

...mais il faut savoir que le pouvoir change profondément celui qui l'exerce ; et cela ne tient pas seulement à une contagion de société ; la raison en est les nécessités du commandement, qui sont inflexibles.

...avant de comprendre il faut d'abord apprendre. [...] ...on croit trop vite que l'on sait. 
...intelligemment ne veut pas dire exactement; c'est ce que la météorologie m’a appris.

\section{Mars ou la guerre jugée}

Il ne faut jamais laisser entendre, ni se permettre de croire que la guerre soit compatible, en un sens quelconque, avec la justice et l'humanité.

— Dis-moi, qu'as-tu appris à la guerre ? [...]

- J'ai appris que rien n'est plus utile à l'homme que l'homme, et que rien n'est meilleur pour l'homme que l'homme.

—Étrange ! Mais encore, qu'as-tu appris à la guerre?

- Aussi que les plus grands maux viennent de l'homme, mais que la menace humaine, continuellement perçue pendant des mois, n'affaiblit nullement cette amitié universelle, mais au contraire, à ce que j'ai éprouvé, la fortifie.

—...Allons, sérieusement qu'as-tu appris à la guerre ?

- J'ai appris que tout pouvoir pense continuellement à se conserver, à s'affirmer, à s'étendre, et que cette passion de gouverner est sans doute la source de tous les maux humains...

\section{Chapitres sur l’Esprit et les Passions}

Toute connaissance est bonne au philosophe, autant qu'elle conduit à la sagesse.

Donner importance à ses propres humeurs, c'est petitesse.

...car il est également ignoré que tous les hommes deviennent meilleurs par la bienveillance.

La politesse varie d'une société à l'autre comme le langage : mais le calme et la mesure sont politesse en tout pays. 


\section{Minerve ou de la Sagesse}

L'erreur n'a rien d'étrange ; c'est le premier état de toute connaissance.

Il faudrait oser ; on n'ose point.

Je conçois qu'un rêve atroce qui revient souvent peut réduire un homme au désespoir. Mais Descartes nous conte que, par sa précaution de considérer toujours les événements du meilleur côté, il était arrivé à n'avoir plus que des rêves raisonnables.

«...Un pas et puis un autre. » J'admire dans l'ouvrier une sorte de lenteur qui va fort vite, et un air d'indifférence, par quoi les maisons sont bâties et les tunnels sont percés.

Penser c'est peser.

Si donc l'on entreprend de se délivrer de la peur, il ne faut pas oublier la peur profonde; et s'en délivrer ce n'est pas autre chose que gouverner sa pensée.

Au reste, si on pouvait imaginer les accidents qui sont à chaque moment possibles, on ne bougerait point, on ne vivrait point. La plus simple de nos actions consiste dans une suite d'accidents mortels évités.

Une phrase ne se fait point d'elle-même ; un beau vers ne se fait point de luimême. On voudrait dire que l'inspiration est involontaire, et qu'il faut l'attendre ; mais c'est là une opinion de paresseux.

La défiance a toujours raison, car tout homme joue le jeu auquel on l'invite.

Il faut que chacun aille à sa perfection propre, tournant pour le mieux les obstacles qu'il trouve en lui-même.

L'escrimeur qui a de grandes jambes s'allonge ; celui qui a de petites jambes bondit. Lequel touchera le mieux ? Je prononce que c'est affaire de travail, de courage et de confiance en soi tout autant qu'affaire de jambes et de bras. 
La bonne humeur plaît, elle donne confiance, elle signifie déjà une suite de petits succès.

Celui qui se plaint de la chance des autres se plaint aussi de la sienne. Il se fait ainsi, sans y prendre garde, le visage d'un homme qui n’a pas réussi.

En imposant de simples gestes de politesse, on gagne beaucoup.

Aimer, c'est soutenir, deviner, porter le meilleur de ce que l'on aime. Et c'est la joie qui est le signe de ce sentiment héroïque.

Un impatient, dans une foule, soufflette un homme qui lui marchait sur les pieds : "Combien vous regretterez cette action, dit l'homme, quand vous saurez que je suis aveugle!»

Espérer sans essayer est une faute ; mais essayer sans espérer est le pire mensonge à soi.

L'homme d'esprit et l'athlète sont doux par leur force, et contrôlent le premier mouvement.

Mais l'homme qui ne sait pas beaucoup, et qui s'instruit en ses rares loisirs, avec une peine incroyable, seulement pour honorer sa propre pensée, voilà celui qui mériterait le beau nom de sage.

Bref la bienveillance et le respect des autres sont des devoirs aussi.

On peut défaire n'importe lequel bonheur par la mauvaise volonté. C'est ainsi qu'un préjugé défavorable, concernant un livre, un spectacle, une excursion, leur rendra difficile la tâche de nous plaire.

Remarquez que les plaisirs n'ont guère de prise sur nous si nous ne nous disposons pas à les goûter.

Descartes conseillait d'écarter les pensées tristes, attendu, disait-il, qu'elles sont mauvaises pour la santé, et contraires au succès de toutes les affaires.

...il n'y a de bonheur possible pour personne sans le soutien du courage.

...l'homme ne peut s'empêcher de penser et c'est souvent son propre supplice... Beaucoup auraient besoin d'un art d'oublier et d'une insouciance étudiée. 
Car il faut vouloir que la vie soit bonne ; et d'abord il faut vouloir qu'on puisse le vouloir. Sans ce décret préalable, le malheur va toujours de soi. Car on sait qu'il n’y a pas de situation qu'une inquiète pensée ne puisse gâter.

Dès qu'on a la foi, l'expérience répond. Un beau poème récité, lu, ou copié changera aussitôt le paysage des pensées; oui ; mais à condition qu'on se mette à réciter, à lire, à copier avec assurance; car un tel remède ne vaut rien si on croit, en l'essayant, qu'il ne vaut rien.

Savoir est le maître mot. Et savoir... c'est gouverner ses pensées et d'abord croire qu'on peut les gouverner ; ce qui est croire aussi qu'on peut gouverner ses passions et finalement, ce qui est moins difficile, que l'on peut gouverner l'événement.

Il me semble que l'amour de la vérité doit toujours nous mettre en garde contre un certain genre de franchise qui est de premier mouvement... Toute pensée veut examen.

Je croirais assez que l'extrême fatigue qui accable souvent dans les grandes affaires vient principalement d'un défaut d'éducation. Le naïf s'irrite en écoutant un ennuyeux ; l'homme bien élevé n'écoute guère, et prend souvent occasion d'un discours confus pour prendre un peu de repos.

Solon donna les lois et s'en alla. Ce sage savait qu'il y a objection à tout ; j'entends objection raisonnable.

Chacun connaît trop bien en lui-même cette fausse sagesse qui toujours raisonne et jamais ne décide.

Je trouve imprudent et même injuste de renoncer à persuader un gendarme, un préfet ou un ministre, et de lui jeter, comme on jette des pierres, des opinions qu'il n'est pas préparé à comprendre. Je le dis très sérieusement, ce ministre, je dois l'honorer du nom d'homme, et l'instruire selon la politesse, c'est-à-dire en partant de son opinion, non de la mienne. Cette règle est de charité, et non point de prudence.

Il s'agit de rompre cette pensée, de refuser de la former; et si l'instant d'après on est revenu à la pensée douloureuse, il faut recommencer l'exorcisme ; il faut refuser encore de penser ; ceux qui essaieront plusieurs fois seront surpris 
par réflexion d'avoir réussi. Toutefois la principale condition du succès, comme en toutes actions, c'est de croire qu'on peut.

Il faut oser refuser audience à une pensée, comme on refuse audience à quelqu'un... car une pensée ne vit point sans vous, et d'une vie à elle propre; c'est vous qui la formez; si vous refusez de la former elle se dissout, ou, mieux, elle reste dissoute dans le chaos élémentaire.

Tous les sages ont dit que, dans une vie utile et occupée, il faut encore des moments de fuite en soi-même, ou de retraite, comme on raconte que faisaient les gens d'autrefois, passant une huitaine en jeûne, silence et prière.

...quand vous savez vous détendre et consentir à vous, ne cherchez point quelles pensées vous devez avoir en cette respiration de nature; elles viendront d'elles-mêmes, et ce seront, je le parie, des pensées d'enfance légères et aimées.

Ce qui fait les suites favorables, dans les affaires réelles, c'est premièrement un visage qui porte la confiance, et qui la jette aux yeux.

Mais dans les choses faisables, et juste mesurées à notre puissance, il est clair que l'idée que nous n'allons pas réussir nous rend inférieurs.

Celui qui n'a pas confiance ne se bat pas avec toutes ses forces. Parce qu'il n'est pas heureux en espoir, il ne sera pas heureux dans le fait.

Et si l'on instituait, dans une grande entreprise, un bureau de bonne humeur, chargé d'entretenir le ton, les regards et les sourires, cela ne me semblerait pas plus ridicule qu'une surveillance organisée contre les voleurs.

Le Besoukhov de Tolstoï s'en va répétant : «Tombe, bonne pluie, mouille-moi bien. » Ami des choses, et confiant en ce monde. Tel est le vraie de la prière.

Un vivant est par lui-même un succès étonnant ; car ce grand univers n'a cessé de l'attaquer; un vivant ne cesse de vaincre et de s'affirmer. Voilà ce que nous sommes premièrement, une victoire en marche.

L'homme libre n'est pas le participant d'une vaste entreprise pour la liberté ; c'est un homme qui sait agir, oser, aux frontières mêmes de son corps. Et une somme d'hommes libres sera toujours une nation libre.

Un des moyens de dominer une tâche qui pourrait être écrasante, c'est d'ajourner, c'est-à-dire de ne penser qu'à une chose à la fois et de ne penser à 
chaque chose qu'au moment qu'on a fixé pour s'en occuper. C'est dire qu'il faut avoir un emploi du temps et ne jamais s'en écarter.

Stendhal conte qu'étant jeune il restait la plume levée, attendant le génie. Il n'a pas eu la chance dit-il, de trouver le bienfaisant ami qui lui aurait dit: «Écrivez vingt lignes tous les jours, génie ou non. »

Les plus grands hommes sont sans doute ceux qui, quand tout va mal d'entrée, reconnaissent aussitôt l'ordinaire des choses et le vrai visage de la nature, et de cela même prennent courage au moment où l'homme naïf perdrait courage. Et ces invincibles sont les vrais optimistes.

La politesse est un hommage au semblable, une reconnaissance du semblable, sans enquête, au seul aspect. C'est supposer dans l'autre l'esprit et le coeur, toute la délicatesse possible, et en tenir compte, par la manière d'aller, de venir, de se ranger, d'aider, de ne pas trop aider, de s'intéresser, de ne pas trop s'intéresser.

Le doute est le sel de l'esprit ; sans la pointe du doute, toutes les connaissances sont bientôt pourries. 


\title{
Texte d'Alain communiqué par Maurice Schumann
}

\author{
Reproduit dans : Alain. Un sage dans la cité. \\ d'André Sernin
}

Si je me crois haï, je serai haï ; pour l'amour de même. Si je crois que l'enfant que j'instruis est incapable d'apprendre, cette croyance écrite dans mes regards et dans mes discours le rendra stupide. Au contraire ma confiance, mon attente, est comme un soleil qui mûrira les fleurs et les fruits du petit bonhomme... Le peuple, méprisé, est bientôt méprisable ; estimez-le, il s'élèvera. La défiance a fait plus d'un voleur; une demi-confiance est comme une injure; mais si je savais la donner toute, qui donc me tromperait ? Il faut donner d'abord.

\section{Les Saisons de l'esprit}

Il faut croire en soi et espérer ; mais il faut vouloir croire en soi et vouloir espérer.

Car, à répéter : «Bonne Année !» on finira par se réveiller soi-même à ce qu'on dit. On ne dit pas que l'année sera bonne; on n'en sait rien; ce qui arrive nous surprend toujours; aussi est-il vain d'y penser d'avance. Ce que l'on dit, c'est qu'il faut choisir de la penser bonne, cette année nouvelle. Et sans doute il n'y a rien de plus dans la fête que ce concert de joie; chacun annonce à l'autre que c'est fête. De là l'égalité ; car tous les messages de joie se valent ; un visage heureux a puissance sur vous, et la foule heureuse encore plus.

L'amour, comme l'amitié, se nourrit seulement de surmonter, de pardonner, de permettre, d'effacer. 
Peu à peu le jour se fera : un autre jour, un autre soleil, comme Platon aimait dire.

Épictète disait rudement : «Ne t'effraie pas de cette grande mer, il suffit de deux pintes d'eau pour te noyer. » En suivant cette idée, je dirais que le nageur n'a jamais que ces deux pintes d'eau à surmonter. Si grand que soit l'Univers, il ne me presse que selon ma petite surface. Je le divise, et par là je le possède.

Il m'est signifié par le poète que la mort n'est rien, et que tout moment est éternel et beau si je sais voir. Chacun a l'expérience de ce bonheur soudain, étranger à la durée, et qui fait que l'on aime cette vie passagère.

...et le ridicule est de croire que l'on sait une fois pour toujours... Douter et encore douter ; il n'y a pas d'autre moyen de saisir le temps présent, qui n'attend pas, et qui n'a rien promis, qui n'a nullement promis de ressembler à nos pensées d'hier.

La vraie intelligence est celle qui règle l'intelligence. Et comment, sinon par un doute assuré ? Tout progrès est fils du doute.

...si une foule d'hommes chante, chaque voix s'appuie sur les autres et s'en trouve fortifiée. C'est ainsi que le puissant signal s'envole, et revient à l'oreille comme un témoin de force. Aussi le bonheur de chanter en choeur n'a point de limites ; il ouvre absolument le ciel.

Comme j'ai dit souvent, et assuré de ne pas me tromper : «Écrivez sur vos manchettes que la morale ne consiste jamais à juger le voisin. »Chacun a assez à faire de se conduire. Peur, colère, convoitise, voilà des compagnons difficiles, avec lesquels je me trouve cousu dans le même sac de peau.

Vous savez ce que disait le terrien ; il disait au marin : «Où donc sont morts tes grands-parents et tes parents?

- Ils sont morts en mer, dit le marin.

- Et tu oses t'embarquer! dit le terrien. »

Là-dessus le marin hausse les épaules et va s'en aller; mais il revient et demande :

«Et toi, terrien, où sont donc morts tes grands-parents et tes parents ? "

Le terrien répond qu'ils sont morts dans leur lit. 
«Et, dit le marin, tu oses te coucher!»

J'apprends ici une sorte de loi de l'homme, c'est que le fait d'hier pèse toujours trop, et que, sous le nom d'expérience, c'est l'expérience même qu'on écrase.

Or nous ne cessons point d'échapper, et de défaire le sort; mais, ce qui est digne d'être remarqué, c'est que l'idée même d'un mauvais sort nous fait manquer le saut.

Le principe du vrai courage, c'est le doute. L'idée de secouer une pensée à laquelle on se fiait est une idée brave.

Et j'ai remarqué que la mort est un événement de courte durée ; c'est une maladie de l'imagination, j'entends dans le vivant, maladie qui ne peut durer.

Qu'est-ce que charité ? C'est l'amour, mais non pas de ce qui est aimable; car c'est trop facile; et chacun aurait donc charité s’il admirait le héros, le grand homme, le savant, le saint et toutes les oeuvres bonnes et belles.

Ce qu'attend Socrate, c'est que l'autre soit enfin lui-même, par intérieur gouvernement, et ne croie personne, et ne flatte personne, attentif seulement à l'idée universelle. À ce point, ils se reconnaissent, et se décrètent égaux. Une autre société se montre.

...je fus assez content de ce que je répondis à un camarade soldat, évidemment de bonne foi. "Qu'est-ce que vous pensez, me demanda-t-il, de Dieu le père, de Jésus-Christ, du diable, et de tout ça ? » [...] Je lui dis : "Ce sont de beaux contes. On ne se lasse point des beaux contes. Cela fait comme un autre monde où la bonne volonté triomphe à la fin. Un monde selon nos meilleurs désirs. Ce sont des récits faits à notre forme, et qui conviennent dans les moments où le monde est trop dur... Personne certes ne dira que les beaux contes sont vrais ; mais personne non plus n'osera dire qu'ils sont faux. »

La première chose dont l'homme ait besoin pour vivre, c'est le pardon.

Comme j'allais déchirant le papier, l'ombre de Marc Aurèle m'apparut, grave et même un peu triste, telle que je l'imagine. Il me dit : «...Instruis les hommes, si tu peux ; si tu ne peux les instruire supportes-les... Les instruire, c'est premièrement les prendre comme ils sont et les aimer comme ils sont... ». 
L'amour maternel est plus pur, et l'amour paternel est plus difficile. L'un est pur parce que de son mouvement naturel il délivre. L'autre est difficile, par le souci de gouverner temporellement. Mais l'un et l'autre sont bien clairement soumis à la loi de tout amour, qui est de ne jamais forcer, ni emprisonner, ni lier. 
Lettres à Jean-Élie.

Clin d'œil aux amants de la sagesse

PARTIE II
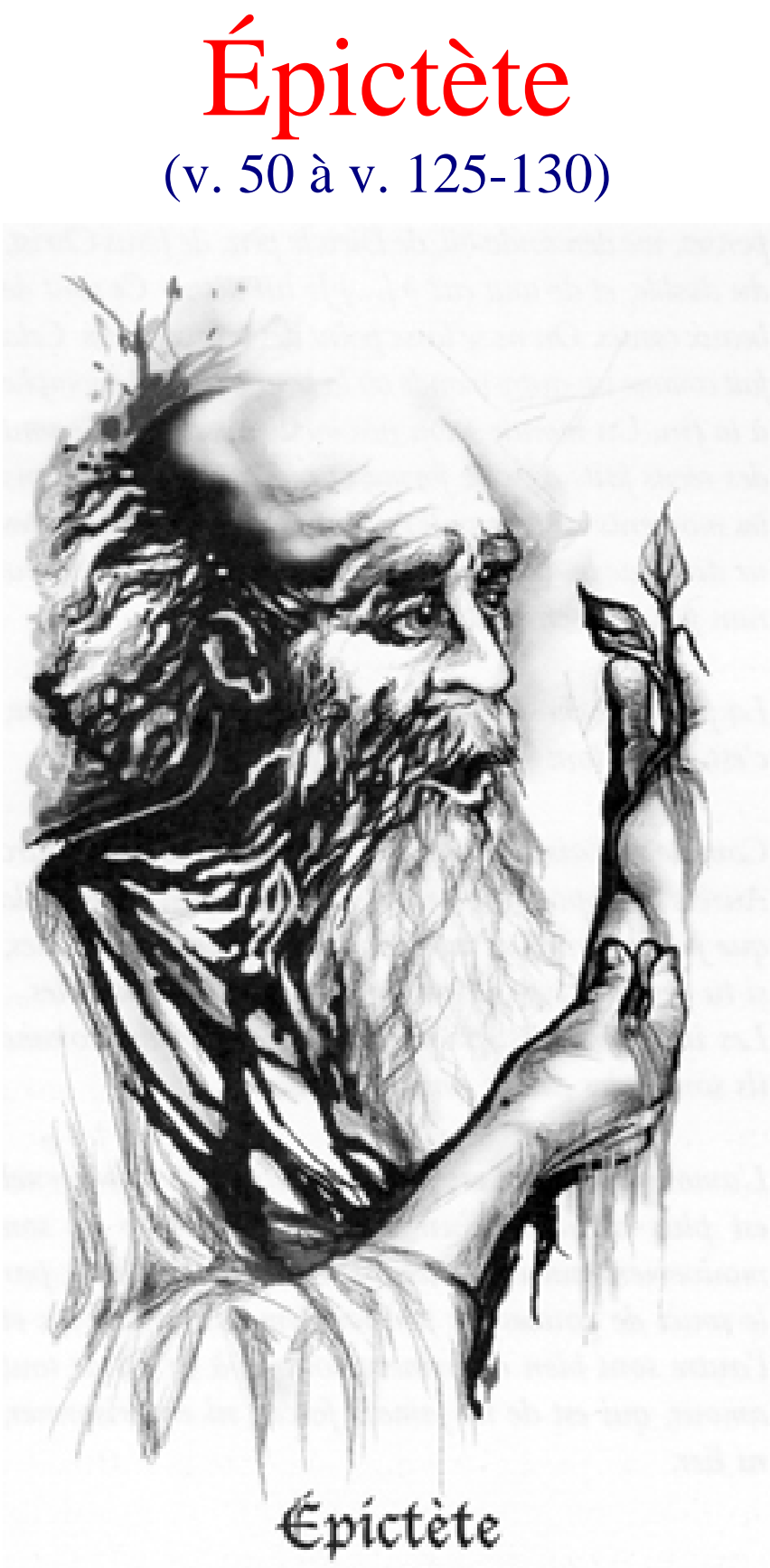

(v. 50 à v. 125-130)

$\underline{\text { Retour à la table des matières }}$ 


\section{EPICTÈTE BIOGRAPHIE}

Épictète, philosophe stoïcien et pédagogue romain, est né à Hiérapolis en Phrygie - dans l'actuelle Turquie - vers l'an 50, et est décédé à Épire entre les années 125 et 130. C'est comme esclave qu'il fut amené à Rome par son maître Épaphrodite, lui-même affranchi de Néron. Charmé de l'esprit et des heureuses dispositions de son esclave, dira Mario Meunier, Épaphrodite autorise Épictète à suivre les cours de Musonius Rufus et lui rend alors sa liberté. C'est donc à Rome que débute l'enseignement d'Épictète. Toutefois, c'est dans la cité grecque de Nicopolis qu'il le poursuivra, l'empereur Domitien ayant banni les intellectuels de Rome et de l'Italie. Son école connaîtra un grand succès. Celui qui nous a légué la plus grande leçon de sagesse de l'Antiquité (Duhot) n'a rien écrit. En effet, c'est grâce aux notes de cours prises par son élève Arrien que son enseignement nous est parvenu et que nous pouvons lire les Entretiens et le Manuel. Au reste, c'est parce que ces notes s'étaient mises à se répandre que l'élève en a accepté la diffusion après en avoir assuré l'authenticité. Et mieux encore, il avait la conviction que les leçons de son maître étaient pleines de richesses et pouvaient dès lors aider les hommes à mieux vivre. Or, mieux vivre, s'instruire c'est, selon Épictète, apprendre à vouloir chaque événement tel qu'il se produit.

\section{SOURCES :}

Jean-Joël Duhot, Épictète et la sagesse stoïcienne, Paris, Éditions Albin Michel, 2003.

Christian Boissinot, Martin Godon et Isabelle Rivard. L'Art de vivre. Les Stoïciens et Épicure, Québec, Les Éditions CEC, 1998.

Marc Aurèle. Pensées pour moi-même, suivies du Manuel d'Épictète, traduction, préface et notes par Mario Meunier, Paris, Flammarion, 1964. 


\title{
Manuel d’Épictète
}

\author{
Traducteur : Mario Meunier
}

Il y a des choses qui dépendent de nous ; il y en a d'autres qui n'en dépendent pas. Ce qui dépend de nous, ce sont nos jugements, nos tendances, nos désirs, nos aversions : en un mot, toutes les oeuvres qui nous appartiennent. Ce qui ne dépend pas de nous, c'est notre corps, c'est la richesse, la célébrité, le pouvoir ; en un mot, toutes les oeuvres qui ne nous appartiennent pas.

Ainsi donc, à toute idée pénible, prends soin de dire : "Tu es idée, et tu n'es pas du tout ce que tu représentes »... Et, si elle se rapporte aux choses qui ne dépendent point de nous, sois prêt à dire : «Cela ne me concerne pas. »

Ne dis jamais de quoi que ce soit : « Je l'ai perdu. » Mais : « Je l'ai rendu. »

Quelqu'un perd-il son fils ou sa femme? Il n'est personne qui ne dise: «C'est dans l'ordre humain. » Mais quand on fait cette perte soi-même, aussitôt on dit: "Hélas! infortuné que je suis !» Il faudrait se souvenir de ce qu'on éprouvait à l'annonce du même événement survenu chez les autres.

Si l'on vient te dire qu'un tel a mal parlé de toi, ne te justifie pas sur ce qu'on te rapporte, mais réponds : "Il faut qu’il ignore tous les autres défauts qui sont en moi, pour ne parler que de ceux-là seuls qui lui sont connus. »

\section{Les Stoïciens Entretiens}

Agrippinus disait : « Je ne me fais pas obstacle à moi-même. »

«[...] Mais on ne devient pas soudain un taureau ni un homme généreux; il y faut de l'exercice, de la préparation; il ne faut pas se lancer à la légère dans des entreprises qui ne répondent pas à ce que nous sommes. »

Quelle est l'oeuvre de la vertu ? Le calme. 
...l'important, c'était de s'exercer à supprimer de sa vie les lamentations, les gémissements, les « hélas! » les «malheureux que je suis! », les malchances, les échecs...

Contre qui résiste à la très grande évidence, il n'est pas facile de trouver une raison qui le persuadera...

Ce que l'on tient de soi-même, il serait bien inutile et vain de le demander à un autre.

...s'instruire, c'est apprendre à vouloir chaque événement tel qu'il se produit.

Quelle est la punition de ceux qui n'acceptent pas les choses ? C'est d'être précisément comme ils sont.

Ne sois pas plus lâche que les enfants; quand la chose ne leur plaît pas, ils disent : « Je ne jouerai plus »;

toi aussi, quand tu crois être en semblable situation, dis : je ne jouerai plus, et va-t’en ; mais si tu restes, ne gémis pas.

Ce n'est pas la mort ni la souffrance qui sont à craindre, c'est de craindre la mort et la souffrance.

Car, en général, ne vous y trompez pas, l'être vivant n'est attaché à rien plus qu'à son intérêt propre.

Quand tu voudras entendre parler un philosophe, ne lui dis pas : "Tu ne me dis rien ", montre-toi seulement capable de l'écouter, et tu verras comment tu feras naître ses discours.

"[...] Sinon supporte les injures; car, en agissant comme le vulgaire, tu te mets toi-même au rang du vulgaire. »

Tu crois que ce n'est rien, de ne pas faire de reproches à Dieu ni aux hommes, de ne blâmer personne, de garder toujours même visage en sortant et en entrant ?

Car toute action a pour cause une opinion.

Qu'est-ce que philosopher ? N'est-ce pas se préparer aux événements?

...il ne faut pas précéder les événements, mais les accompagner.

...en se frottant à un objet couvert de suie, on ne peut éviter de se noircir. 
Lorsque l'on t'annonce une nouvelle capable de te troubler, aie toujours présente cette idée qu'une nouvelle ne se rapporte à rien qui dépende de ta volonté.

Et celui qui m'insulte devient celui qui m'exerce : il m'exerce à la patience, au calme, à la douceur.

Car là où il y a de l'agitation, des chagrins, des craintes, des désirs, des insatisfaits, des objets détestés qu'on ne peut éviter, des haines, des jalousies, par où pourrait passer le bonheur? Quand les jugements mêmes sont gâtés, tous ces malheurs sont une conséquence nécessaire.

Le bonheur n'est jamais compatible avec le regret des choses absentes.

- Alors je ne serai plus?

- Tu ne seras pas ce que tu es, mais autre chose dont le monde aura actuellement besoin. De même, tu n'es pas né quand tu l'as voulu, mais quand le monde a eu besoin que tu naisses. 
Lettres à Jean-Élie.

Clin d'œil aux amants de la sagesse

PARTIE II

\section{MARC AURÈLE \\ (121-180)}

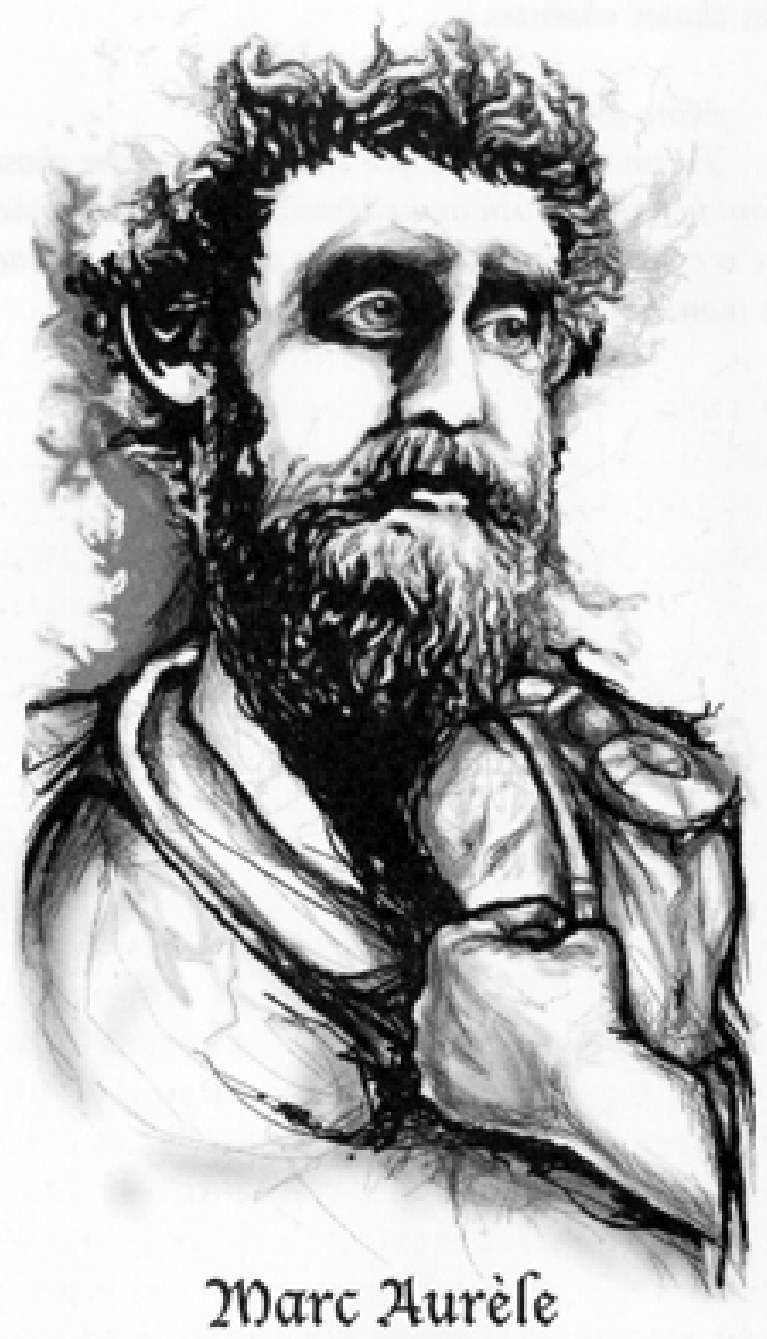

(121-180)

$\underline{\text { Retour à la table des matières }}$ 


\section{MARC AURÈLE BIOGRAPHIE}

Marc Aurèle, empereur et philosophe romain, est né à Rome, d’une famille riche, le 26 avril 121 et est mort à Vienne le 17 mars de l'an 180. Curieux et manifestant de l'intérêt pour différentes choses, il étudia la littérature, la musique, le chant, la danse, le dessin et la peinture. Mais cette âme noble (Hippolyte Taine) s’est laissé guider très jeune par la philosophie avec ses maîtres à penser : Fron-

ton, Ariston, Épictète, pour ne nommer que ceux-là. Croyant à l'importance de cette discipline, c'est-à-dire à la connaissance par la raison, il apporta, lors de son passage à Athènes, ville mère de toutes les sagesses (Meunier), un soutien financier aux titulaires de chaires qui enseignaient la rhétorique et la philosophie, puis il en créa quatre nouvelles. Sa force de caractère suppléait à une santé fragile. Et c'est à travers des moments troubles de guerres et de différents désastres qu’il écrira ses Pensées. Rappelons ici que c’est en grec qu’elles furent rédigées. Avec sensibilité, reconnaissance et tendresse, Marc Aurèle nous livre ses réflexions, présente ses émotions et nous invite à porter nos pas sur le chemin de la sagesse. Mais qu'est-ce donc qui peut nous guider? dit-il. Une seule et unique chose : la philosophie.

\section{SOURCES :}

Marc Aurèle. Pensées pour moi-même, suivies du Manuel d'Épictète, traduction, préface et notes par Mario Meunier, Paris, Flammarion, 1964.

Christian Boissinot, Martin Godon et Isabelle Rivard. L'Art de vivre. Les Stö̈ciens et Épicure, Québec, Les Éditions CEC, 1998. 


\section{Pensées pour moi-même}

Il faut donc se hâter, non seulement parce qu'à tout moment nous nous rapprochons de la mort, mais encore parce que nous perdons, avant de mourir, la compréhension des questions et le pouvoir d'y prêter attention.

Pour toi donc, dis-je, choisis simplement et librement ce que tu vois de meilleur et persiste en ce choix.

Hâte-toi donc au but ; renonce aux vains espoirs et porte-toi secours, si tu as, tant que c'est possible encore, quelque souci de toi-même.

Nulle part, en effet, l'homme ne trouve de plus tranquille et de plus calme retraite que dans son âme...

N'agis point comme si tu devais vivre des milliers d'années. L'inévitable est sur toi suspendu. Tant que tu vis, tant que cela t'est possible, deviens homme de bien.

Tout ce qui arrive est aussi habituel et prévu que la rose au printemps et les fruits en été ; il en est ainsi de la maladie, de la mort, de la calomnie, des embûches et de tout ce qui réjouit ou afflige les sots.

Ceci n'est pas un revers, mais c'est un bonheur que de noblement le supporter.

Telles que sont le plus souvent tes pensées, telle sera ton intelligence, car l'âme se colore par l'effet des pensées.

Ne suppose pas, si quelque chose t'est difficile, que cette chose soit impossible à l'homme. Mais, si une chose est possible et naturelle à l'homme, pense qu'elle est aussi à ta portée.

Il est honteux que, dans le temps où ton corps ne se laisse point abattre, ton âme, en ce même moment, se laisse abattre avant lui. 
Celui qui aime la gloire met son propre bonheur dans les émotions d'un autre ; celui qui aime le plaisir, dans ses propres penchants ; mais l'homme intelligent, dans sa propre conduite.

Que les choses à venir ne te tourmentent point. Tu les affronteras, s’il le faut, muni de la même raison dont maintenant tu te sers dans les choses présentes.

Le bonheur, c'est de posséder un bon génie, ou une bonne raison. Que fais-tu donc ici, imagination ? Vat'en, par les Dieux, comme tu es venue ! Je n'ai pas besoin de toi. Tu es venue, selon ta vieille habitude; je ne t'en veux pas; seulement, retire-toi.

Un visage où la colère est empreinte est tout à fait contre nature.

L'art de vivre est plus semblable à celui de la lutte qu'à celui de la danse, en ce qu'il faut se tenir prêt et sans broncher à parer les coups directs et non prévus.

...il est honteux d'être surpris qu'un figuier porte des figues !...

Qu'exiges-tu de plus, si tu as fait du bien à quelqu'un?

Ai-je fait acte utile à la communauté ? Je me suis donc rendu service. Aie toujours et en toute occasion cette maxime à ta portée, et ne t'en dépossède jamais.

Mais tiens-toi sur tes gardes pour observer deux choses : non seulement un jugement et une conduite inébranlables, mais aussi une inébranlable douceur envers ceux qui tenteraient de te faire obstacle ou de te causer d'autres ennuis.

...lorsque tu t'indignes ou que tu t'affliges outre mesure, songe que la vie est de très courte durée et que sous peu nous seront étendus.

Combien est ridicule et étrange l'homme qui s'étonne de quoi que ce soit qui arrive en la vie!

Chasse dehors l'opinion et tu seras sauvé. Qui donc t'empêche de la chasser ? 
Lettres à Jean-Élie.

Clin d'œil aux amants de la sagesse

PARTIE II

\section{Montaigne (1533-1592)}

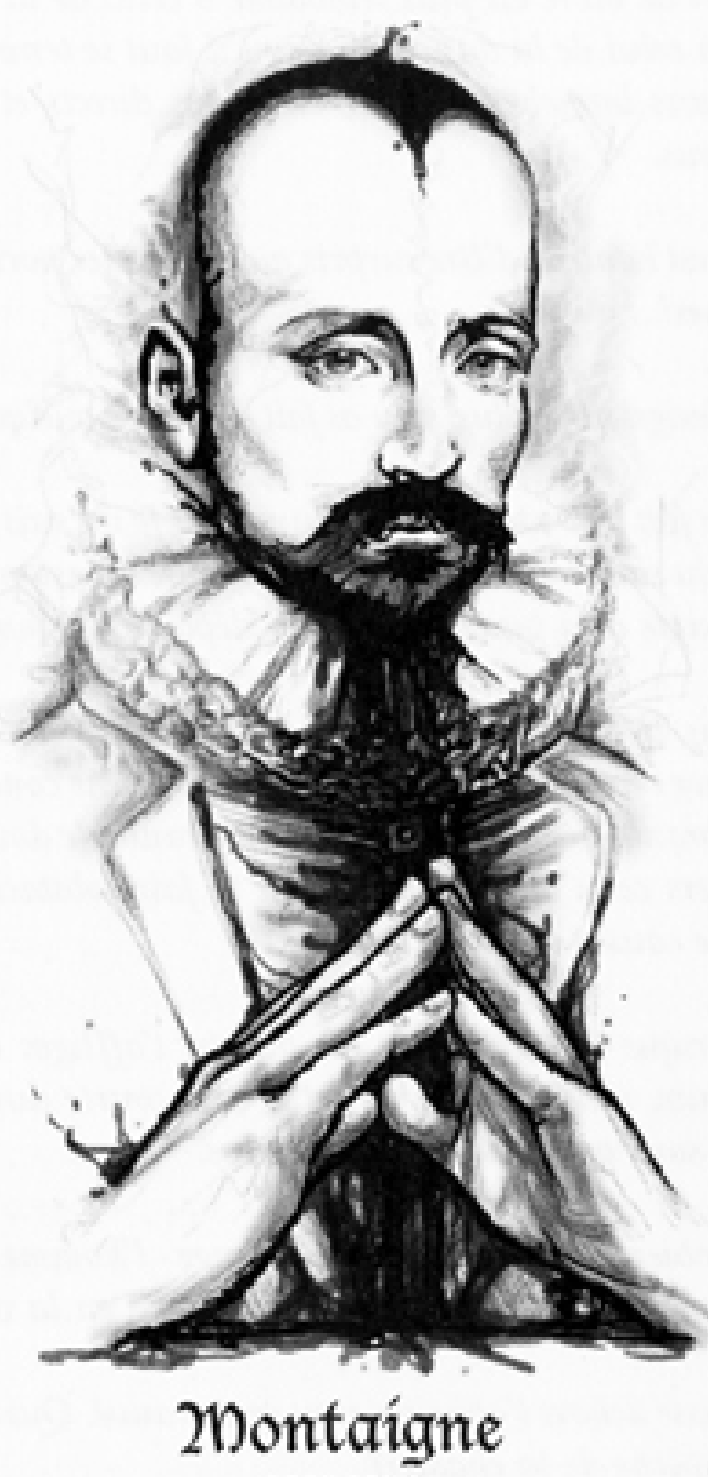

(1588-1592)

$\underline{\text { Retour à la table des matières }}$ 


\section{MONTAIGNE BIOGRAPHIE}

Montaigne (Michel de), écrivain et philosophe français, est né au château de Montaigne, dans le Midi de la France, le 28 février 1533 ; il y meurt le 13 septembre 1592. Jeune, il étudie le latin tout en s’intéressant aux oeuvres d'Ovide (tout comme Sénèque, d’ailleurs), de Virgile, de Térence et de Plaute. Il fait ses

études de droit à Toulouse. Son amitié avec Étienne de La Boétie fut des plus marquantes. C’est avec lui, nous révèle Pierre Michel, qu’il admire les héros stoïciens tels Épictète, Sénèque et Marc Aurèle. Au début des années 1570, à l’âge de trente-huit ans, il se retire dans son château. Étude et réflexion sont alors au rendez-vous. Il dresse commerce, dira-t-il, avec les livres de Sénèque et de Plutarque. Après avoir fait publier les oeuvres de La Boétie, il s'attaque à sa propre production. Débute alors l'écriture des Essais dont la première édition paraîtra en 1580. Après cette date, il s'investira à nouveau dans l'action. En effet, il occupe la fonction de maire de Bordeaux pendant quelques années. Ensuite s’amène la retraite dont le véritable but sera de peaufiner et d'améliorer son oeuvre : ses Essais qui, soit dit en passant, ont été vendus à dix mille exemplaires en un an, au Japon, au lendemain de la Seconde Guerre mondiale. Pour Montaigne, il n'est science si ardue que de bien et naturellement savoir vivre sa vie. Dès lors, il nous convoque à l'étude ; elle nous aidera à avancer sur le chemin de la sérénité et de la sagesse.

\section{SOURCES :}

Montaigne. Essais, édition présentée, établie et annotée par Pierre Michel, Paris, Librairie générale française (Livre de poche), 1972.

Harold Höffding, Histoire de la philosophie moderne, tome I, Paris, Félix Alcan éditeur, 1906. 


\section{Essais *}

\section{Tome I}

...ainsi est-il des esprits. Si on ne les occupe pas à certain sujet, qui les bride et contraigne, ils se jettent déréglés, par-ci par là, dans le vague champ des imaginations.

...et ailleurs, - notable exemple de la forcenée curiosité de notre nature, s'amusant à se préoccuper des choses futures, comme si elle n'avait pas assez affaire à digérer les présentes...

«Dans sa prudence, la Divinité couvre d'une nuit épaisse les événements de l'avenir et se rit du mortel qui s'inquiète au-delà de ce qui est permis. Celui-là est maître de lui-même et passe joyeusement sa vie, qui peut dire chaque jour : j'ai vécu; qu'importe que demain Jupiter obscurcisse le ciel de sombres nuées ou nous donne un ciel serein. » (Horace)

C'est, au demeurant, une très utile science que la science de l'entregent. Elle est, comme la grâce et la beauté, conciliatrice des premiers abords de la société et familiarité ; et par conséquent nous ouvre la porte à nous instruire par les exemples d'autrui, et à exploiter et produire notre exemple, s'il a quelque chose d'instruisant et communicable.

La mort ne se sent que par le discours, d'autant que c'est le mouvement d'un instant...

Il n’importe pas seulement qu'on voie la chose, mais comment on la voit.

J'observe en mes voyages cette pratique, pour apprendre toujours quelque chose par la communication d'autrui (qui est une des plus belles écoles qui puisse être), de ramener toujours ceux avec qui je confère, aux propos des choses qu'ils

* Pour faciliter la lecture des pensées de Montaigne, les citations qu'il formule ont été écrites en français telles qu'on les retrouve dans les notes en bas de pages des Essais, édition présentée, établie et annotée par Pierre Michel. 
savent le mieux. "Le pilote parle des vents, le laboureur de ses taureaux, le soldat dénombre ses blessures, le berger ses brebis », dit Properce.

...toute la sagesse et discours du monde se résout afin à ce point, de nous apprendre à ne craindre point de mourir.

Or, des principaux bienfaits de la vertu est le mépris de la mort, moyen qui fournit notre vie d'une molle tranquillité, nous en donne le goût pur et aimable...

Et, bien que les règles nous conduisent aussi toutes d'un commun accord à mépriser la douleur, la pauvreté, et les autres accidents à quoi la vie humaine est sujette, ce n'est pas pareil soin, tant parce que les accidents ne sont pas tellement nécessité (la plupart des hommes passent leur vie sans goûter de la pauvreté...). [...] Mais quant à la mort, elle est inévitable.

Le but de notre carrière, c'est la mort, c'est l'objet nécessaire de notre visée : si elle nous effraie, comment est-il possible d'aller un pas en avant, sans fièvre? Le remède du vulgaire, c'est de n'y penser pas... Mais de quelle brutale stupidité lui peut venir un si grossier aveuglement ? Il lui faut faire brider l'âne par la queue, «lui qui s'est mis en tête d'avancer à reculons », dit Lucrèce.

D’avantage, pauvre fol, que tu es, qui t'a établi les termes de ta vie ? Tu te fondes sur les contes des médecins. Regarde plutôt l'effet et l'expérience. Par le commun train des choses, tu vis depuis longtemps par faveur extraordinaire.

«L'homme ne peut jamais prendre assez de précautions pour les dangers qui le menacent à chaque heure. » (Horace)

La préméditation de la mort est préméditation de la liberté. Qui a appris à mourir, il a désappris à servir. Le savoir mourir nous affranchit de toute sujétion et contrainte. Il n'y a rien de mal en la vie pour celui qui a bien compris que la privation de la vie n'est pas mal.

"Imagine-toi que chaque jour est le dernier qui luit pour toi : elle te sera agréable l'heure que tu n'espérais plus. » (Horace)

...car jamais homme ne se défia tant de sa vie, jamais homme ne fit moins d'état de sa durée. Ni la santé, que j'ai joui jusques à présent très vigoureuse et peu souvent interrompue, ne m'en allonge l'espérance, ni les maladies ne me l'accourcissent. À chaque minute il me semble que je m'échappe. Et me rechante sans cesse : "Tout ce qui peut être fait un autre jour, le peut être aujourd'hui. » 
Et Lucrèce : "Bientôt le temps présent ne sera plus et jamais plus nous ne pourrons le rappeler. » Et Sénèque: "Aucun homme n'est plus fragile que les autres, aucun n'est plus assuré du lendemain. »

Il faut toujours être botté et prêt à partir, en tant qu'en nous est, et surtout se garder qu'on n'ait lors affaire qu'à soi. " Pourquoi dans une vie si courte, visonsnous audacieusement des buts si nombreux ? », demande Horace.

Je ne suis pour cette heure en tel état, Dieu merci, que je puis déloger quand il lui plaira, sans regret de chose quelconque, si ce n'est de la vie, si sa perte vient à me peser.

Nature même nous prête la main, et nous donne courage. Si c'est une mort courte et violente, nous n'avons pas loisir de la craindre; si elle est autre, je m'aperçois qu'à mesure que je m'engage dans la maladie, j'entre naturellement en quelque dédain de la vie.

Je trouve que j'ai bien plus affaire à digérer cette résolution de mourir quand je suis en santé, que quand je suis en fièvre. D'autant que je ne tiens plus si fort aux commodités de la vie, à raison que je commence à en perdre l'usage et le plaisir, j'en vois la mort d'une vue moins effrayée.

Votre mort est une des pièces de l'ordre de l'univers ; c'est une pièce de la vie du monde.

Le premier jour de votre naissance vous achemine à mourir comme à vivre. "La première heure qui t'a donné la vie, l'a entamée », dit Sénèque.

Si vous avez fait votre profit de la vie, vous en êtes repu, allez-vous-en satisfait: "Pourquoi ne pas se retirer comme un convive rassasié de la vie? ?, dit Lucrèce.

Et si vous avez vécu un jour, vous avez tout vu. Un jour est égal à tous jours. Il n'y a point d'autre lumière, ni d'autre nuit. Ce Soleil, cette Lune, ces Étoiles, cette disposition, c'est celle même que vos aïeux ont joui, et entretiendra vos arrière-neveux: "Vos pères n'en ont pas vu d'autre, et vos descendants n'en contempleront pas d'autre », dit Manilius.

Nul ne meurt avant son heure. Ce que vous laissez de temps n'était non plus vôtre que celui qui s'est passé avant votre naissance; et ne vous touche non plus... 
L'utilité de vivre n'est pas dans l'espace, elle est en l'usage...

Pourquoi crains-tu ton dernier jour ? il ne confère non plus à ta mort que chacun des autres. Le dernier pas ne fait pas la lassitude : il la déclare. Tous les jours vont à la mort, le dernier y arrive.

Je trouve que nos plus grands vices prennent leur pli de notre plus tendre enfance... [...] Et c'est une très dangereuse institution d'excuser ces vilaines inclinations par la faiblesse de l'âge et la légèreté du sujet.

C'est par l'entremise de la coutume que chacun est content du lieu où la Nature l'a planté...

Fais ce que font les médecins, quand les recettes accoutumées ne peuvent servir : ils en essaient de contraires.

...il n'y a point de doute, qu'il ne fut plus beau et plus généreux à celui qui avait reçu l'offense, de la pardonner, que s'il eût fait autrement.

Nous nous enquérons volontiers : «Sait-il du grec ou du latin ? Écrit-il en vers ou en prose ? » Mais s'il est devenu meilleur ou plus avisé, c'est le principal, et c'est ce qui demeure derrière. Il fallait s'enquérir qui est mieux savant, non qui est plus savant.

Quand bien nous pourrions être savants du savoir d'autrui, au moins sages ne pouvons-nous être que de notre propre sagesse.

Qui suit un autre, il ne suit rien.

Le gain de notre étude, c'est en être devenu meilleur et plus sage.

Puisque la philosophie est celle qui nous instruit à vivre, et que l'enfance y a sa leçon, comme les autres âges, pourquoi ne la lui communique-t-on pas?

Le sage, il ne dira pas tant sa leçon, comme il la fera. Il la répétera en ses actions. On verra s’il a de la prudence dans ses entreprises, s'il a de la bonté et de la justice en ses débordements ; s'il a du jugement et de la grâce en son parler, de la vigueur en ses maladies, de la modestie en ses jeux, de la tempérance en ses voluptés, de l'indifférence en son goût, soit chair, poisson, vin ou eau, de l'ordre en son économie. 
Au demeurant, ce que nous appelons ordinairement amis et amitiés, ce ne sont qu'accointances et familiarités noués par quelque occasion ou commodité, par le moyen de laquelle nos âmes s'entretiennent.

Si on me presse de dire pourquoi j’aimais La Boétie, je sens que cela ne peut s'exprimer qu'en répondant : "Parce que c'était lui ; parce que c'était moi. »

Ceux qui disent qu'il n'y a jamais d'excès en la vertu, d'autant que ce n'est plus vertu si l'excès y est, se jouent des paroles d'Horace : «Le sage mériterait le nom d'insensé, le juste celui d'injuste, s'il visait à la vertu même, au-delà de ce qui est suffisant. »

Nous avons une âme contournable en soi-même ; elle se peut faire compagnie ; elle a de quoi assaillir et de quoi défendre, de quoi recevoir et de quoi donner; ne craignons pas en cette solitude nous croupir d'oisiveté ennuyeuse. «Dans la solitude sois une foule pour toi-même », dit Tibulle.

La plus grande chose du monde, c'est de savoir être à soi.

«La renommée qui enchante par sa douce voix les orgueilleux mortels, et qui semble si belle, n'est qu'un écho, un songe, l'ombre d'un songe, qu'un souffle disperse et fait évanouir. » (Tasse)

«Ne voyons-nous pas que la Nature ne réclame rien d'autre qu'un corps sans douleur et une âme sereine, exempte de soucis et de craintes. » (Lucrèce)

«La fièvre brûlante n'abandonne pas ton corps plus vite, si tu es étendu sur des broderies et une étoffe de pourpre que si tu dois coucher sur un drap plébéien. » (Lucrèce)

Les biens de la fortune, tous tels qu'ils sont, encore faut-il avoir du sentiment pour les savourer. C’est le jouir, non le posséder, qui nous rend heureux...

«C'est notre caractère qui modèle pour chacun de nous notre sort. » (Cornelius)

Démocrite et Héraclite ont été deux philosophes, desquels le premier, trouvant vaine et ridicule l'humaine condition, ne sortait en public qu'avec un visage moqueur et riant ; Héraclite, ayant pitié et compassion de cette même condition, en portait le visage continuellement attristé, et les yeux chargés de larmes... 
«Pendant qu'il est loin, l'objet de nos désirs semble l'emporter sur tout le reste : est-il en notre possession, nous désirons autre chose : notre soif est aussi grande. » (Lucrèce)

Quelle rêverie est-ce de s'attendre de mourir d'une défaillance de forces que l'extrême vieillesse apporte, et de se proposer ce but à notre durée, vu que c'est l'espèce de mort la plus rare de toutes et la moins en usage?

«Ne voyons-nous que l'homme ne sait pas ce qu'il veut, qu'il est toujours en quête, qu'il change de lieu comme s'il pouvait se décharger de son fardeau.» (Lucrèce)

Nul vent n'agit pour celui qui n’a point de port destiné.

Platon défend aux enfants de boire [du] vin avant dix-huit ans, et avant quarante de s'enivrer ; mais à ceux qui ont passé les quarante, il ordonne de s'y plaire ; et mêler largement en leurs convives l'influence de Dionysius, ce bon dieu qui redonne aux hommes la gaieté, et la jeunesse aux vieillards, qui adoucit et amollit les passions de l'âme, comme le fer s'amollit par le feu.

Car il y a en la vie plusieurs accidents pires à souffrir que la mort même.

«La vertu ne consiste pas comme tu le penses, mon père, à craindre la vie, mais à faire front aux pires maux et à ne jamais tourner le dos. » (Sénèque)

"La crainte même du malheur à venir a précipité bien des gens dans les plus grands périls : l'homme le plus courageux est celui qui, prêt à affronter les dangers quand ils les pressent, sait aussi les éviter. » (Lucain)

Le vice contraire à la curiosité, c'est la nonchalance.

\section{Tome II}

Car je fais dire aux autres ce que je ne puis si bien dire, tantôt par faiblesse de mon langage, tantôt par faiblesse de mon sens. Je ne compte pas mes emprunts, je les pèse. 
Je ne cherche aux livres qu'à m'y donner du plaisir par un honnête amusement; ou si j'étudie, je n'y cherche que la science qui traite de la connaissance de moi-même, et qui m’instruise à bien mourir et à bien vivre...

«Il dédaigne ce qui est à sa portée et poursuit ce qui fuit. » (Horace)

Il y a deux parties à cette gloire: savoir est, de s'estimer trop, et n'estimer pas assez autrui.

La philosophie ne me semble jamais avoir si beau jeu que quand elle combat notre présomption et vanité, quand elle reconnaît de bonne foi son irrésolution, sa faiblesse et son ignorance.

Ne pouvant régler les événements, je me règle moi-même, et m'applique à eux s’ils ne s'appliquent à moi.

«Il est honteux de se charger la tête d'un poids qu'on ne saurait porter, pour fléchir bientôt le genou et déposer le fardeau. » (Properce)

«Quand l'esprit est dans le doute, le moindre poids le fait pencher d'un côté ou de l'autre. » (Terrence)

«S’il y a quelque chose de beau, rien ne l'est assurément plus que l'égalité de conduite aussi bien dans l'ensemble de la vie que dans les actions particulières : or tu ne pourrais la conserver, si, en imitant la nature d'autrui, tu abandonnes la tienne. » (Cicéron)

L'extrême degré de traiter courageusement la mort, et le plus naturel, c'est la voir non seulement sans étonnement, mais sans soin, continuant libre le train de la vie jusque dans elle.

"Si avons-nous une très douce médecine que la philosophie : car des autres, on n'en sent le plaisir qu'après la guérison, celle-ci plaît et guérit ensemble. » (Sénèque)

La philosophie ne pense pas avoir mal employé ses moyens quand elle a rendu à la raison la souveraine maîtrise de notre âme et l'autorité de tenir en bride nos appétits. 


\section{Tome III}

...chaque homme porte la forme entière de l'humaine condition.

À mon avis, c'est le vivre heureusement, non, comme disait Antisthène, le mourir heureusement qui fait l'humaine félicité.

Si j’avais à revivre, je revivrais comme j'ai vécu ; ni je ne plains le passé, ni je ne crains l'avenir.

Je porte bien plus doucement les maux que j'ai, d'autant qu'ils sont en leur point et qu'ils me font aussi plus favorablement souvenir de la longue félicité de ma vie passée.

C'est être, mais ce n'est pas vivre, que se tenir attaché et obligé par nécessité à un seul train. Les plus belles âmes sont celles qui ont plus de variété et de souplesse. Voilà un honorable témoignage du vieux Caton : "Il avait une intelligence si souple, et si propre à tout, que quelque chose qu'il fit, il semblait être uniquement né pour celle-là. »

La lecture me sert spécialement à éveiller par divers objets mon raisonnement, à embesogner mon jugement, non ma mémoire...

[...] ils [les livres] portent secours à ma vie. C'est la meilleure munition que j'ai trouvée à cet humain voyage.

"Ô l'argile infortunée que d'abord modela Prométhée; comme il a manqué de prudence dans la conduite de son oeuvre ! En formant le corps de l'homme, il ne vit pas l'importance de l'âme ; il aurait dû commencer par elle ! »(Properce)

«C'est vivre deux fois que de pouvoir jouir de la vie passée. » (Martial)

La sagesse a ses excès et n’a pas moins besoin de modération que la folie.

J'ai été toujours chatouilleux et délicat aux offenses ; je suis plus tendre à cette heure, et ouvert partout. "Une âme malade ne peut rien endurer de pénible », dit Ovide. 
Mon jugement m'empêche bien de regimber et gronder contre les inconvénients que nature m’ordonne à souffrir, mais non pas de les sentir.

...il n'est rien qui nous jette tant aux dangers qu'une faim inconsidérée de nous en mettre hors. " D’ordinaire, moins on a peur, moins on court de danger », dit Tite-Live.

Le plus âpre et difficile métier du monde, à mon gré, c'est faire dignement le roi. [...] Il est difficile de garder mesure à une puissance si démesurée.

Qui ne participe au hasard et difficulté, ne peut prétendre intérêt à l'honneur et plaisir qui suit les actions hasardeuses.

«Il ne peut y avoir de discussion sans contradiction. » (Cicéron)

Je me sens bien plus fier de la victoire que je gagne sur moi quand, en l'ardeur même du combat, je me fais plier sous la force de la raison de mon adversaire, que je me sens gré de la victoire que je gagne sur lui par sa faiblesse.

Nos yeux ne voient rien derrière. Cent fois du jour, nous nous moquons de nous sur le sujet de notre voisin et détestons en d'autres les défauts qui sont en nous plus clairement, et les admirons d'une merveilleuse impudence et inadvertance.

«Un homme ne s'élève que dans la mesure où il est servi par la fortune, et dès lors tout le monde vante son habileté. » (Plaute)

C'est chose tendre que la vie et aisée à troubler.

On peut regretter les meilleurs temps, mais non pas fuir aux présents...

Nos plus grandes agitations ont des ressorts et causes ridicules.

C'est injuste de se plaindre qu'il soit advenu à quelqu'un ce qui peut advenir à chacun, "indigne-toi, si c'est à toi seul qu'on impose une contrainte injuste », dit Sénèque. Voyez un vieillard qui demande à Dieu qu'il lui maintienne sa santé entière et vigoureuse, c'est-à-dire qu'il le remette en jeunesse.

Les plus belles vies sont, à mon gré, celles qui se rangent au modèle commun et humain, avec ordre, mais sans miracle et sans extravagance. Or la vieillesse a un peu besoin d'être traitée plus tendrement. 
«Si les hommes savaient mettre à profit la parole des sages, ils s'accommoderaient sans reproche de notre situation présente, ils conserveraient un souvenir agréable du passé et l'avenir se présenterait à eux avec les couleurs propices et brillantes de l'espérance; enfin, ils vivraient exempts de craintes et d'inquiétudes. » (Plutarque, La Sérénité intérieure) 
Lettres à Jean-Élie.

Clin d'œil aux amants de la sagesse

PARTIE II
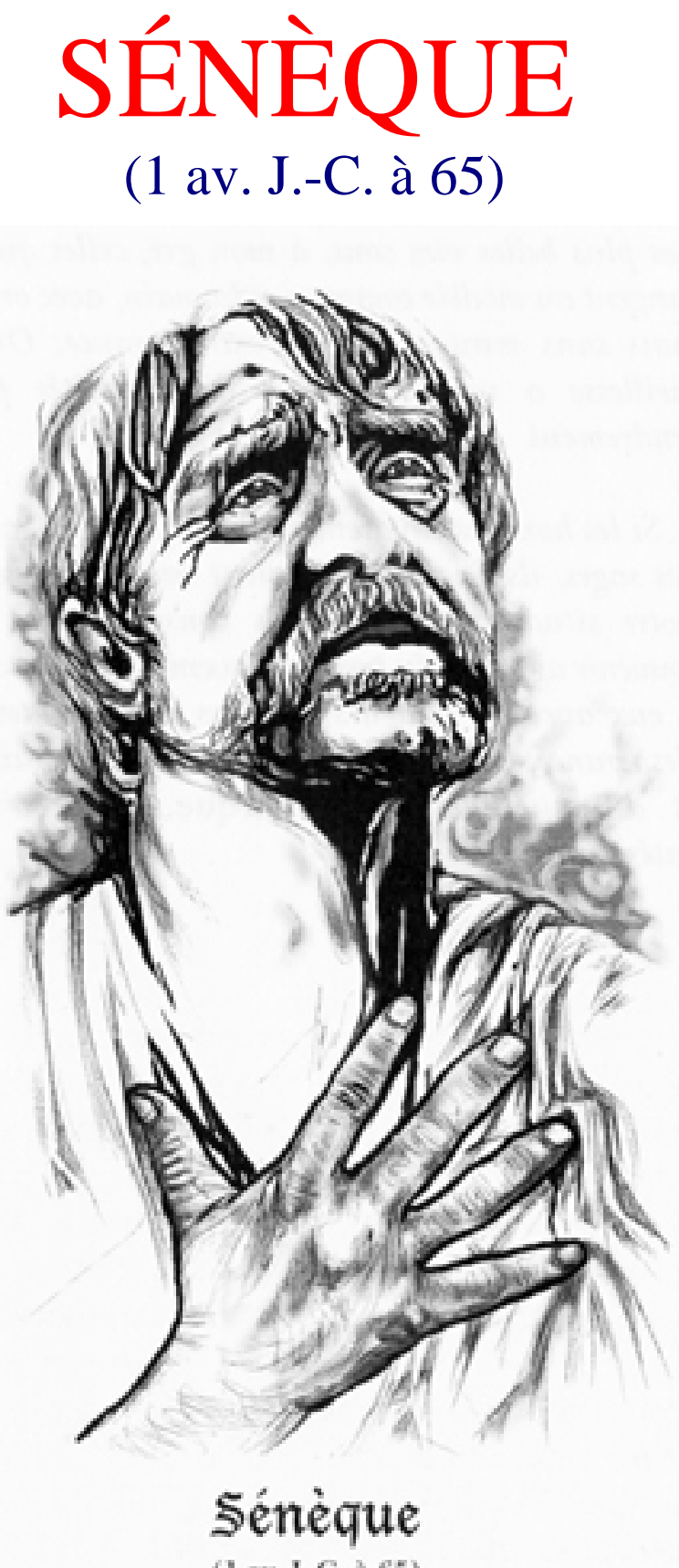

(1 av. J-C. à 65) 


\section{SÉNÈQUE BIOGRAPHIE}

Sénèque, homme politique, philosophe et écrivain romain, est né d'une famille aisée à Cordoue - en Espagne - en l'an 1 avant Jésus-Christ (cette date ne fait toutefois pas consensus) et est mort en l'an 65. Une carrière sénatoriale l'attendait. Du reste, il fut l'un des plus grands orateurs de sa génération, nous dira Pierre Grimal. Il aimait la poésie : Horace, Virgile, Ovide figuraient parmi ses favoris. Sa santé fragile l’amena en Égypte pendant quelques années et, sous le règne de l'empereur Claude, il dut s'exiler en Corse pendant une période de plus de sept ans. Dans cette île - qu'il n'aima guère au demeurant - de beaux textes ont été produits, entre autres Consolation à Helvia, sa mère. C’est comme précepteur qu'il exerça une influence sur Néron qui l’obligera néanmoins à se donner la mort. Homme d'une grande éloquence, il a connu le succès : oratoire, financier aussi. Ce qu'on ne manquera pas de lui reprocher d'ailleurs. Auteur prolifique, génial, dira Bordes, il a produit des consolations, des dialogues, des tragédies. Au reste, il écrivait en latin, cette langue lui paraissant plus riche que le grec. Mais toujours est-il que c'est à compter de 62, en pleine retraite, qu'il écrira les célèbres Lettres à Lucilius ; elles seront publiées après sa mort. Celui que Diderot appela le précepteur du genre humain nous convie à demander de l'aide afin de marcher à la rencontre de la sagesse. Mais à qui s'adresser ? Est-ce à celui-ci ou à celui-là ? Retournons aux anciens, dit-il, qui toujours sont disponibles ; aussi bien que les vivants, ceux qui ne sont plus peuvent nous venir en aide.

\section{SOURCES :}

Tacite. Annales, texte présenté, traduit et annoté par Pierre Grimal, Paris, Gallimard, 1990. 
Pierre Grimal. Sénèque ou la conscience de l'Empire, Paris, Fayard, 1991 et Sénèque, Paris, Presses universitaires de France (Collection Que sais-je ?), 1994.

Sénèque. Apprendre à vivre. Lettres à Lucilius, lettres choisies et traduites par Alain Golomb, Paris, Arléa, 1996.

Sénèque. Sur la brièveté de la vie, traduit du latin et postface par Xavier Bordes, Paris, Éditions Mille et Une Nuits, 1994. 


\section{Lettres à Lucilius}

Traducteur : Alain Golomb

\section{Tomes I et II}

On remet la vie à plus tard. Pendant ce temps, elle s'en va.

Celui qui fuit la peine est un homme sans énergie et sans vaillance puisque la difficulté de la situation n'accroît pas son courage.

Quelqu'un s'étant plaint en des termes comparables, Socrate répondit: «Pourquoi t'étonner si tes voyages ne te sont d'aucun profit? »C'est toi que tu traînes partout.

Enseigne-moi que le prix de la vie n'est pas dans sa durée mais dans son usage...

Avoir assez vécu, nous ne le devons ni aux jours ni aux années mais à notre âme.

Ah, si seulement nous nous occupions d'être heureux avant que la mort soit en vue!

La vie, c'est une pièce de théâtre: ce qui compte ce n'est pas qu'elle dure longtemps mais qu'elle soit bien jouée.

Imagine que c'est la nature qui te parle : " Ce dont tu te plains est pour tous identique. Je ne peux rien offrir de plus facile à personne. Mais celui qui le voudra pourra de lui-même se les rendre plus faciles. »

Tu ne comprends pas que tout le mal provient non pas de ce qui t'arrive mais de ton indignation et de tes plaintes ?

Calamité, qu'une âme inquiète du futur et malheureuse avant le malheur et sans cesse angoissée à l'idée de ne pouvoir conserver jusqu'au bout ce qu'elle aime! Elle ne connaîtra jamais le repos et perdra, dans l'attente de l'avenir, le présent dont elle aurait pu jouir. 
De toute façon, ce n'est pas sur les flots calmes que naît la tempête. Rien de plus affligeant et de plus stupide que d'avoir peur à l'avance. Ridicule folie d'anticiper sur son malheur !

Souffrir avant qu'il soit nécessaire c'est souffrir plus qu'il n'est nécessaire.

Le futur et le passé ont leurs charmes : l'un c'est l'attente, l'autre le souvenir.

Considère la vitesse du temps, tellement rapide.

Songe à la brièveté de cet espace que nous parcourons à toute allure.

Se plaindre qu'un homme soit mort, c'est se plaindre qu'il ait été homme. La même condition nous tient tous enchaînés. Il t'a été donné de vivre ? Il te reste à mourir.

Les difficultés ne sont pas la cause de notre manque d'audace, c'est notre manque d'audace qui est la cause de nos difficultés.

Horace dit admirablement que la soif se moque bien de la coupe dans laquelle on verse l'eau et de la main délicate qui la sert. En vérité, si tu accordes de l'importance à la chevelure du garçon qui te sert, à la transparence de la coupe qu'il te tend, c'est que tu n'as pas soif.

\section{Tome II}

Je te recommande de ne pas être malheureux avant l'heure, car ce dont tu redoutes l'imminence n'arrivera peut-être jamais, en tout cas n'est pas encore arrivé.

...fais ton miel de ce précepte des sages : "Plus important que ce qu’on donne est de savoir à qui l'on donne. »

...on ne doit parler qu'à celui qui est prêt à entendre.

Or, la sagesse est un art.

Or ce qui importe avant tout c'est l'opinion que tu as de toi-même et non l'opinion que les autres ont de toi. 
En effet, alors que l'essence du bonheur réside dans une sérénité sans faille et dans la confiance inébranlable d'y parvenir, les hommes s'inventent des soucis et, sur la route de la vie semée d'embûches, ils les portent comme de gros bagages, ou plutôt ils les traînent.

Incroyable, la force de la philosophie, pour repousser les coups du sort !

Si l'on n'expulse pas cette peur [de la mort] de sa poitrine, on passe sa vie le coeur battant.

En effet, bonheur et peur sont incompatibles. On vit mal au milieu des soupçons.

Les choses passées comme les choses à venir sont loin de nous. Nous ne les sentons pas. On ne peut souffrir que de ce qui touche notre sensibilité.

Deux écueils : la crainte de l'avenir et le souvenir des malheurs passés. L'une ne me concerne pas encore, l'autre ne me concerne plus.

Les maux sont plus légers d'avoir été prévus.

Pourquoi suspecter, tout autour de toi, des événements qui peuvent peut-être se produire mais, tout aussi bien, ne pas se produire?

Toutefois, que le danger vienne de l'homme ne doit pas te faire oublier ton devoir d'homme. Attention : évite qu'on te blesse, évite de blesser. Réjouis-toi de la joie d'autrui, sois sensible à ses malheurs et souviens-toi de ce que tu dois faire, de ce que tu dois fuir. À vivre ainsi, que gagneras-tu ? D'être victime peutêtre, sûrement pas dupe.

\section{Lettres à Lucilius (1-29)}

Traductrice : Marie-Ange Jourdan-Gueyer

Et la preuve justement qu'une âme s'est améliorée, c'est qu'elle voit ses défauts que jusque-là elle ignorait.

Fouille-toi, scrute-toi, observe-toi dans tous les sens; avant toute chose, vois si tu as progressé dans la philosophie ou dans la vie même. 
Bien au contraire, je ne veux pas que te manque jamais la bonne humeur. Je veux qu'elle naisse en ta maison; elle y naît à condition de se produire au-dedans de toi.

Il est sot, sans aucun doute, sous prétexte qu'un jour ou l'autre tu seras malheureux d'être déjà malheureux.

En prison, Socrate fit une conférence, il ne voulut pas sortir, alors qu'il y en avait qui lui promettaient de le faire fuir, et il y demeura afin d'ôter aux hommes la peur des deux choses les plus pénibles qui soient, la mort et la prison.

C'est au lourd poids de mon corps que la nature me tient serré. Je mourrai : tu veux dire, je cesserai de pouvoir être malade, je cesserai de pouvoir être enchaîné, je cesserai de pouvoir mourir.

Chaque jour nous mourons ; chaque jour, en effet, est ôtée une partie de la vie et alors même que notre âge s'accroît, la vie décroît.

\section{Lettres à Lucilius (Tomes I à V)}

Tratucteur : Henri Noblot

\section{Tome I}

...le premier indice d'une pensée en équilibre, c'est, à mon sens, de savoir se fixer et séjourner avec soi.

Évitons ces deux extrémités : c'est un tort de se confier à tout le monde ; c'est un tort de ne se confier à personne ; mais je dirai qu'il y a plus d'honnêteté dans l'un, plus de sûreté dans l'autre.

Les bêtes prennent la fuite devant le danger visible ; hors de danger, elles retrouvent la quiétude. Nous nous tourmentons, nous, et de l'avenir et du passé. Bon nombre de nos biens sont pour nous sources de misères : la mémoire ramène le tourment de la peur ; la prévoyance l'anticipe. Ce n'est jamais du présent seul que viennent nos peines. 
... je te dirai ce que j'ai trouvé aujourd'hui pour mon plaisir chez Hécaton. «Tu veux savoir, dit-il, quel progrès j'ai accompli ? Je suis devenu l'ami de moimême. » Progrès considérable : il ne sera jamais seul. < Ami de soi-même! > Une telle amitié, sache-le, est à la portée de tous.

Sans aucun doute il y a ressemblance entre l'amitié et l'amour. Nous dirons même de l'amour qu'il est la folie de l'amitié.

Oui, mon cher Lucilius, une excessive colère aboutit au délire. Évitons donc la colère, non tant par goût de la mesure que pour sauvegarder notre raison...

Commençons, dans la vieillesse, à plier bagage.

Pourrait-on nous en vouloir ? Nous avons vécu dans le ressac; mourons au port.

Mais il est une chose, mon cher Lucilius, dont je te prie, à quoi je t'exhorte: fais descendre au fond de ton coeur la philosophie; fonde l'expérience de ton progrès non sur la chose dite ou écrite, mais sur la fermeté de l'âme et la réduction des désirs.

...certains ont cessé de vivre avant d'avoir commencé.

Oui, Lucilius, loin d'avoir à redouter la mort, nous lui devons de n'avoir plus rien à redouter.

Repasse en ton esprit ces maximes que tu as souvent entendues, souvent prononcées. Mais les entendais-tu, mais les prononçais-tu avec sincérité ? Prouve-le en les mettant en pratique. Car il n'est rien de plus honteux que l'imputation souvent dressée contre nous, de manier le langage de la philosophie, non les actions qu'elle inspire.

Comme la vieillesse succède à la maturité, ainsi la mort succède à la vieillesse. Refuser de mourir, c'est de ne pas avoir accepté de mourir ; la mort est le terme où l'on va. En avoir peur est donc une folie. Il y a dans la mort une nécessité égale pour tous et invincible. Qui peut se plaindre d'une obligation à laquelle personne n'échappe ? L'égalité est la condition première de l'équité.

Qu'est-ce donc que le bien ? La science. Qu'est-ce que le mal ? L'ignorance.

La trace d'une main amie, imprimée sur des pages, assure ce qu'il y a de plus doux dans la présence : retrouver. 
À l'homme sage convient, ainsi qu'une démarche vraiment modeste, un discours serré, sans rien d'aventureux. En somme et au total je te commande d'être lent à parler.

\section{Tome II}

...inspire-leur le respect plutôt que la crainte. [...] Le respect crée l'affection ; et l'affection ne se combine pas avec la peur.

Notre existence est un point, moins encore; mais la nature, en divisant cette chose minime, lui a donné l'apparence d'une plus longue durée.

Si j'ai besoin d'un fou pour me distraire, je n'ai pas à chercher loin : je me ris de moi.

Nous rougissons d'apprendre la sagesse. Ah ! Ciel, s'il est honteux de chercher qui l'enseigne, il ne faut pas non plus compter qu'un si grand bien se déversera en nous par un effet du hasard.

En amitié, c'est par le coeur que s'assure la possession. Or, le coeur n'est jamais absent.

"Le monde reposait dans le calme de la nuit », disait-il. C'est faux! Il n'est point de calme apaisant si la raison n'y a présidé. La nuit n'enlève pas le chagrin ; elle le suspend et ne fait que changer nos soucis.

Nul d'entre nous, au réveil, n'est l'homme qu'il fut la veille. Nos corps sont emportés d'un mouvement pareil à celui des fleuves. Tout ce que tu vois court au rythme du temps. Rien de ce que nous voyons ne demeure. Le temps que je dise que cela change, moi-même j'ai changé.

La sobriété peut allonger la vieillesse, que j'estime chose à ne pas convoiter, à ne pas refuser non plus. Il est doux de séjourner avec soi-même le plus longtemps possible, quand on s'est rendu digne d'être soi-même un objet de jouissance.

On refuse de réformer, parce qu'on s'estime parfait. 
Le sage idéal est plein de joie, gai et paisible, inébranlable; il vit de pair avec les dieux. Et maintenant examine-toi. Jamais tu n'es d'humeur chagrine? Nulle espérance n'éveille dans ton âme la préoccupation de l'avenir ? Au cours des jours et des nuits, remarques-tu en toi cette égalité permanente, cette tenue d'une âme qui plane haut, dans la satisfaction de soi-même? Alors tu es parvenu au comble du bonheur humain.

Cessons de vouloir ce que nous avons voulu. Pour mon compte personnel, je veille à ce que mes volontés de vieillard se distinguent bien de mes volontés d'enfant. Le but tant de mes jours que de mes nuits, mon ouvrage, ma pensée, c'est de mettre fin aux erreurs anciennes. Je tâche qu'une de mes journées équivaille à une vie entière.

Les remèdes de l'âme ont été trouvés par les anciens ; étudier de quelle manière, dans quelles circonstances il faut les appliquer, c'est notre besogne.

Toute vertu a la modération pour base. Or, la modération suppose de justes proportions bien établies.

Rien n'est beau moralement de ce qui s'accomplit à contrecoeur ou par contrainte. [...] La beauté morale ne peut être là où manque la liberté : craindre, c'est être esclave.

Épicure reconnaît deux sortes de biens, qui composent la suprême béatitude : un corps affranchi de toute douleur, une âme sans trouble.

Eh ! oui, mon cher Lucilius, à mon âge je n'ai pas besoin d'un complément de froideur ; c'est à peine si je dégèle au milieu de l'été... [...] Je rends grâces à la vieillesse de m'avoir cloué sur mon lit. Et pourquoi ne la remercierais-je pas à ce titre ? Tout ce que je devais éviter de vouloir, je n'ai plus la possibilité de le faire.

Ainsi, ce ne sont pas les incommodités qui sont souhaitables, mais la vertu qui les fait supporter.

Dis-toi encore, si tu veux : nul ne meurt à son jour. De ton temps tu ne perds rien : ce que tu laisses ne t'appartient pas. 


\section{Tome III}

Nul ne se retrouve au point de progression où il en était demeuré. Courage donc et persévérance ! Il reste plus de besogne que nous n'en avons abattu; mais c'est déjà grande avance prise que de vouloir avancer.

Songer à recevoir, c'est oublier que l'on a reçu. Le pire malheur de la cupidité, c'est qu'elle est ingrate.

L'homme heureux n'est pas celui qui sait seulement, mais qui fait.

...il faut apprendre l'art de vivre tant que dure la vie.

«Que seront mes progrès ? » dis-tu. Proportionnés à ton effort.

Que te faut-il pour être bon ? Vouloir.

...aucune vertu ne fait plus honneur à l'âme que la reconnaissance.

Or, l'âme humaine ne s'élèvera jamais à la vertu, si elle continue de croire que la mort est un mal.

La distance devient bien vite très grande entre deux personnes qui vont en sens contraire.

...ce que nous avons récolté de nos diverses lectures, classons-le : les choses soigneusement classées se conservent mieux.

Ainsi, du mal ne peut naître le bien non plus que la figue de l'olivier. Le fruit répond de la semence.

\section{Tome IV}

Étudie, non pour en savoir davantage, mais pour mieux savoir.

Gouverner, ce n'est pas régner, c'est servir.

La nature en effet, ne donne pas la vertu : c'est un art que d'être homme de bien. 
Souvent un tort subi prépare la place à une plus grande destinée.

Qu'est-ce que le bonheur ? Un état de paix, de sérénité continuelle.

Quel est le principal caractère de la vertu ? C'est de n'avoir pas besoin de l'avenir et de ne pas compter ses jours.

...la mort, comme loi des êtres, offre cette grande consolation qu'elle ne nous fait pas plus d'une visite.

...tu dois apprendre, et puis confirmer par l'action ce que tu as appris.

Souvent nos voeux ne correspondent pas à nos vrais désirs et aux dieux mêmes nous ne disons pas la vérité.

La douleur elle aussi a sa bienséance et le sage s'y conformera ; dans les larmes même, comme dans tout le reste, il y a pour lui une limite, chez l'insensé les douleurs débordent comme les joies.

Que les gens sachent que l'on peut te blesser sans suites dangereuses. Qu'avec toi la réconciliation soit facile, loyale.

...j'ai suivi en l'occurrence l'exemple de Cicéron. [...] «Les destins conduisent une volonté docile ; ils entraînent celle qui résiste. »

On doit proportionner la charge à ses forces et ne pas en prendre au delà de ce qu'on en saurait porter.

Les gens de bien se rendent mutuellement service.

Oui, j'y reviens toujours. De quel profit m'est ce passetemps ? Rendez-moi enfin plus courageux, plus juste, plus modéré en mes désirs. Après cela vous m'enseignerez à défaire les noeuds, dissiper les équivoques, percer les ténèbres de la dialectique. Pour l'instant, enseignez-moi l'indispensable.

Penser qu'une épouse, un ami, ne valent pas la peine qu'on prolonge son existence, s'obstiner à mourir, c'est être mol égoüste. S'imposer de vivre, quand l'intérêt des personnes aimées le veut ainsi, compte parmi les devoirs de l'âme.

Car est-il rien de plus agréable que de se voir chérir de sa femme au point d'en devenir plus cher à soi-même.

Celui qui vient au cours d'un philosophe doit y recueillir chaque jour quelque fruit, s'en retourner ou bien en voie de guérison ou plus facilement guérissable. 


\section{Tome V}

...ils [les dieux] sont bienveillants pour quiconque trouve faveur auprès de luimême.

Nous ne pouvons nous plaindre que de nous-mêmes.

Rien toutefois ne te disposera à la tempérance en toutes choses, autant que de songer fréquemment comme la vie comprend peu de jours et ce peu encore non garanti : quoi que tu fasses, donne un regard à la mort.

Voici donc l'avantage, - le plus important qui soit à mes yeux - que la philosophie t'assurera : à nul moment tu ne seras mécontent de toi-même.

De cet étroit et rapide courant des jours, qui nous emporte, que sert d'en jeter le meilleur au néant?

Portons la main sur nos maux plutôt que sur ceux d'autrui...

Tous nous souffrons du même mal : l'ignorance du vrai. Sur la foi de rumeurs mensongères on se laisse emporter vers ce qu'on prend pour le bonheur.

Lequel te semble préférable, d'avoir beaucoup ou d'avoir à sa suffisance? Qui a beaucoup désire davantage ; preuve qu'il n'a point encore assez.

Tant est profond l'aveuglement de nos coeurs, tant chacun est prompt, lorsqu'il est allé de l'avant, à oublier ses débuts !

Déjà les jours perdent, ayant rétrogradé sensiblement devant les nuits ; mais, est encore laissé pas mal de temps à qui se lèverait, si je puis dire, avec le jour.

Mais la journée, grands dieux, est-elle jamais trop longue pour l'activité humaine? Sachons agrandir notre vie : son office et son critère, c'est l'action.

Raccourcissons nos nuits ; prélevons sur elles de quoi élargir nos journées.

Tenons donc, Lucilius, le chemin que nous a tracé la nature; n'en dévions jamais. Pour qui la suit, tout est facile, simplifié. S'obstiner contre elle dans la conduite de la vie, c'est ramer contre courant. 
...combien peu de mésaventures sont pénibles lorsqu'on leur fait accueil d'un coeur léger, combien peu méritent notre dépit si nous ne grossissions nous-mêmes par notre dépit la réalité.

La mort n'est pas un mal. Tu veux savoir ce qu'elle est ? L'unique loi d'égalité de ce monde!

\section{La Providence La Constance du sage}

Je considère comme un malheur de n'avoir jamais été malheureux.

Nager constamment dans la félicité, traverser la vie sans connaître la moindre angoisse, c'est ignorer une moitié de la réalité.

L'épreuve est nécessaire à la connaissance de soi.

Je t'ai déjà entendu consoler les autres mais je ne saurai vraiment qui tu es que lorsque je t'aurai entendu te consoler toi-même, t'interdisant de sombrer dans la douleur.

On ne prête jamais à rire quand on rit de soi le premier.

\section{Sur la brièveté de la vie}

...je ne doute pas que le plus grand des poètes, en matière d'oracle, ait dit vrai : «Mince est la part de la vie que nous vivons. »

N'est-ce pas un étrange retard que de commencer à vivre juste quand on doit finir ? Quel oubli imbécile de la condition de mortel que de repousser à la cinquantième et à la soixantième année les saines résolutions...

...on doit apprendre à vivre toute la vie et, ce qui est peut-être plus surprenant, toute la vie on doit apprendre à mourir. 
Mais quelqu'un qui garde tout son temps pour son usage personnel, qui organise toutes ses journées à l'instar d'une vie, ne souhaite ni ne redoute le lendemain.

Toute chose à venir flotte dans l'incertain : vis dans l'immédiat.

C'est d'ailleurs une très belle trouvaille du poète, pour blâmer l'expectative indéfinie, de dire non pas : «la meilleure époque », mais : «le meilleur jour.»

Par conséquent la vie du sage offre de vastes perspectives... [...] Une période est-elle passée ? Il s'en saisit par la mémoire. Présente ? Il en use au mieux. Estelle à venir ? Il l'anticipe. Il se fait une longue vie par conjugaison de tous les temps en un seul.

\section{La Vie heureuse}

Il faut, donc, déterminer d'abord à quoi nous aspirons, puis examiner comment nous pouvons y arriver le plus rapidement...

Heureux, donc, celui dont le jugement est droit ; heureux celui qui se contente des biens qui s'offrent à lui aujourd'hui, quels qu'ils soient, et aime ce qu'il possède ; heureux celui pour qui la raison décide de la valeur de tout ce qui lui appartient !

Nous sommes engagés à supporter ce qui est propre à notre condition de mortels, et à ne point nous laisser troubler par ce qu'il n'est pas en notre pouvoir d'éviter.

Les méditations salutaires, fussent-elles sans résultat immédiat, sont une occupation louable.

Je serai agréable à mes amis, conciliant et indulgent pour mes ennemis. Je céderai avant qu'on me prie et irai au-devant des demandes honnêtes.

Celui qui croit que donner est une chose aisée se trompe : cet acte représente un grand nombre de difficultés, si l'on veut distribuer avec discernement, et non dissiper ses biens au hasard ou au gré des impulsions. 


\section{Consolations}

Or l'ampleur d'une douleur hors du commun empêche toujours inévitablement de choisir les bons mots car souvent, elle ne laisse pas même passer le son de la voix.

...aucune boisson ne suffira à désaltérer celui dont le désir provient non d'un

manque mais d'une fièvre qui le brûle intérieurement : ce n'est pas de la soif, c'est une maladie.

On n'est jamais méprisé par autrui que si on commence par se mépriser soimême.

...le temps atténue les effets d'une absence.

...une âme qui souffre par amour ne peut en effet être délivrée de ses tourments que par la raison ou alors par une noble occupation.

Syrus dit : «Ce qui peut arriver à un individu peut arriver à n’importe qui. »

On ôte un peu de leur violence aux maux présents quand on les a vus venir.

...ce que nous appelons la vieillesse est un cycle de bien peu d'années.

Mais si tu reconnais que celui que tu pleures t'a fait connaître de grandes joies, tu n'as pas à te plaindre pour ce qui t'a été retiré mais à rendre grâces de la chance que tu as eue.

...nombreux furent ceux qui adoucirent la rigueur de leurs maux en les supportant avec calme.

Combien compte-t-on de familles qui ont gardé jusqu'au bout tous leurs membres en vie?

La nature des mortels, il est vrai, est ainsi faite que rien ne plaît davantage que ce qu'ils ont perdu; nous sommes trop injustes envers ce qui nous reste à cause de notre regret de ce qu'on nous a retiré brutalement. 
On est né pour voir les autres mourir, pour périr soi-même, pour espérer, craindre, tourmenter les autres et se tourmenter soi-même, craindre la mort tout en la souhaitant et, ce qu'il y a de pire, ne jamais savoir quelle est sa situation.

Songe qu'un défunt n'éprouve aucune souffrance.

Ainsi la mort prématurée de ton fils ne lui a fait le moindre mal ; elle l'a même dispensé de subir toutes sortes de maux.

Toutes choses humaines sont brèves, périssables et occupent une part négligeable de l'éternité.

Dès l'instant où l'on voit la lumière du jour, on prend le chemin de la mort, on se rapproche du terme fatal et les années mêmes qui allongeaient la jeunesse raccourcissaient la vie.

\section{L’Homme apaisé Colère et Clémence}

...certains sages ont dit : « La colère est une courte folie. » [...] Elle est exactement comme un mur qui s'écroule : elle fracasse par-dessus ce qu'elle écrase.

C'est à se demander si ce vice est plus détestable que laid ou le contraire ! Tous les autres, on peut les cacher, on peut les nourrir en secret. La colère vient s'afficher sur la figure.

Qui aime plus son prochain que l'homme? Qui le hait plus que la colère ? L'homme est sur terre pour l'entraide, la colère pour l'entre-destruction.

Je rappellerai un mot de Platon... [...] L'homme de bien ne blesse pas.

En toutes choses, les débuts sont en notre pouvoir ; les suites nous entraînent par leur dynamique propre et rendent impossible le retour en arrière.

Le plus incontestable des courages, c'est celui qui a longtemps regardé autour de lui, et soigneusement, qui s'est maîtrisé, qui avance à pas lents en sachant où il va. 
Il n'est pas très prudent de haïr ceux qui s'égarent: on se hä̈ra soi-même. Qu'il compte combien de ses actes à lui ont été contraires à la morale, combien il en a à se faire pardonner!

Comme il est plus humain de tourner vers ceux qui font le mal un regard doux et paternel! De ne pas les poursuivre mais de les rappeler! Quand quelqu'un divague dans tes champs parce qu'il a perdu sa route, il vaut mieux lui montrer le chemin que le chasser.

Et si je te disais que la terreur rejaillit toujours sur ses auteurs ? Que quiconque se fait craindre n'est jamais en sécurité ?

Autre leçon à tirer : ne nous excitons pas pour les futilités les plus insignifiantes... [...] Il est malade, il n'a pas de santé, celui que la moindre brise fait frissonner...

L'esprit, il faut le traiter à la dure pour qu'il ne sente le coup que s'il est grave.

Le grand remède à la colère, c'est le temps. [...] N'essaie pas non plus de la supprimer d'un seul coup. Tu la vaincras morceau par morceau.

En chacun de nous bat un coeur de roi qui veut que tout lui soit permis...

Le grand esprit regarde de haut les offenses. Le plus grand mépris, c'est de signifier à l'offenseur que nous ne le jugeons pas digne de notre vengeance.

Donc il faut faire abstinence de colère, que celui qui l'a provoquée soit un égal, un supérieur ou un inférieur. Ne jamais se battre : contre un égal c'est risqué, contre un supérieur c'est dément, contre un inférieur c'est sordide.

Cet homme qui est en colère contre toi ? Provoque-le en lui faisant du bien.

Il est plus facile de rester à l'écart d'une querelle que d'en sortir.

La flèche n'arrive pas du même côté pour tous. Il faut que tu saches où est ton point faible pour mieux le protéger.

Tu ne veux pas être en colère ? Sois mieux curieux. Celui qui se renseigne sur ce qu'on dit de lui et va déterrer les propos malveillants, même confidentiels, se tourmente lui-même. 
Quand Socrate reçut une gifle, il dit seulement : "Dommage qu'on ne sache jamais quand il faut sortir avec un casque! »

La plupart des gens créent leurs problèmes de leurs propres mains, en soupçonnant ce qui est faux, ou en grossissant ce qui n'est pas grave.

Confie au temps ce que tu veux vraiment connaître : dans les remous, on ne peut rien voir correctement.

On savait que Socrate était en colère quand il baissait le ton et s'exprimait sobrement.

Mais, tant que rien ne nous semble assez intolérable pour nous chasser de la vie, supprimons la colère, quelque soit notre rang.

Aucun joug n'est si serré qu'il ne fasse moins mal quand on l'accepte que si on le repousse. Face à des maux immenses, il n'est qu'un réconfort : supporter, obéir à la nécessité.

La colère me ferait plus de mal que l'offense ; pourquoi ? parce que l'offense, je la connais, alors que la colère, je ne sais pas jusqu'où elle pourrait me conduire.

S'il regarde ce qu'ont les autres, nul ne sourit à ce qu'il a. [...] Sois donc reconnaissant de ce que tu as eu ! Et pour le reste, attends, et sois heureux de n'être pas déjà comblé de tout.

...la fin est proche et même très proche, pour le vaincu comme pour le vainqueur. Vivons plutôt tranquilles, apaisés, le peu de temps qui nous reste.

Tant que nous respirons, tant que nous sommes parmi les hommes, soyons humains. N’intimidons personne ! Ne menaçons personne!

Oui, la vraie récompense de nos belles actions c'est de les avoir faites.

Mais, comme le dosage est souvent difficile, si quelque chose doit être un peu en excédent, que ce soit la composante la plus humaine.

...le sage anticipe le mal, et se tient prêt d'avance, car jamais on ne fixe une conduite claire et pure en plein orage.

Le chagrin est inapte à distinguer les choses, à trouver les issues, à tourner les périls, à peser équitablement les torts subis. 
Et le propre de l'esprit grand, c'est d'être calme, tranquille, de regarder de haut affronts et déplaisirs.

\section{De la tranquillité de l’âme}

Il en est du mal comme du bien : à force de le fréquenter, on se prend à l'aimer.

Écris donc avec des mots simples, et non pour la gloire. On peut doser ses efforts quand on travaille au jour le jour.

D’après moi, beaucoup de gens auraient pu parvenir à la sagesse s’ils n’avaient pas cru qu’ils y étaient déjà parvenus.

On entreprend voyage après voyage et les spectacles succèdent aux spectacles. Comme le dit Lucrèce : "De cette façon, chacun passe son temps à se fuir. » Mais quelle utilité si on n'échappe pas à soi-même?

...il faut toujours avoir en soi plus de ressource que n'en exige l'ouvrage à accomplir ; on se brise forcément les reins à porter des charges au-dessus de ses forces.

Toutefois évitons principalement les gens moroses, toujours en train de geindre, qui se jettent sur la moindre occasion de se plaindre. Même loyal et bienveillant, un compagnon mal dans sa peau et toujours gémissant est l'ennemi de la tranquillité.

Comme il a de la chance, celui qui n'a de devoirs qu'envers l'être auquel il peut le plus facilement dire non : lui-même !

Une abondance de livres écrase celui qui veut s'instruire sans l'instruire et il est nettement préférable de s'intéresser à un nombre limité d'écrivains que de se perdre à en lire beaucoup.

Tu trouveras, en n'importe quelle circonstance de la vie, de quoi te divertir, te détendre et éprouver du plaisir à condition de prendre le parti de relativiser tes malheurs plutôt que de te les rendre intolérables. 
Soumets à ta réflexion les difficultés que tu rencontres : ce qui résistait peut s'assouplir, ce qui était étroit peut s'élargir et une charge peut se faire moins pesante pour qui sait la porter.

Tournons le dos à ce qui est irréalisable ou difficilement irréalisable; recherchons plutôt ce qui est à notre portée et sourit à notre espérance.

Qu'y a-t-il de pénible à retourner d'où l'on vient ? Il vivra mal, celui qui ne saura pas bien mourir.

Un grand nombre de gens ne prévoient pas d'avoir un jour à naviguer en pleine tempête.

Quand survient l'épreuve, il est trop tard pour préparer son âme à l'assumer.

Sache donc dans l'avenir que toute situation est sujette à revirement et que tout ce qui arrive à quiconque peut t'arriver à toi aussi.

Ainsi, chaque effort doit correspondre à un projet précis, se donner un but précis.

Il est, par ailleurs, inévitable que l'âme ressente moins profondément une douleur due à une déception, quand on n'a pas cru d'avance la réussite assurée.

La tranquillité de l'âme a deux ennemis: l'inaptitude à rien changer, l'inaptitude à rien supporter.

...il est plus conforme à la nature humaine de rire de la vie que d'en pleurer.

Cela dit, nous devons combiner par alternance solitude et vie en société.

Autorisons notre esprit à se détendre : [...] il suffira d'un peu de repos et de délassement pour récupérer nos capacités.

On n’a pas appelé l'inventeur du vin Liber parce qu'il délie la langue mais parce qu'il délivre notre âme des soucis qui l'asservissent, la soutient, la vivifie et lui redonne du courage pour toutes ses entreprises.

En effet, si nous en croyons le poète grec, "il est doux d'être fou, de temps en temps »; ... et si nous en croyons Aristote, "aucun génie n'a jamais vu le jour sans un grain de folie. » 


\section{Lettres à Jean-Élie. \\ Clin d'œil aux amants de la sagesse \\ BIBLIOGRAPHIE CHOISIE}

$\underline{\text { Retour à la table des matières }}$

Alain. Propos sur le bonheur, Paris, Gallimard (coll. Folio/Essais), 1985. [Livre disponible dans Les Classiques des sciences sociales. JMT.]

Alain. Les Passions et la Sagesse, édition établie et présentée par Georges Bénézé, préface d’André Bridoux, Paris, Gallimard (Bibliothèque de La Pléiade), 1960.

Alain. Les Saisons de l'esprit, Paris, Gallimard, 1965. [Livre disponible dans Les Classiques des sciences sociales. JMT.]

Alain. Propos sur l'esthétique, Paris, Presses universitaires de France, 1975. [Livre disponible dans Les Classiques des sciences sociales. JMT.]

Alain. Études, Paris, Gallimard, 1968.

Alain. Minerve ou de la Sagesse, Paris, de La Table Ronde, 2001.

Alain. Propos I, Préface d'André Maurois, édition présentée, établie et annotée par Maurice Savin, Éditions Gallimard (Bibliothèque de La Pléiade), 1970.

Alain. Propos II, texte établi, présenté et annoté par Samuel S. De Sacy, Éditions Gallimard (Bibliothèque de La Pléiade), 1956.

Alain. Les Dieux, Paris, Gallimard, 1947. [Livre disponible dans Les Classiques des sciences sociales. JMT.]

Alain. Les Idées et les Âges, suivi d'annexes et de documents réunis et présentés par S. de Sacy, Paris, Le Club du meilleur livre. Reproduit avec l'autorisation 
des Éditions Gallimard, exemplaire numéro 271, 1961. [Livre disponible dans Les Classiques des sciences sociales. JMT.]

Balzac. La Comédie humaine, édition présentée par Pierre Dufief, Paris, Omnibus, 1999.

Boèce. Consolation de la philosophie, préface de Marc Fumaroli, traduit du latin par Colette Lazam, Éditions Rivages, 1989.

Boissinot, Christian, Godon, Martin, Isabelle Rivard. L'Art de vivre, Les Stö̈ciens et Épicure, Québec, Les Éditions CEC, 1998.

Bréhier, Émile. Introduction à l'étude du stoïcisme, traduction par E. Bréhier, revue par P. Aubenque (Bibliothèque de La Pléiade), Paris, Gallimard, 1962, p. 801 à 1110.

Bridoux, André. Alain. Sa vie, son oeuvre avec un exposé de sa philosophie, Paris, Presses universitaires de France, 1964.

Cicéron. Devant la mort, présenté par Pierre Grimal, traduit du latin par Danièle Robert, Paris, Arléa, 1991.

Cicéron. Savoir vieillir. Cato Maior, De Senectute, traduit du latin par Christiane Touya, Paris, Arléa, 1995.

Cicéron. Le Bonheur (IV et V Tusculanes), traduit du latin et présenté par Chantal Labre, Paris, Arléa, 1996.

Cicéron. Devant la souffrance (II et III Tusculanes), traduit du latin et présenté par Danièle Robert, Paris, Arléa, 1996.

Confucius. Entretiens, traduit du chinois par Anne Cheng, Paris, Éditions du Seuil, 1981.

Duhot, Jean-Joël. Épictète et la sagesse stoïcienne, Paris, Éditions Albin Michel, 2003.

Eckhart (Maître), Du Détachement, traduit et présenté par Gwendoline Jarczyk et Pierre-Jean Labarrière, Paris, Éditions Payot et Rivages, 1995.

Épictète. Entretiens (livres I, II, III, IV) dans Les Stoïciens, préface par PierreMaxime Schull. Introduction à l'étude du stoïcisme par Émile Bréhies, Éditions Gallimard (Bibliothèque de La Pléiade), 1962. 
Épictète. Manuel dans Les Stoïciens, traduction, notice et notes par J. Pépin, Paris, Gallimard (Bibliothèque de La Pléiade), 1962, p. 1111 à 1132.

Épicure. Lettres, maximes, sentences, traduction, introduction et commentaires par Jean-François Balaudé, Paris, Livre de Poche (Classiques de la philosophie), 1994.

Godbout, Jacques T. Ce qui circule entre nous. Donner, Recevoir, Rendre, Paris, Éditions du Seuil, 2007.

Godbout, Jacques T. L'Esprit du don, en collaboration avec Alain Caillé, Paris, Éditions La Découverte, 1992, Montréal, Éditions du Boréal, 1992.

Goethe, Johann Wolfgang. Les Années d'apprentissage de Wilhelm Meister, édition de Bernard Lortholary, Paris, Gallimard, 1954, pour la traduction française, 1999.

Goethe, Johann Wolfgang. Les Souffrances du jeune Werther, présentation et traduction par Joseph-François Angelloz, Paris, Flammarion, 1968.

Gracián, Baltasar. L’Art de la prudence, préface de Jean-Claude Masson, Paris, Éditions Payot et Rivages, 1994.

Grimal, Pierre. Sénèque ou la conscience de l’Empire, Paris, Fayard, 1991.

Grimal, Pierre. Sénèque, Paris, Presses universitaires de France (Collection Que sais-je ?), 1994.

Khayyâm, Omar. Les Quatrains, traduit du persan par Madhy Fouladvind, Paris, Les Éditions du Rocher (Les grands textes spirituels), 1996.

Lenz, Jacob Machael Reinhold. Cours philosophiques pour âmes sentimentales, préface de Daniel Binswanger, traduit de l'allemand par Philippe Ivernel, Paris, Éditions Payot et Rivages, 2001.

Marc Aurèle. Pensées pour moi-même suivies du manuel d'Épictète, traduction, préface et notes par Mario Meunier, Paris, Flammarion, 1964.

Montaigne, Michel Eyquem de. Essais, tome I, édition présentée, établie et annotée par Pierre Michel, Paris, Librairie générale française (Livre de Poche), 1972. 
Montaigne, Michel Eyquem de. Essais, tome II, édition présentée, établie et annotée par Pierre Michel, Paris, Librairie générale française (Livre de Poche), 1972.

Montaigne, Michel Eyquem de. Essais, tome III, édition présentée, établie et annotée par Pierre Michel, Paris, Librairie générale française (Livre de Poche), 1972.

Montesquieu. Lettres persanes, Paris, Booking international (Maxi-Poche, Classique français), 1993, Phidal pour le Canada, 1995.

Péguy, Charles. Le Porche du mystère de la deuxième vertu, préface de Jean Bastaire, Paris, Gallimard/Poésie, 1986.

Platon. Le Banquet ou de l'Amour, traduit du grec par Léon Robin et M.J. Moreau, préface de François Châtelet, Paris, Gallimard (Folio/Essais), 1973.

Plutarque. Comment tirer profit de ses ennemis, traduit du grec et présenté par Pierre Maréchaux, Paris, Éditions Payot et Rivages, 1993.

Plutarque. Comment écouter, traduction du grec et postface de Pierre Maréchaux, Paris, Éditions Payot et Rivages, 1995.

Plutarque. La Sérénité intérieure, traduit du grec et présenté par Pierre Maréchaux, Paris, Éditions Payot et Rivages, 2001.

Sand, George. Consuelo. La Comtesse de Rudolstadt, tome I, texte établi, présenté et annoté par Simone Vierne et René Bourgeois, Grenoble, Éditions de l'Aurore, 1988.

Sand, George. Consuelo. La Comtesse de Rudolstadt, tome II, texte établi, présenté et annoté par Simone Vierne et René Bourgeois, Grenoble, Éditions de l'Aurore, 1988.

Sand, George. Consuelo. La Comtesse de Rudolstadt, tome III, texte établi, présenté et annoté par Simone Vierne et René Bourgeois, Grenoble, Éditions de l’Aurore, 1988.

Sénèque. De la brièveté de la vie, traduit par E. Bréhier, revu par J. Brunschwig dans Les Stoïciens, Paris, Gallimard (Bibliothèque de La Pléiade), 1962.

Sénèque. De la vie heureuse, traduit par E. Bréhier, revu par L. Bourgey, dans Les Stoïciens, Paris, Gallimard (Bibliothèque de La Pléiade), 1962. 
Sénèque. Des bienfaits, tome I, texte établi et traduit par François Préchac, Paris, Les Belles Lettres, 1972.

Sénèque. De la tranquillité de l'âme, précédé d'un essai de Paul Veyne, traduit du latin par Colette Lazam, Paris, Éditions Rivages, 1988.

Sénèque. Consolations, préface de Ilsetraut Hadot, traduit du latin par Colette Lazam, Paris, Éditions Rivages, 1992.

Sénèque. Sur la brièveté de la vie, traduit du latin et postface par Xavier Bordes, Paris, Éditions Mille et Une Nuits, 1994.

Sénèque. L'Homme apaisé, suivi de Colère et Clémence, traduit du latin par Paul Chemla, Paris, Arléa, 1995.

Sénèque. La Vie heureuse, suivi de La Brièveté de la vie, traduit du latin par François Rosso, suivi de la correspondance entre Descartes et la princesse Élizabeth sur La Vie heureuse, Paris, Arléa, 1995.

Sénèque. La Providence, suivi de La Constance du Sage, traduit du latin par François Rosso, Paris, Arléa, 1996.

Sénèque. Lettres à Lucilius, Livres I-IV, texte établi par François Préchac, traduit par Henri Noblot, Paris, Les Belles Lettres, 2002.

Sénèque. Lettres à Lucilius, Livres V-VII, texte établi par François Préchac, traduit par Henri Noblot, Paris, Les Belles Lettres, 2003.

Sénèque. Lettres à Lucilius, Livres VIII-XIII, texte établi par François Préchac, traduit par Henri Noblot, Paris, Les Belles Lettres, 2003.

Sénèque. Lettres à Lucilius, Livres XIV-XVIII, texte établi par François Préchac, traduit par Henri Noblot, Paris, Les Belles Lettres, 2003.

Sénèque. Lettres à Lucilius, Livres XIX-XX, texte établi par François Préchac, traduit par Henri Noblot, Paris, Les Belles Lettres, 2003.

Sénèque. Apprendre à vivre. Lettres à Lucilius, tome I, lettres choisies et traduites du latin par Alain Golomb, Paris, Arléa, 1996.

Sénèque. Apprendre à vivre. Lettres à Lucilius, tome II, lettres choisies et traduites du latin par Alain Golomb, présentées par Gabriel Matzneff, Paris, Arléa, 1996. 
Sénèque. Lettres à Lucilius (1-29), traduction inédite, introduction et notes par Marie-Ange Jourdan-Gueyer, Paris, Flammarion, 1992.

Sernin, André. Alain. Un sage dans la cité, Biographies sans masque, Paris, Robert Laffont, 1985.

Stendhal (Henri Beyle, dit). Le Rouge et le Noir, tome I, Paris, Les Éditions Jean-Claude Lattès, 1968.

Stendhal (Henri Beyle, dit). Le Rouge et le Noir, tome II, Paris, Les Éditions Jean-Claude Lattès, 1968.

Stendhal (Henri Beyle, dit). La Chartreuse de Parme, présentation par Fabienne Bercegol, Paris, Flammarion, 2000.

Tacite. Annales, texte présenté, traduit et annoté par Pierre Grimal, Paris, Gallimard, 1990.

Valéry, Paul. La Jeune Parque, l'ange, Agathe, histoire brisée, préface et commentaire de Jean Levaillant, Paris, Éditions Gallimard, 1974.

Voilquin, Jean. Les Penseurs grecs avant Socrate, De Thalès de Milet à Prodicos, traduction, introduction et notes par Jean Voilquin, Paris, Flammarion, 1964. 
Lettres à Jean-Élie.

Clin d'œil aux amants de la sagesse

\section{REMERCIEMENTS}

\section{$\underline{\text { Retour à la table des matières }}$}

Un livre, avant toute chose, laisse paraître une aventure mystérieuse porteuse d'espérances. J’ai pris le risque de vivre la mienne en acceptant de monter sur un navire. Toutefois, ce n’est pas en solitaire que j’ai effectué la traversée. Dès lors, le retour au port appelle la gratitude. C'est ainsi que, dans un premier temps, je tiens à exprimer ma plus vive reconnaissance à tous les membres de l'équipage. En effet, chacun d'eux, à un moment ou l'autre de l'itinéraire, a joué un rôle important en me manifestant sa compétence, sa disponibilité et son amitié. Je tiens à les présenter. Il s’agit de : Vincent Lemieux, René Tremblay, Annie Rioux, Roland Bourdeau, Yvon Joly, Christian Beaulieu, Martin Blais, Johanne Laberge, Michelle Perron, Claude Gilbert, la remarquable équipe des Éditions JCL, Chantale Vincelette, illustratrice, et tous ceux qui, de leur plume agile et élégante, ont traduit, du grec et du latin, la pensée des amis de la sagesse. Je suis également redevable envers l'institution qui m'accueille. Les conditions favorables qu'autorise une année de perfectionnement ont considérablement facilité le parcours. Il y a aussi d'autres personnes, chères à mon coeur qui, par leur bienveillance et leur affection, ont embelli le trajet. J’ai nommé ma mère, mes soeurs, mes amies ; ici le féminin englobe le masculin. De même, certaines personnes ont joué un rôle essentiel : Jean-Claude Larouche a accueilli l'épisode et lui a donné la forme combien merveilleuse d'un livre ; Jacques T. Godbout a accepté avec générosité d'en écrire la préface ; Jean-Élie, mon père, est demeuré un véritable complice, à la fois intentionné et dévoué ; mes amis les philosophes, de là-haut, ont 
pris part à l'expédition et m’ont guidée avec tendresse et fidélité. Et le merci de la fin s'adresse au capitaine de ce bateau imaginaire : Jean, mon amour ; mon ami. À certains moments, il fut les voiles de mon inspiration, à d'autres, les vagues d'une critique obligée : tantôt exigeant, tantôt indulgent, mais jamais complaisant. Son écoute, jointe à son goût du rêve et du voyage, a grandement contribué au plaisir de la traversée. Sa présence accueillante m'a aidée à comprendre le mot de Bouddha : Il n'y a pas de chemin vers le bonheur. Le bonheur est le chemin.

\section{Fin du texte}

